\title{
WestVirginiaUniversity
}

THE RESEARCH REPOSITORY @ WVU

Graduate Theses, Dissertations, and Problem Reports

2008

\section{In vitro elucidation of the metabolic fate of the anticancer drug busulfan}

Islam Rasem Younis

West Virginia University

Follow this and additional works at: https://researchrepository.wvu.edu/etd

\section{Recommended Citation}

Younis, Islam Rasem, "In vitro elucidation of the metabolic fate of the anticancer drug busulfan" (2008). Graduate Theses, Dissertations, and Problem Reports. 2719.

https://researchrepository.wvu.edu/etd/2719

This Dissertation is protected by copyright and/or related rights. It has been brought to you by the The Research Repository @ WVU with permission from the rights-holder(s). You are free to use this Dissertation in any way that is permitted by the copyright and related rights legislation that applies to your use. For other uses you must obtain permission from the rights-holder(s) directly, unless additional rights are indicated by a Creative Commons license in the record and/ or on the work itself. This Dissertation has been accepted for inclusion in WVU Graduate Theses, Dissertations, and Problem Reports collection by an authorized administrator of The Research Repository @ WVU.

For more information, please contact researchrepository@mail.wvu.edu. 


\title{
IN VITRO ELUCIDATION OF THE METABOLIC FATE OF THE ANTICANCER DRUG BUSULFAN
}

\author{
Islam Rasem Younis
}

\author{
A Dissertation \\ Submitted to \\ The School of Pharmacy \\ At \\ West Virginia University \\ In partial fulfillment of the requirements for \\ The degree of \\ Doctor of Philosophy \\ In Pharmaceutical and Pharmacological Sciences \\ Patrick S. Callery, Ph.D., Chair \\ William P. Petros, Pharm.D. \\ Robert Griffith, Ph.D. \\ Lisa L. Holland, Ph.D. \\ Paula Jo. Stout, Ph.D. \\ Department of Basic Pharmacuetical Sciences \\ Morgantown, West Virginia \\ 2008
}

Keywords: Busulfan, glutathione, sulfonium ion, dehydroglutathione, $\beta$-lyase, cytstathionine $\gamma$-lyase, N,N-dimethylacetamide. 


\section{ABSTRACT \\ IN VITRO ELUCIDATION OF THE METABOLIC FATE OF THE ANTICANCER DRUG BUSULFAN}

\section{Islam Rasem Younis}

Busulfan is a bifunctional alkylating agent that is used to treat mylogenous leukemia. The major elimination pathway of busulfan is through glutathione-Stransferase (GST) catalyzed conjugation to form glutathione sulfonium conjugate. The aim of this work is to elucidate the novel metabolic pathways of busulfan that may explain its toxicity. The observed data showed that busulfan is not a substrate for CYP450. The sulfonium ion conjugate of busulfan was found to be inactive as it did not inhibit GST in human liver cytosol, did not react with 4-(4-nitrobenzyl)pyridine, did not induce apoptosis in NCI-H460 cells, and was not stable in basic conditions with a half life of 6.0 hours at $\mathrm{pH}$ 7.4. The degradation products were identified to be tetrahydrothiophene and dehydroglutathione. Dehydroglutathione is a glutathione analogue in which the cysteine moiety is replaced by dehydroalanine moiety, which makes it a Michael acceptor. This secondary metabolite of busulfan produced cytotoxicity against C6 glioma cells and reacted in vitro with sulfhydryl nucleophiles such as glutathione and cysteine. An alternative metabolic pathway for the sulfonium ion conjugate of busulfan is through the mercapurate pathway which will lead to the formation of the cysteine sulfonium conjugate of busulfan (THT-A). THT-A was found to undergo a non-enzymatic $\beta$-elimination reaction at $\mathrm{pH} 7.4$ and $37^{\circ} \mathrm{C}$ to yield tetrahydrothiophene, pyruvate and ammonia. This reaction is accelerated by a) rat liver, kidney and brain homogenates, b) isolated rat liver mitochondria, and c) pyridoxal 5'phosphate (PLP). A PLP-dependent enzyme in rat liver cytosol that catalyzes a $\beta$-lyase reaction with THT-A was identified as cystathionine $\gamma$-lyase. This unusual drug metabolism pathway represents an alternate route for intermediates in the mercapturate pathway. 


\section{DEDICATION}

\section{To the soul of my Dad Dr. Rasem M. Younis "may he rest in peace" and my beloved Mom Fatima A. Faraj}




\section{ACKNOWLEDMENTS}

The process of conducting research is obviously not possible without the personal and practical support of numerous people. Thus, I owe my gratitude to all those people who have made this dissertation possible and because of whom my graduate experience has been one that I will cherish forever.

I am deeply indebted to my esteemed advisor Dr. Patrick Callery, whose help, stimulating discussions, suggestions, understanding, encouragement, and patience helped me all the time to finish up the work. I am eternally grateful to my co-advisor Dr. William Petros for his assistance, guidance, and giving me the opportunity to perform pharmacokinetics studies. I was lucky to have the opportunity to work with both distinguished investigators. Their mentorship was paramount in providing a well rounded experience consistent with my long-term career goals. They encouraged me to not only grow as an experimentalist but also as an instructor and an independent thinker. I am not sure how many graduate students are given the opportunity to develop their own individuality and self-sufficiency by being allowed to work with such independence.

My thanks go to Dr. Arthur Cooper and Dr. John Pinto from New York Medical College who collaborated on an important section of this dissertation. I would like to acknowledge Dr. Lisa Holland, Dr. Paula Stout, and Dr. Robert Griffith for their service on my advisory committee and their support of my research goals and timeline for completion. .

I am thankful for the department secretaries Penny Daily and Donna Mathess for their help and friendship.

Many friends have helped me stay sane through these difficult years. Their support and care helped me overcome setbacks and stay focused on my graduate study. I greatly value their friendship and I deeply appreciate their belief in me. 


\section{TABLE OF CONTENTS}

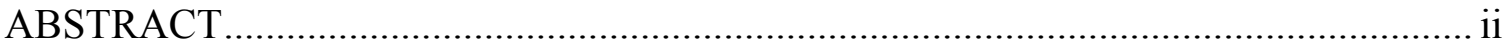

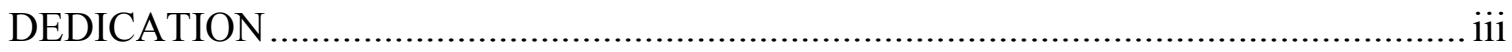

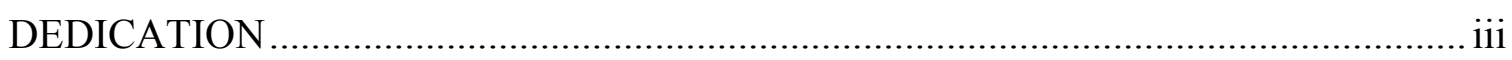

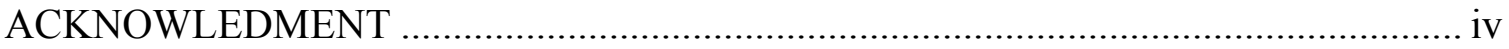

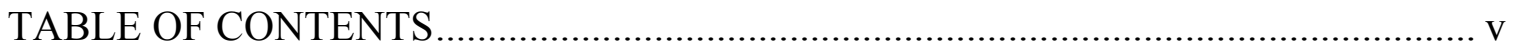

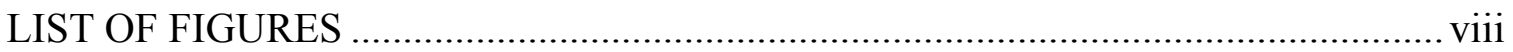

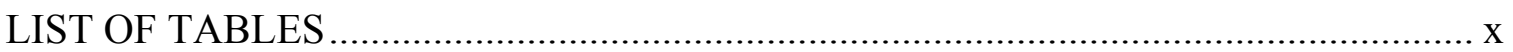

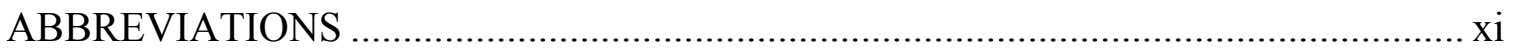

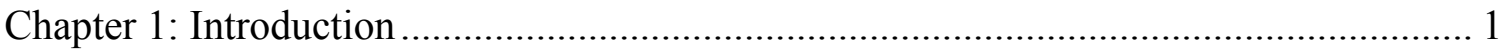

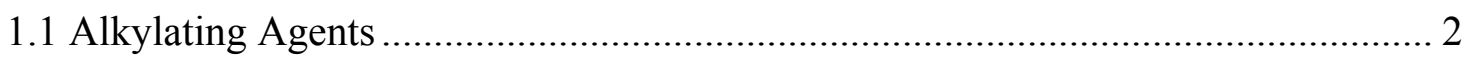

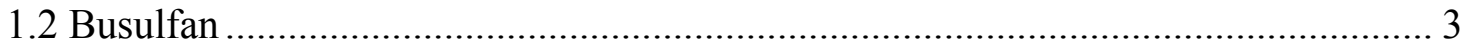

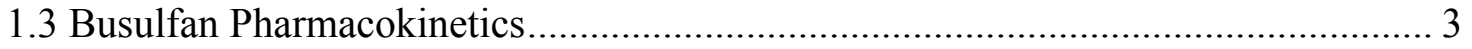

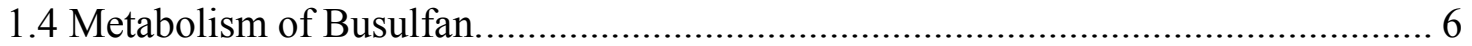

1.5 The Mercapturic Acid Pathway ............................................................................... 9

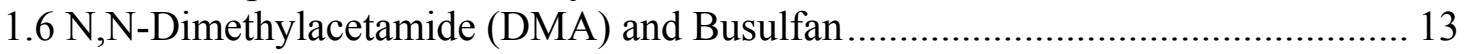

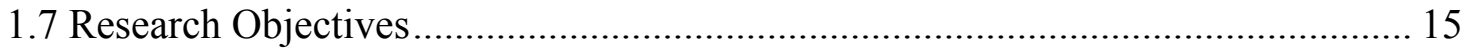

Chapter 2: Experimental Section ............................................................................ 17

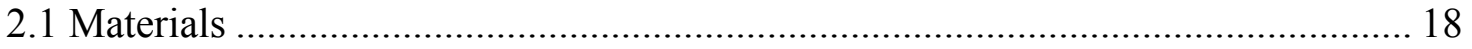

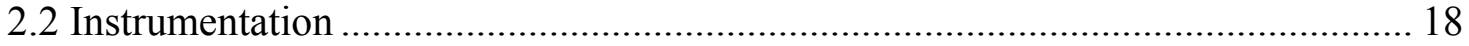

2.3 In Vitro Metabolism of Busulfan by Liver Microsomes ........................................ 19

2.3.1 Incubation of busulfan with liver microsomes............................................. 19

2.3.2 Enzymatic Conversion of 1-Chloro-2,4-dinitrobenzene (CDNB) to S-(2,4-

Dintrophenyl)-glutathione (GS-DNB) ................................................................. 21

2.3.3 Inhibition of Cytosolic GST Activity by Ketoconazole .................................. 21

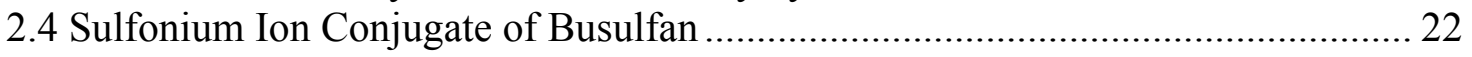

2.4.1 Synthesis of $\gamma$-Glutamyl- $\beta$-(S-tetrahydrothiophenium)alanylglycine ( $\gamma$-E-THT-

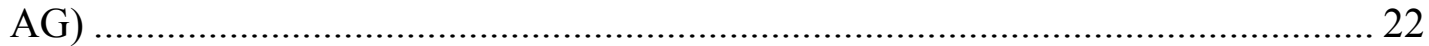

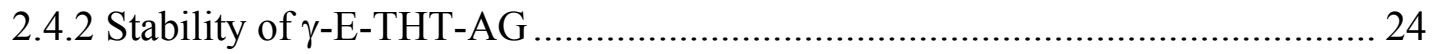

2.4.3 Relative Alkylation Reactivity of $\gamma$-E-THT-AG............................................ 25

2.4.5 Cytotoxicity of $\gamma$-E-THT-AG................................................................. 25

2.4.6 Effect of $\gamma$-E-THT-AG on glutathione-S-transferase (GST) ……………...... 26

2.5 Busulfan-Cysteine Sulfonium Ion Conjugate .......................................................... 27 
2.5.1 Synthesis of S- $\beta$-Alanyltetrahydrothiophenium (THT-A) ............................ 27

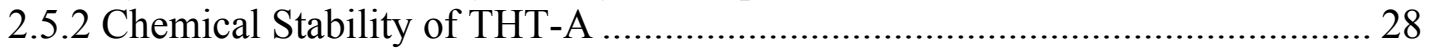

2.5.3 Reaction of cysteine with busulfan.......................................................... 28

2.5.4 Enzymatic Conversion of THT-A to Pyruvate and Ammonium ..................... 29

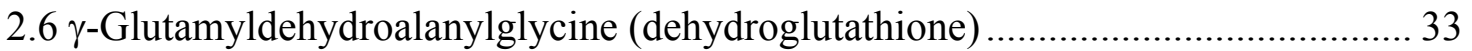

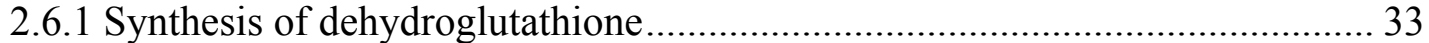

2.6.2 Reactivity of Dehydroglutathione Toward Nucleophiles ............................. 35

2.6.3 In Vitro Cytotoxicity of Dehydroglutathione................................................ 36

2.7 Effect of N,N-Dimethylacetamide (DMA) on the Catalytic Activity of CYP450

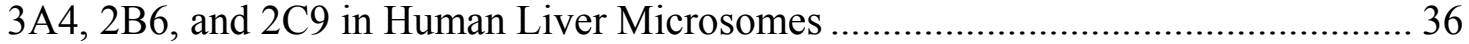

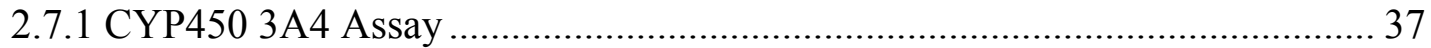

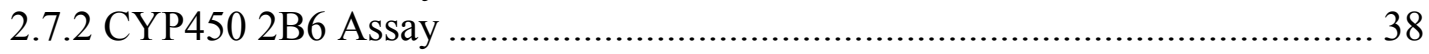

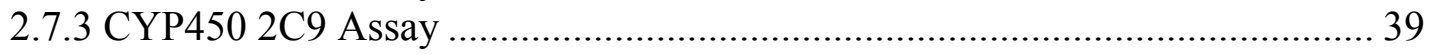

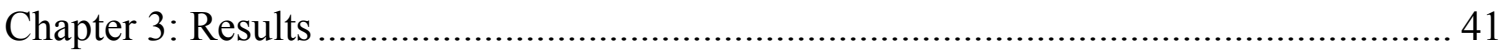

3.1 In Vitro Metabolism of Busulfan by Liver Microsomes ................................... 42

3.2.1 Synthesis of $\gamma$-Glutamyl- $\beta$-(S-tetrahydrothiophenium)alanylglycine ( $\gamma$-E-THT-

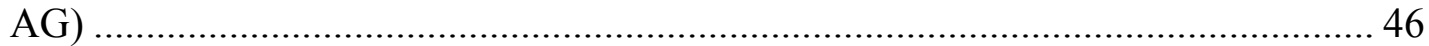

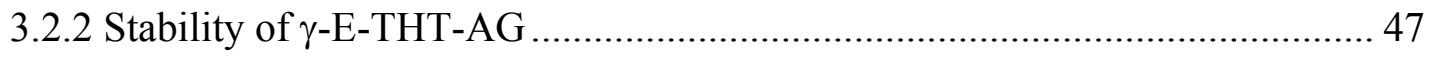

Figure 3.5. Stability of $\gamma$-glutamyl- $\beta$-(S-tetrahydrothiophenium)alanylglycine $\quad \gamma$ -

E-THT-AG) at $\mathrm{pH} 7.4$ and $\mathrm{pH}$ 8.0. The data points are the average of two

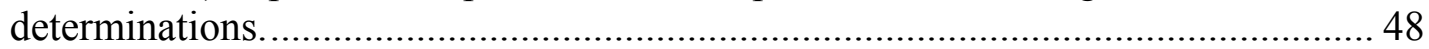

3.2.3 Relative Alkylation Reactivity of $\gamma$-E-THT-AG.......................................... 49

3.2.4 Cytotoxicity of $\gamma$-E-THT-AG................................................................... 49

Figure 3.7. Percent apoptosis induced by busulfan and $\gamma$-E-THT-AG in NCI-H460

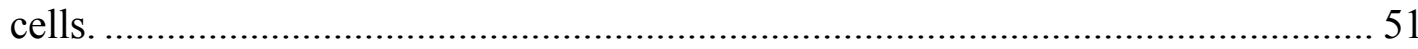

3.2.5 Effect of $\gamma$-E-THT-AG on glutathione-S-transferase (GST) ......................... 52

3.3 Busulfan-Cysteine Sulfonium Ion Conjugate ....................................................... 53

3.3.1 Synthesis of S-( $\beta$-alanyl)tetrahydrothiophenium (THT-A) .......................... 53

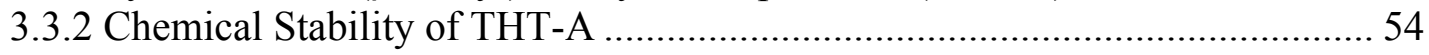

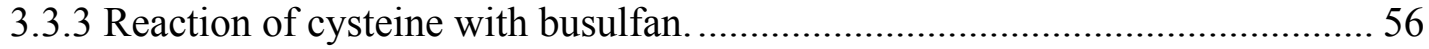

3.3.4 Enzymatic Conversion of THT-A to Pyruvate and Ammonium .................... 58

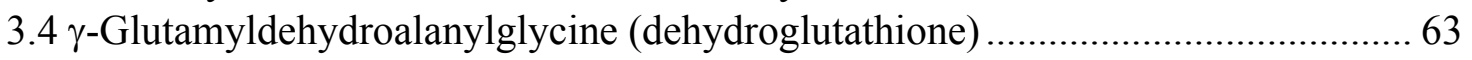

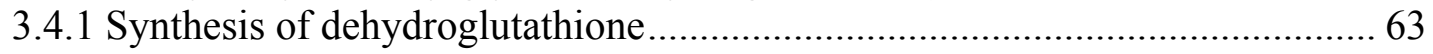

3.4.3 In Vitro Cytotoxicity of Dehydroglutathione.............................................. 70

3.5 Effect of N,N-Dimethylacetamide (DMA) on the Catalytic Activity of CYP450

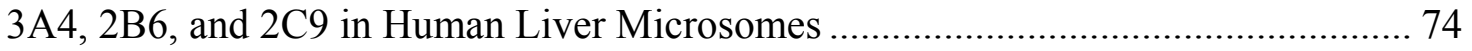

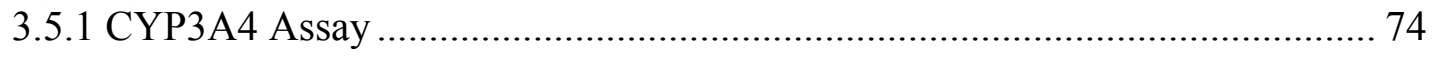

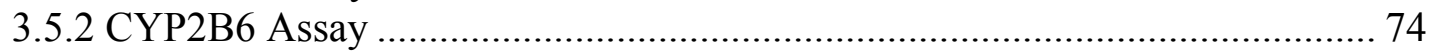

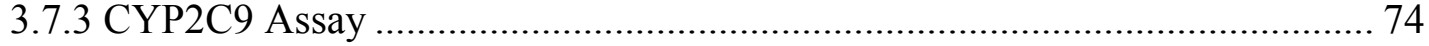

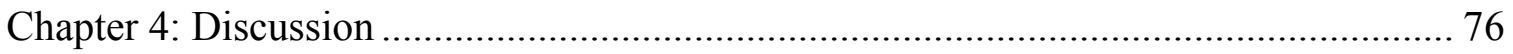


Chapter 5: Summary and Conclusion...

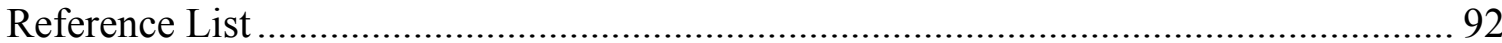




\section{LIST OF FIGURES}

Figure 1.1 Metabolic Scheme of Busulfan......................................................... 7

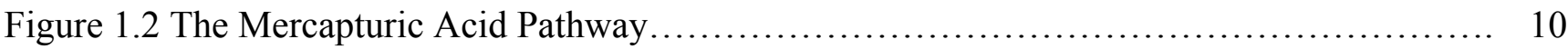

Figure 3.1 Busulfan substrate disappearance studies........................................... 43

Figure3.2. Enzymatic conversion of 1-chloro-2,4-dinitrobenzene to its glutathione adduct in

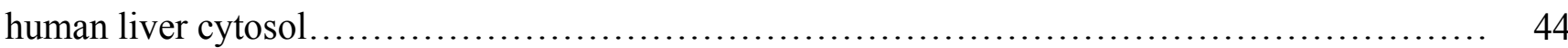

Figure 3.3. Inhibition of glutathione-S-transferases by ketoconazole......................... 45

Figure 3.4. MS/MS of $\gamma$-glutamyl- $\beta$-(S-tetrahydrothiophenium)alanyl-glycine.................. 46

Figure 3.5. Stability of $\gamma$-glutamyl- $\beta$-(S-tetrahydrothiophenium)alanyl-glycine ( $\gamma$-E-THT-AG) at $\quad 48$ $\mathrm{pH} 7.4$ and $\mathrm{pH} 8.0$

Figure 3.6. Reactivity of busulfan and $\gamma$-E-THT-AG with 4-(4-nitrobenzyl)-pyridine. 50

Figure 3.7. Percent apoptosis induced by busulfan and $\gamma$-E-THT-AG in NCI-H460 cells 51

Figure 3.8. Inhibitory effect of $\gamma$-E-THT-AG on the catalytic activity of glutathione-Stransferases 52

Figure 3.9. MS/MS of S- $\beta$-alanyltetrahydrothiophenium (THT-A) ........................... 53

Figure 3.10. Stability of S- $\beta$-alanyltetrahydrothiophenium (THT-A) at $\mathrm{pH} 7.4$ and $\mathrm{pH} 8.0 \ldots \ldots \ldots \ldots . . . \quad 55$

Figure 3.11. Reaction of busulfan with cysteine in $100 \mathrm{mM}$ potassium phosphate buffer (pH8.0).. 57

Figure 3.12. $\beta$-lyase activity toward S- $\beta$-alanyltetrahydrothiophenium(THT-A) in rat liver, brain, and kidney homogenate. 60

Figure 3.13. $\beta$-lyase activity toward S- $\beta$-alanyltetrahydrothiophenium (THT-A) in rat liver homogenate, cytosol, and mitochondria.

Figure 3.14. Non-enzymatic and enzymatic degradation of THT-A 62

Figure 3.15. ${ }^{1} \mathrm{H}$ NMR spectrum of S-(2,4-dinitrophenyl)glutathione 
Figure 3.16. COSY NMR spectrum of S-(2,4-dinitrophenyl)glutathione $\ldots \ldots \ldots \ldots \ldots \ldots \ldots \ldots \ldots .66$

Figure 3.17. ${ }^{1} \mathrm{H}$ NMR spectrum of $\gamma$-gutamyldehydroalanylglycine (dehydroglutathione)......... 67

Figure 3.18. HETCOR NMR spectrum of $\gamma$-gutamyldehydroalanylglycine ..................... 68

Figure 3.19. The second order reaction between cysteine and $\gamma$-gutamyldehydroalanylglycine

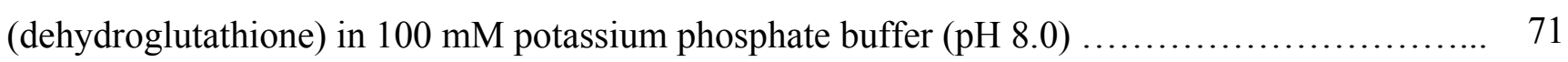

Figure 3.20. MS/MS of the glutathione- dehydroglutathione adduct....................... 72

Figure 3.21. Busulfan and $\gamma$-gutamyldehydroalanylglycine (dehydroglutathione) cytotoxicity

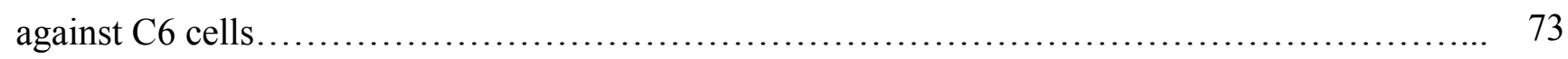

Figure 3.22. Effect of DMA on the catalytic activity of CYP40s in human liver microsomes....... 75

Figure 4.1. Proposed mechanisms of non-enzymatic degradation of L- $\gamma$-glutamyl- $\beta$ - $(S-\quad 80$ tetrahydrothiophenium)-L-alanylglycine ( $\gamma$-E-THT-AG), $\mathrm{SN}_{2}$ hydrolysis (A), $\beta$-elimination (B)... Figure 5.1. Proposed mechanism for the metabolic conversion of busulfan to THT.............. 91 


\section{LIST OF TABLES}

Table 3.1. NMR proton assignments of S-2,4-dinitrophenylglutathione (DNPGSH),

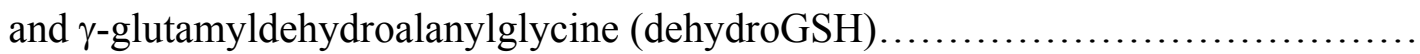




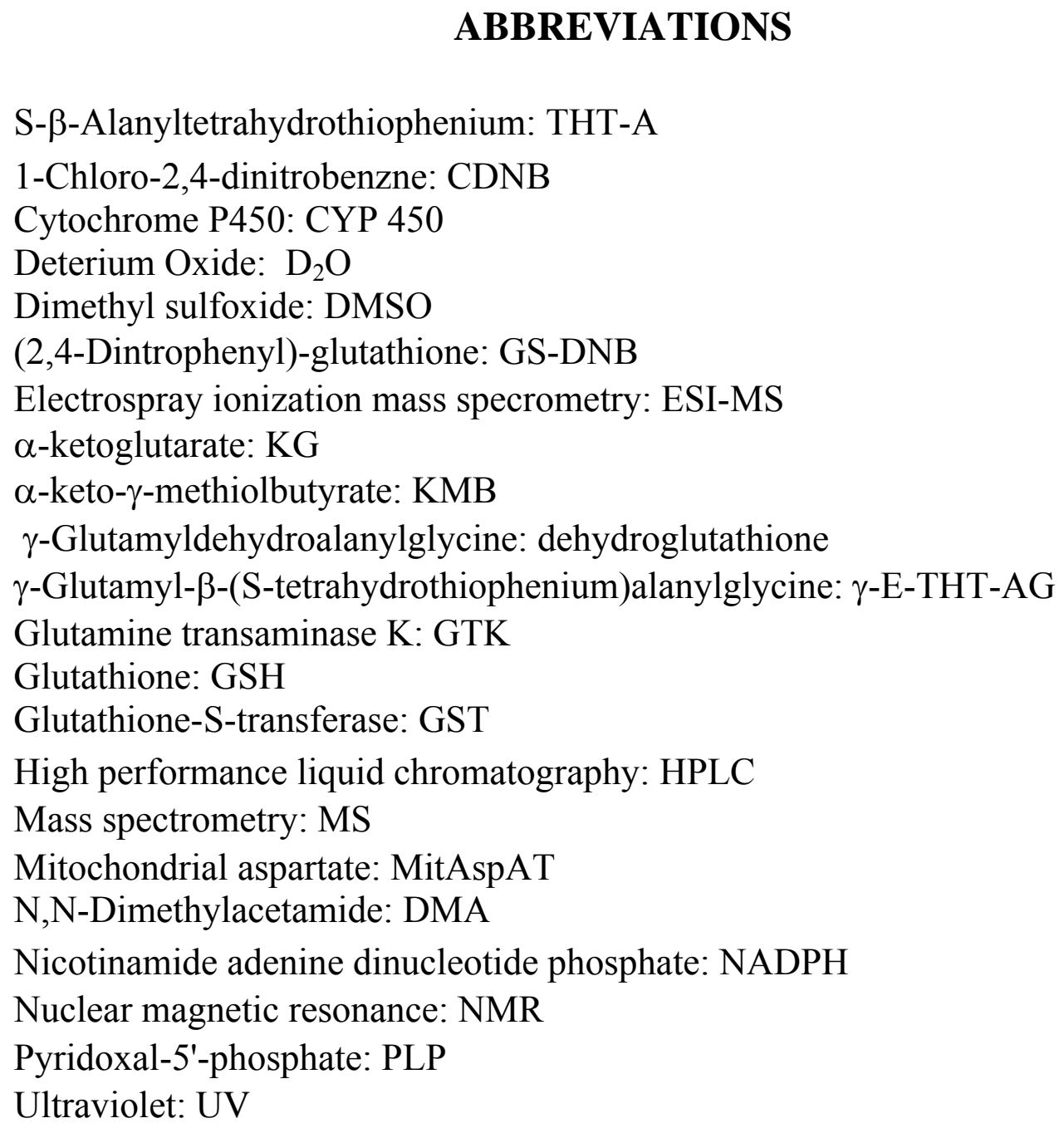




\section{Chapter 1: Introduction}




\subsection{Alkylating Agents}

Alkylating agents are anticancer drugs that are formed from a diverse group of chemical compounds. These agents have in common the capacity to donate, under physiological conditions, alkyl groups to biologically vital macromolecules such as DNA. By becoming reactive electrophiles, through the formation of carbonium ion intermediates or of transition complexes with the target molecules, these agents can form adducts with cellular DNA. Adduct formation may be associated with the inhibition of cancer cell growth $(1,2)$. Up to date, these agents represent an important treatment for various types of cancer.

Alkylation of the DNA produces the chemotherapeutic and cytotoxic effects of alkylating agents. Bifunctional alkylating agents form covalent bonds with the N-7 of guanine on DNA. On the other hand, it must be noted that other atoms in the purine and pyrimidine bases of the DNA can be alkylated. This includes the N-1 and N-3 of adenine, the N-3 of cytosine, the O-6 of guanine, and the phosphate oxygen atoms of the DNA chains. Amino and sulfhydryl groups of proteins may also be alkylated.

Based on chemical structure, these agents can be classified into five groups (3): nitrogen mustards (e.g., chlorambucil and cyclophosphamide), ethylenimines (e.g., thiotepa and altretamine), alkyl sulfonates (e.g., busulfan), triazenes (e.g., decarbazine), and nitrosoureas (e.g., carmustine, lomustine, and semustine). 


\subsection{Busulfan}

Busulfan [1,4-butanediol dimethanesulfonate] is an alkyl sulfonate bifunctional alkylating agent. Busulfan has been in clinical use since 1959, and is used in the treatment of myeloproliferative disorders. The drug was initially introduced (4) to treat chronic myelogenous leukemia $(5,6)$. It was also used in the treatment of polycythemia rubra vera (7-9), and essential thrombocythemia $(10,11)$. Busulfan is used in high doses in hematopoietic stem cell transplantation (12).

As an alkylating agent, the mechanism of action of busulfan is thought to involve DNA alkylation. Busulfan induces dose dependent DNA damage by forming an intrastrand cross-link at the 5'-GA-3' sequence, in addition to monoalkylation (13). On the other hand, it was reported that busulfan produced interstrand DNA alkylation, but to a lesser extent than other alkanediol dimethansulfonates. Monoalkylation was mainly observed on the N-7 of guanine (14). It was also suggested that the mechanism of action of busulfan may include esterification of the phosphate groups, and changing cell permeability (15).

\subsection{Busulfan Pharmacokinetics}

The disposition of busulfan is generally well described by a one compartment pharmacokinetic model (16-18). Busulfan pharmacokinetics display high interpatient and intrapatient variability (16). Some of the factors affecting the interpatient-variability were identified as circadian rhythmicity (19), age $(19,20)$, 
disease state $(21,22)$, drug interaction $(23-25)$, variation in busulfan absorption (21), and busulfan bioavailability (26).

A circadian rhythmicity in busulfan plasma levels was observed, especially in young children, in patients undergoing conditioning therapy prior to stem cell transplantation. In some patients a three fold increase in busulfan concentration measured during the night compared to that obtained during daytime was observed (19). The apparent volume of distribution and clearance of busulfan in children was twice that in adults (20). The total body clearance of busulfan decreased with increasing age and was significantly higher in young children $\left(7.3 \mathrm{~mL} \mathrm{~min}^{-1} \mathrm{~kg}^{-1}\right)$, lower in older children $\left(3.02 \mathrm{~mL} \mathrm{~min}^{-1} \mathrm{~kg}^{-1}\right)$, and lowest in adults $\left(2.7 \mathrm{~mL} \mathrm{~min}^{-1}\right.$ $\left.\mathrm{kg}^{-1}\right)(19)$. Busulfan pharmacokinetics can be influenced by the underlying disease and its status. A higher volume of distribution, a higher clearance, and a longer elimination half-life were found among children with lysosomal storage disease (21). The systemic exposure of busulfan was significantly higher in children with leukemia compared to children with inherited disorders (22). A large interindividual variation in the bioavailability of oral busulfan was observed. In eight children between the age of 1.5 and 6 years, the bioavailability ranged from 0.22 to 1.20 , and in eight children and adults between 13 and 60 years, it was within the range from 0.47 to 1.03 (26).

Absorption: The absorption kinetics of busulfan from the gastrointestinal tract was described by zero $(17,18)$ and first order absorption $(16,27,28)$. Ehrsson et al reported zero order absorption of busulfan in patients with chronic myelogenous 
leukemia following an oral dose of 2, 4, and $6 \mathrm{mg}$. It was postulated that the zero order absorption could be attributed to the zero order dissolution of busulfan (18).

In addition to description as a zero order process, the absorption of busulfan following oral administration was described to follow first order kinetics $(16,27,28)$. In a population pharmacokinetics study, a lag time with first order absorption was sufficient to describe the absorption of busulfan in seventy two patients. Based on this it appears that the kinetics of absorption of busulfan can not be described solely by zero or first order kinetics.

Distribution: Following administration of busulfan, a high percentage of the administered dose will be distributed to the liver (29). The central nervous system toxicities of busulfan can be attributed to the ability of the drug to cross the blood brain barrier. It was reported that $20 \%$ of the administered busulfan crossed the blood brain barrier in patients treated with high doses of busulfan (30). In the human brain, radioactivity of ${ }^{11} \mathrm{C}$-busulfan reached a maximum within five minutes in the cerebellum, cortex, and white matter. Busulfan radioactivity showed a cortex to white matter ratio of 1.6. The activity in the cortex declined to yield a ratio of 1 within 30 minutes (29). Busulfan concentration in the cerebrospinal fluid was detected in all nine children at 3.25-7 hours after the last dose of busulfan ( $1 \mathrm{mg} / \mathrm{kg}$ every 6 hours over 4 days), a mean cerebrospinal fluid to plasma concentration ratio of 0.95 (range, $0.5-1.4$ ) was calculated (17). In another study, the cerebrospinal fluid to plasma concentration ratio of busulfan was $1.3(31)$. 
Busulfan has a relatively low affinity for plasma proteins. Ehrsson and Hassan reported that busulfan irreversibly bound to plasma proteins. The percentage of busulfan bound to plasma proteins was $32.4 \%$. Busulfan was found to be evenly distributed between blood cells and plasma. The fraction of busulfan irreversibly bound to the blood cells was $46.9 \%$ (32). In another study, busulfan showed nominal protein binding in plasma (7.4\%) (31).

Elimination: The elimination of busulfan is well described by a one-compartment pharmacokinetic model (16-18). There was no difference in the reported elimination half-life of busulfan between adults and children. The elimination half-life of busulfan in adults is 2.75 hours $(18,33)$, while the elimination half life of busulfan in children is about 2.5 hours $(27,28,34-36)$. A very low percentage of the administered busulfan dose is excreted unchanged in the urine. Ehrsson and coworkers reported that only $1 \%$ of busulfan is excreted unchanged in the urine in patients with chronic myelocytic leukemia treated with an oral doses of 2, 4, and 6 mg of busulfan (18).

\subsection{Metabolism of Busulfan.}

Busulfan is mainly cleared from the body after reaction with glutathione.

All the identified metabolites of busulfan indicate that the first step in its elimination is through conjugation with GSH (Figure 1.1). It was concluded initially that the major busulfan clearance pathway is through conjugation with cysteine or a cysteinyl moiety to form a cyclic sulfonium ion which undergoes 
<smiles>CS(=O)(=O)OCCCCOS(C)(=O)=O</smiles>

I

\section{Mercapturic Acid Pathway}
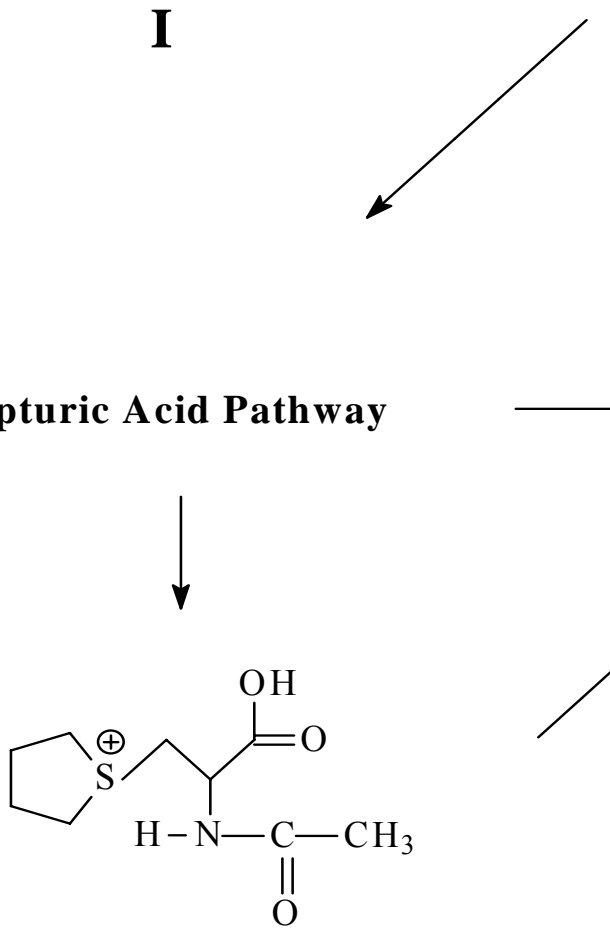

\section{VII}

I : Busulfan

II : Sulfonium ion conjugate of busulfan

III : Tetrahydrothiophene

IV : Tetrahydrothiophene 1-oxide

$\mathrm{V}$ : Sulfolane

VI : 3-hydroxysulfalone

VII : sulfonium ion of $\mathrm{N}$-acetyl-L-cysteine<smiles>NC(CCC(=O)NN(C(=O)NCC(=O)O)C(C[Se]1CCCC1)C(=O)O)C(=O)O</smiles>

II

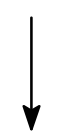

III $\langle>$

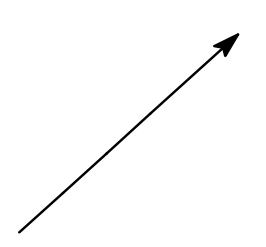

$\mathbf{I V}\langle\underset{\substack{\mathrm{S} \\ \mathrm{O}}}{ }$
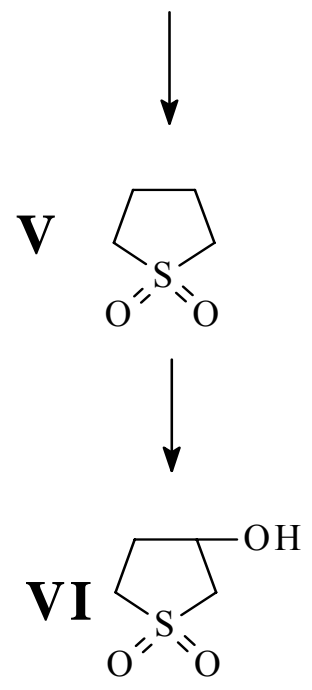

Figure 1.1. Metabolic Scheme of Busulfan (Adapted from reference 38) 
decomposition to tetrahydrothiophene (37). However, Hassan and Ehrsson showed that the sulfonium ion of glutathione was the one main metabolite of busulfan in isolated perfused rat liver (38). They also showed that this sulfonium ion is either cleaved to tetrahydrothiophene or follows the meracpturic acid pathway to produce either tetrahydrothiophene or sulfonium ion of N-acetyl-L-cysteine (39). After intravenous busulfan administration to rats, the glutathione- sulfonium ion of busulfan was identified in the bile (40). 3-Hydroxysulfolane, tetrahydrothiophene 1-oxide, and sulfolane were identified in urine following intrapleural and oral administration of busulfan to rats and human, respectively $(31,39)$.

Busulfan conjugation with glutathione was catalyzed when incubated with human liver cytosol, purified human liver glutathione-S-transferases, and cDNAexpressed glutathione-S-transferase $\alpha 1-1$. The addition of ethacrynic acid, a nonspecific glutathione-S-transferases inhibitor, to the incubation inhibited the enzymatic catalyzed conjugation in a concentration dependent manner (41). Czerwinski et al showed that busulfan conjugation with glutathione is catalyzed by the major classes of human glutathione-S-transferases $(\alpha, \mu, \pi)$. GSTA1-1 was found to be the major isoform contributing to the clearance of busulfan in the body (42).

Role of CYP450 in the metabolism of busulfan: The apparent elimination pathway for busulfan from the body is through conjugation with glutathione. Busulfan is not an inhibitor of CYP450 3A4 (43). The involvement of CYP450 enzymes in the metabolism of busulfan was not previously reported. However, 
some published clinical studies suggested that busulfan undergoes oxidative metabolism. It was shown that the clearance of busulfan is induced upon the coadministration of hepatic enzyme inducing drugs such as phenytoin, phenobarbital, and Aroclor 1254 (polychlorinated biphenyls) (23). These drugs induce CYPP450 enzymes indicating a role of CYP450 in the metabolism of busulfan. It is also worth noting that phenobarbital also induces hepatic glutathione-S-transferases. A continuous decrease in the steady-state level of busulfan was observed in $40 \%$ of phenytoin-treated patients (19). Moreover, patients treated with phenytoin along with labeled busulfan demonstrated a significantly high clearance, a shorter elimination half life and lower AUCs for the last dose of labeled busulfan relative to the first dose, no such effects were observed when phenytoin was replaced by diazepam (24). Phenytoin induces both CYP450 and $\gamma$-glutamyltransferase (44). Itraconazole, an inhibitor of both CYP450 and lipoxygenase, significantly decreased the clearance of busulfan suggesting the involvement of an oxidative catabolism in the clearance of busulfan (25).

\subsection{The Mercapturic Acid Pathway}

The mercapturic acid pathway is a multi-step enzyme catalyzed detoxification process by which many electrophiles are detoxified from the body (Figure 1.2).

The first step of the mercapturic acid pathway is the glutathione-S-transferase (GST) catalyzed formation of the glutathione S-conjugate of the electrophile. GST 


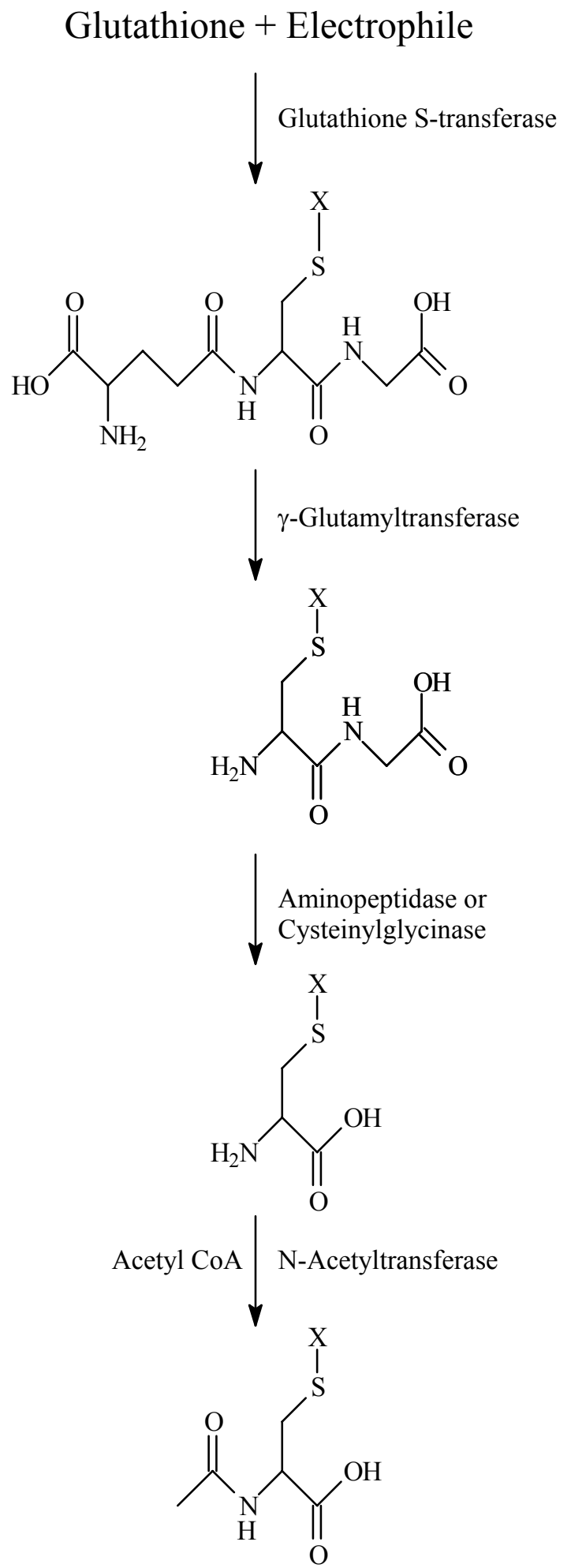

Figure 1.2 The Mercapturic Acid Pathway 
substrates are generally hydrophobic in nature and bear an electrophilic center. Epoxides, quinones, lactones, and $\alpha-\beta$-unsaturated carbonyl compounds are examples of GST substrates (45). GSTs are classified into three major families: cytosolic, mitochondrial, and microsomal. The cytosolic and mitochondrial GSTs consist of soluble enzymes that share similarities in their three-dimensional fold, on the other hand, they have low structural homology with the microsomal GSTs which are membrane associated proteins (46).Cytosolic GSTs are classified based on their amino acid sequence similarities into seven supergene families including: alpha (A), mu (M), theta (T), pi (P), zeta (Z), sigma (S), and omega (O) (47), which in turn are subdivided into 16 subunits. Cytosolic GST isoenzymes typically share $>40 \%$ identity and $<25 \%$ identity, within a class and between classes, respectively. Mitochondrial GSTs comprise one class of enzymes called kappa, while microsomal GSTs comprises four families, with six identified human isoenzymes (48).

The glutathione S-conjugate is then metabolized to the cysteinylglycine Sconjugate. This step is catalyzed by the enzyme $\gamma$-glutamyltransferase, which hydrolyzes the $\gamma$-glutamyl moiety from the glutathione S-conjugate. This cystienylglycine S-conjugate is subsequently converted to the corresponding cysteine S-conjugate, which is catalyzed by the enzymes cysteinylglycine dipeptidase or aminopetidase $\mathrm{M}$. The cysteine S-conjugate is N-acetylated by N- 
acetyltransferase to an $\mathrm{N}$-acetyl derivative as a terminal product in the mercapturic acid pathway (49).

The cysteine S-conjugate could also be a substrate for a group of enzymes collectively called cysteine S-conjugate $\beta$-lyases. These lyases are a group of enzymes that are capable of cleaving the thioether linkage in cysteine Sconjugates. Such a reaction will lead to the formation of sulfur containing moiety and dehydrocystine, which rearrange non-enzymatically to the $\alpha$-imino acid followed by hydrolysis to pyruvate and ammonium. It should be noted that while the mercapturic acid pathway is regarded as a detoxification pathway, the involvement of $\beta$-lyases may lead to the formation of toxic sulfur containing metabolites (50).

Cysteine S-conjugate $\beta$-lyases contain pyridoxal 5'-phosphate as a coenzyme. Eleven cysteine S-conjugate $\beta$-lyases were identified in mammalian tissues, six of which are cytosolic and five are mitochondrial. The cytosolic cysteine S-conjugate $\beta$-lyases include kynureninase (51), glutamine transaminase K (GTK) (52), cytosolic aspartate aminotransferase (CytAspAT) (53), alanine aminotransferase (AlaAT) (53), cytosolic branched-chain aminotransfrese $\left(\mathrm{BCAT}_{\mathrm{c}}\right)(54)$, and $\gamma$-cystathionase (55). The mitochondrial $\beta$-lyases list includes mitochondrial branched-chain aminotransferase $\left(\mathrm{BCAT}_{\mathrm{m}}\right)(54)$, mitochondrial aspartate (MitAspAT) (56), alanine-glyoxylate aminotransferase isoenzyme II, 
GABA aminotransferase (57), and a high- $\mathrm{M}_{\mathrm{r}} \beta$-lyase which also occur in the cytosol (58).

\subsection{N,N-Dimethylacetamide (DMA) and Busulfan}

Busulfan was originally formulated in a tablet dosage form $\left(\right.$ Myleran $\left.{ }^{\circledR}\right)$.

Many studies have shown inter- and intra-individual variability in the disposition of busulfan (12). This was attributed in part to the high difference in busulfan bioavailability; six times in children and two times in adults (26), or to the variation in busulfan absorption (21). One way to overcome this is by formulating the drug in a suspension dosage form. Hospital pharmacists usually prepare oral busulfan suspension using Myleran ${ }^{\circledR}$ tablets to be administered to children and adults with swallowing difficulties (59), although such suspensions are not stable at room temperature, but are stable for 30 days at $4^{\circ} \mathrm{C}(60)$. Another way is by formulating busulfan in an intravenous dosage form. Several IV formulation were prepared and evaluated (61-64), and an IV dosage form is currently commercially available (Busulfex ${ }^{\circledR}$ ).

Busulfex ${ }^{\circledR}$ Injection is intended for intravenous administration. It is supplied as a clear, colorless, sterile, solution in $10 \mathrm{~mL}$ single use ampoules. Each ampoule of Busulfex ${ }^{\circledR}$ contains $60 \mathrm{mg}(6 \mathrm{mg} / \mathrm{mL})$ of busulfan. Busulfan is dissolved in N,N-dimethylacetamide (DMA) 33\% w/w and polyethylene glycol $400,67 \% \mathrm{w} / \mathrm{w}$.

DMA is an organic solvent used in industrial processes such as polymers, resins, fibers, films, coating and gums manufacturing. The toxicity of DMA in 
experimental animals is well established (65). In humans, exposure to DMA produced several clinical effects such as delirium, hallucinations, and hepatitis (66). An abnormal mental state was observed following exposure to DMA of more than $300 \mathrm{mg} / \mathrm{kg}(67)$. In a phase I clinical study, DMA showed activity as anticancer agent for the treatment of adenocarcinoma of the prostate, fibrosarcoma of deltoid, multiple myeloma, and adenocarcinoma of colon. Mild, transient impairment of liver function was reported as one of the dose limiting toxicities of DMA (68). Hepatotoxicity at relatively low chronic exposure (400 $\mathrm{mg} / \mathrm{kg} /$ day) is considered the most important toxic effect of DMA (69), and is believed to be caused by reactive metabolites through metabolism by CYP450. In rats, CYP450 2E1 was identified as the major isoform responsible for the metabolism of DMA (70). In humans, the metabolism of DMA produces acetamide and Nmethylacetamide, as identified in the urine of workers exposed to the compound (71). It was proposed that the attack on heme by free radical metabolites is responsible for the hepatotoxicity of DMA (72).

DMA constitutes $33 \%$ of the solvent system used to solubilize busulfan in parenteral dosage form. Busulfan is co-administered with cyclophosphamide in high doses in conditioning chemotherapy prior to bone marrow transplantation. Cyclophosphamide is a prodrug, and has to be metabolized to the 4hydroxycyclophophamide to show activity. This activation is mediated by CYP450 2C9, 3A4, and 2B6 (73). Since DMA is known to produce hepatotoxicity, and is introduced to the body in high quantity $(3.89 \mathrm{~g} /$ busulfan IV 
dose) in the conditioning chemotherapy, it is possible that DMA could inhibit liver CYP450 isoforms, which in turn might reduce the effectiveness of cyclophosphamide therapy.

\subsection{Research Objectives}

Since busulfan might be a substrate for CYP450s, its cytotoxicity might be related to its metabolites as well as the drug itself, and the fate of its glutathione conjugate is not well characterized, the main research objectives are the following:

1. To determine the effect of N,N-dimethylacetamide, a major constituent of busulfan parenteral formulation, on the catalytic activity of CYP450 3A4, 2B6, and 2C9 in human liver microsomes.

2. To investigate the CYP450 oxidative metabolism of busulfan.

3. To synthesize the glutathione conjugate of busulfan [ $\gamma$-glutamyl- $\beta$-(Stetrahydrothiophenium)alanylglycine].

4. To characterize the reactivity, alkylating activity, cytotoxicity, and effect on glutathione-S-transferases of the glutathione sulfonium conjugate of busulfan

5. To determine the chemical stability of the glutathione sulfonium conjugate of busulfan, and characterize the degradation products.

6. To synthesize the identified degradation product of the busulfan glutathione conjugate, and characterize its reactivity and cytotoxicity. 
7. To synthesize the cysteine S-conjugate of busulfan which could be produced in vivo from the glutathione sulfonium conjugate of busulfan through the action of mercapturic acid pathway enzymes.

8. To investigate the chemical formation of the cysteine sulfonium conjugate of busulfan, and study its chemical stability.

9. To determine the $\beta$-lyase activity toward the cysteine conjugate of busulfan in tissue fractions, and identify $\beta$-lyase enzymes that catalyze this reaction. 
Chapter 2: Experimental Section 


\subsection{Materials}

Busulfan, L-cysteine, glutathione, $\operatorname{Trizma}^{\circledR}-\mathrm{HCl}$, ketoconazole, NADPH, ethacrynic acid, thio-TEPA, ammonium acetate, 1-bromo-4-chlorobutane, diethylether, deuterium oxide, formic acid, acetone, 4-(4-nitrobenzyl)pyridine,

triethylamine, butanol, Dowex ${ }^{\circledR}-50 \mathrm{~W}, \mathrm{~d}_{6}$-methyl sulfoxide, ammonium hydroxide, $\mathrm{N}, \mathrm{N}$-dimethylacetamide, testosterone, $6 \beta$-hyroxytestosterone, bupropion, tolbutamide, sulfaphenazole, and 1-chloro-2,4-dinitrobenzne (CDNB) were obtained from Sigma Chemical Company (St. Louis, MO). Acetic acid, sodium bicarbonate, dibasic potassium phosphate, monobasic potassium phosphate, sodium hydroxide, hydrochloric acid, hexane (optima), acetonitrile (optima), methanol (HPLC grade), methylene chloride (optima) were obtained from Fisher Scientific (Pittsburgh, PA). Ethanol (200 proof) was obtained from Aaper Alcohol and Chemical Co. (Shelbyville, KY). $\mathrm{d}_{8}$-Busulfan was obtained from Cambridge Isotope Laboratories, Inc. (Andover, MA). Human liver microsomes, human liver cytosol, and Aroclor 1254 induced rat liver microsomes were obtained from In Vitro Technologies (Baltimore, MD).

\subsection{Instrumentation}

UV/VIS absorbance was measured on a Beckman DU 640 spectrophotometer (Beckman Coulter, Fullerton, CA). NMR spectra were obtained using either a Varian Gemini 2000, $300 \mathrm{MHz}$ broadband spectrometer or Varian Inova 600 spectrometer (Varian, Palo Alto, CA). 
LC/MS analysis was performed using a Waters ${ }^{\circledR}$ Alliance 2695 separation module equipped with a Waters ${ }^{\circledR} 996$ Photodiode Array Detector, and coupled to a Waters Micromass ZMD mass spectrometer with electrospray ionization (Waters ${ }^{\circledR}$, Milford, MA). Semi-preparative HPLC was carried on a BAS 200A HPLC equipped with BAS UV/VIS detector (Bioanalytical Systems, West Lafayette, IN). A Waters ${ }^{\circledR}$ Alliance 2695 separation module with a Waters ${ }^{\circledR} 2487$ Dual Absorbance Detector was used for HPLC analysis.

A Finnigan LCQ DECA (ThermoQuest, San Jose, CA) ion trap mass spectrometer was used for direct injection mass spectrometry analysis and multistage mass spectrometry analysis.

A Thomas-Hoover melting point apparatus was used for melting point determination. Samples were evaporated to dryness using a Rotavapor-R (Büchi, Flawil, Switzerland) rotavap system.

\subsection{In Vitro Metabolism of Busulfan by Liver Microsomes}

\subsubsection{Incubation of busulfan with liver microsomes}

Busulfan at various concentrations $(0.8 \mu \mathrm{M}-800 \mu \mathrm{M})$ was incubated with various human liver microsomes concentrations $(0.2 \mathrm{mg}-1.0 \mathrm{mg})$ for $10,20,30$, 40, and 60 minutes. A typical incubation (total volume $400 \mu \mathrm{L}$ ) consisted of busulfan, liver microsomes, Trizma ${ }^{\circledR}-\mathrm{HCl}$ buffer (100 mM, pH 7.4), and NADPH $(1 \mathrm{mM})$. Reactions were carried in a shaking water bath at $37^{\circ} \mathrm{C}$, and were started with the addition of NADPH, which was omitted in control incubations. Reactions were terminated by the addition of $100 \mu \mathrm{L}$ ice cold acetonitrile containing $\mathrm{d}_{8^{-}}$ 
busulfan $(5 \mu \mathrm{g} / \mathrm{mL})$. Samples were then centrifuged at 13,400 rpm for 10 minutes to precipitate the protein, and $150 \mu \mathrm{L}$ of the supernatant were transferred to HPLC vials for analysis. In substrate disappearance studies the same incubations described above were performed using human liver microsomes or Aroclor 1254 induced rat liver microsomes, and busulfan concentration of 1,2 , and $4 \mu \mathrm{M}$. Incubations were carried out for 30 minutes and busulfan concentration in the incubation mixture was compared to that in the control (no NADPH).

Busulfan was assayed by LC/MS according to the method described by Murdter et al (74) with minor modifications. Busulfan was resolved using a Luna $\mathrm{C}_{8}$ analytical column (5 $\mu \mathrm{m}$ particle size, $150 \times 2 \mathrm{~mm}$ i.d.; Phenomenex, Torrance, CA), with gradient elution using a binary solvent system composed of $10 \mathrm{mM}$ ammonium acetate and $10 \mathrm{~mL} / \mathrm{L}$ acetic acid (solution A), and acetonitrile (solvent B) at flow rate of $0.4 \mathrm{~mL} / \mathrm{min}$. Gradients were programmed as follows: $15 \%$ solvent $\mathrm{B}$ at 0 minutes, increased to $45 \%$ over 7 minutes, decreased back to $15 \% \mathrm{~B}$ over 0.1 minutes, and then left at $15 \% \mathrm{~B}$ for 3 minutes to re-equilibrate. Electrospray settings were as follows, capillary voltage $2.0 \mathrm{kV}$; sample cone, 18 $\mathrm{V}$; and extraction cone $4.0 \mathrm{~V}$. The source block temperature was set at $120^{\circ} \mathrm{C}$ and desolvation gas temperature at $300{ }^{\circ} \mathrm{C}$. The desolvation gas $\left(\mathrm{N}_{2}\right)$ flow and cone gas $\left(\mathrm{N}_{2}\right)$ flow were $853.8 \mathrm{~L} / \mathrm{h}$ and $249.4 \mathrm{~L} / \mathrm{h}$, respectively. Positive ionization with selected ion monitoring was used to detect the ammonium adduct of busulfan $(\mathrm{m} / \mathrm{z}$ 264), and $\mathrm{d}_{8}$-busulfan ammonium adduct $(\mathrm{m} / \mathrm{z} 272)$. 


\subsubsection{Enzymatic Conversion of 1-Chloro-2,4-dinitrobenzene (CDNB) to S- (2,4-Dintrophenyl)-glutathione (GS-DNB)}

The glutathione-S-transferase (GST) catalyzed conversion of 1-chloro-2,4dinitrobenzene (CDNB) to S-(2,4-dintrophenyl)-glutathione adduct (GS-DNB) was assayed according to the method described by Habig et al (75). A typical incubation consisted of human liver cytosol (total protein $0.08 \mathrm{mg}$ ), reduced glutathione $(1.0 \mathrm{mM})$, and CDNB $(5.0-1000 \mu \mathrm{M})$ in $100 \mathrm{mM}$ Trizma ${ }^{\circledR}-\mathrm{HCl}$ buffer ( $\mathrm{pH} 7.4$, total volume $1.0 \mathrm{~mL}$ ). CDNB was dissolved in methanol, and the total methanol concentration was less than $0.5 \%$. Reactions were initiated by the addition of human liver cytosol and carried out at room temperature; human liver cytosol was omitted from control incubations. The formation of the GS-DNB

adduct $\left(\varepsilon_{340}=9.6 \mathrm{mM}^{-1} \mathrm{~cm}^{-1}\right)$ was determined spectrophotometerically. The change in absorbance at $340 \mathrm{~nm}$ due to the formation of the GS-DNB adduct was followed for five minutes, and the rate of change in absorbance with time (dA/dt) was determined. The apparent velocity of the reaction (nmole $/ \mathrm{mg} / \mathrm{min}$ ) was determined according to the following equation:

nmole GS-DNB/mg/min $=(\mathrm{dA} / \mathrm{dt}) /[$ total protein concentration $* 0.0096]$

\subsubsection{Inhibition of Cytosolic GST Activity by Ketoconazole}

The enzymatic inhibition of CDNB-SG adduct formation in single donor human liver cytosol by the presence of ketoconazole was evaluated. The reaction mixture (total volume $1.8 \mathrm{~mL}$ ) containing Trizma ${ }^{\circledR}-\mathrm{HCl}$ buffer $(0.1 \mathrm{M}, \mathrm{pH} 7.4)$, human liver cytosol (total protein $0.08 \mathrm{mg}$ ), CDNB (final concentration $1.0 \mathrm{mM}$ in methanol), and ketoconazole (final concentration $0,12.5,25,50,100$, and $250 \mu \mathrm{M}$ 
in methanol) was incubated at $37^{\circ} \mathrm{C}$. The reaction was started by the addition of $200 \mu \mathrm{L}$ of $10 \mathrm{mM} \mathrm{GSH}$ (final concentration $1.0 \mathrm{mM}$ ), and the absorbance was monitored for 3 minutes. The non-enzymatic rate (excluding cytosol) was subtracted from the enzymatic rate to obtain an apparent velocity calculation. To obtain an apparent Ki for ketoconazole inhibition of GST, incubations as described above were performed using various concentrations of CDNB (final concentration $0,0.125,0.25,0.5$, and $1 \mathrm{mM})$, in the presence of ketoconazole $(0,100,250 \mu \mathrm{M})$. All determinations were performed at least two times. Reaction rate data was fitted to Michaelis-Menton kinetics using Enzyme Kinetics Module (version 1.1.1, Systat Software, Inc.).

\subsection{Sulfonium Ion Conjugate of Busulfan}

\subsubsection{Synthesis of $\gamma$-Glutamyl- $\beta$-(S-tetrahydrothiophenium)alanylglycine ( $\gamma$-E- THT-AG)}

The sulfonium ion conjugate of busulfan was prepared using the method of Marchand et al with some modifications (40). Briefly, reduced glutathione (764 $\mathrm{mg}$ ) was dissolved in a $7.5 \mathrm{~mL}$ of $1 \mathrm{M} \mathrm{NaOH}, 310 \mu \mathrm{L}$ of 1-bromo-4-chlorobutane were added, and then ethanol was added until a clear solution was obtained (approximately $12.0 \mathrm{~mL}$ ). The reaction mixture was stirred for $1 \mathrm{~h}$ at room temperature, and then the $\mathrm{pH}$ was adjusted to 5.4 by addition of $1 \mathrm{M} \mathrm{HCl}$. The reaction mixture was stirred for $20 \mathrm{~h}$ at room temperature, and then was extracted 3 times with hexane and 3 times with diethyl ether $(80 \mathrm{~mL}$ each). The organic 
layers were discarded and the aqueous phase was evaporated using a rotary evaporator.

$\gamma$-E-THT-AG was purified by semi-preparative HPLC equipped with an Econosphere $\mathrm{C}_{8}$ column $(10 \times 250 \mathrm{~mm})$, and a UV/VIS detector set at wavelength of $210 \mathrm{~nm}$. Elution was carried out isocratically using 50: 50 methanol/water (v/v) at flow rate of $3.0 \mathrm{~mL} / \mathrm{min}$. The crude reaction mixture was dissolved in distilled water and $100 \mu \mathrm{L}$ were injected to the $\mathrm{LC}$ system. The sulfonium ion band was collected, all the collected bands were pooled and the solvent was evaporated using rotary evaporation.

The sulfonium ion conjugate of busulfan was characterized using mass spectrometry and ${ }^{1} \mathrm{H}$ NMR. ${ }^{1} \mathrm{H}$ NMR spectrum was obtained on a sample of sulfonium ion conjugate of busulfan dissolved in $\mathrm{D}_{2} \mathrm{O}(10 \mathrm{mg} / \mathrm{mL})$. MS and MS/MS spectra were obtained using $1.0 \mu \mathrm{g} / \mathrm{mL}$ of $\gamma$-E-THT-AG dissolved in a solution of $0.1 \%$ formic acid in methanol/water $(50 / 50, \mathrm{v} / \mathrm{v})$. The electrospray source (ESI) included: positive ion detection; sheath $\mathrm{N}_{2}$ gas flow rate 20 (arbitrary units); spray voltage $5.2 \mathrm{kV}$; capillary temperature $175.0^{\circ} \mathrm{C}$; capillary voltage $38.00 \mathrm{~V}$; and tube lens offset 15.0 V. Product $(40 \mathrm{mg}) ;{ }^{1} \mathrm{H}$ NMR $\left(\mathrm{D}_{2} \mathrm{O}\right): \delta 2.15-$ $2.25(\mathrm{~m}, 2 \mathrm{H}) ; 2.37-2.45(\mathrm{~m}, 4 \mathrm{H}), 2.59-2.64(\mathrm{~m}, 2 \mathrm{H}), 3.48-3.80$ (broad m, 7H), $3.84(\mathrm{~s}, 2 \mathrm{H})$, and $5.09 \mathrm{ppm}(\mathrm{t}, 1 \mathrm{H})$. ESI-MS; $\mathrm{M}^{+} \mathrm{m} / \mathrm{z} 362$ (positive ion mode); MS/MS: $m / z$ 274, $\mathrm{M}^{+}$- tetrahydrothiophene; $m / z$ 199, $\mathrm{M}^{+}$- tetrahydrothiophene and glycine; $m / z$ 145, $\mathrm{M}^{+}$- tetrahydrothiophene and pyroglutamic acid. 


\subsubsection{Stability of $\gamma$-E-THT-AG}

The stability of $\gamma$-E-THT-AG at $\mathrm{pH} 7.4$ and 8.0 was determined by measuring its rate of disappearance. Stock solutions were made in distilled water ( $2 \mathrm{mg} / \mathrm{mL})$, and further diluted in $100 \mathrm{mM}$ potassium phosphate buffer $(\mathrm{pH} 7.4$ or $\mathrm{pH}$ 8.0) to produce a final concentration $30 \mu \mathrm{g} / \mathrm{mL}$. Solutions were incubated in a shaking water bath at $37^{\circ} \mathrm{C}$. Aliquots $(6.0 \mu \mathrm{L})$ taken at $0,0.25,0.5,0.75,1.0,1.5$, $2,3,4,5$, and $6 \mathrm{~h}$, were diluted in $1.5 \mathrm{~mL}$ distilled water and $50-\mu \mathrm{L}$ aliquots were injected into the LC/UV/MS system. The photodiode array detector was programmed to scan between 200 and $300 \mathrm{~nm}$, and a mass spectrometer was programmed to utilize electrospray ionization in a positive ion mode with selected ion recording of $\mathrm{m} / \mathrm{z} 362$ for $\gamma$-E-THT-AG. The mobile phase consisted of methanol/water $(50 / 50, \mathrm{v} / \mathrm{v})$ pumped at $0.4 \mathrm{~mL} / \mathrm{min}$ through an Agilent Zorbax SB-NC C ${ }_{18}(150$ x $4.6 \mathrm{~mm})$ reversed phase column (Agilent, Santa Clara, CA). Ion optics (ESP+) were as follows: capillary, $3.0 \mathrm{kV}$; sample cone, $21 \mathrm{~V}$; and extraction cone, $3.0 \mathrm{~V}$. The source block temperature was set at $120^{\circ} \mathrm{C}$ and desolvation gas temperature was set at $300^{\circ} \mathrm{C}$. The desolvation gas flow and cone gas flow (both $\mathrm{N}_{2}$ ) were $473 \mathrm{~L} / \mathrm{h}$ and $117 \mathrm{~L} / \mathrm{h}$, respectively.

Non-enzymatic breakdown of $\gamma$-E-THT-AG via a $\beta$-elimination reaction is predicted to generate $\gamma$-glutamyldehydroalanylglycine. The appearance of vinyl protons associated with this tripeptide was detected by NMR. $\gamma$-E-THT-AG (14 $\mathrm{mg}$ ) was dissolved in $1.0 \mathrm{~mL}$ of $\mathrm{D}_{2} \mathrm{O}$ and proton spectra were recorded to follow 
chemical changes upon the addition of dibasic phosphate ( $15 \mathrm{mg}$; final $\mathrm{pD} \sim 8.0$ ) and incubation for $12 \mathrm{~h}$ correct at $37^{\circ} \mathrm{C}$.

\subsubsection{Relative Alkylation Reactivity of $\gamma$-E-THT-AG}

The method of Linford et al (76) was used to determine the relative alkylating activity of busulfan and $\gamma$-E-THT-AG. Aliquots of busulfan $(15 \mathrm{mg} / \mathrm{mL}$ in acetone) and $\gamma$-E-THT-AG conjugate $(15 \mathrm{mg} / \mathrm{mL}$ in water) stock solution were introduced to a series of round-bottom test tubes (total volume of acetone or water $250 \mu \mathrm{L})$, followed by $250 \mu \mathrm{L}$ of distilled water, $500 \mu \mathrm{L}$ of $2.5 \% 4-(4-$ nitrobenzyl)pyridine, and $500 \mu \mathrm{L} 1.0 \mathrm{M}$ acetic acid. Final concentrations were $0.25,0.5,1.25,2.5,5.0,7.5,10 \mu \mathrm{g} / \mathrm{mL}$. Busulfan and $\gamma$-E-THT-AG were omitted from controls, and thio-TEPA in methanol $(250 \mu \mathrm{g}-1.0 \mathrm{mg})$ was used as positive control. All tubes were capped, vortexed, and incubated at $56{ }^{\circ} \mathrm{C}$ in a water bath for 20 minutes. Each tube was then allowed to cool at room temperature. After cooling, $2.0 \mathrm{~mL}$ of triethylamine in propylene glycol $(50 / 50, \mathrm{v} / \mathrm{v})$ was added to each tube, vortexed, allowed to react for 2 minutes, and the absorbance at $580 \mathrm{~nm}$ was determined spectrophotometerically.

\subsubsection{Cytotoxicity of $\gamma$-E-THT-AG}

Apoptosis : Human lung cancer epithelial NCI-H460 cells were cultured in RPMI-1640 medium supplemented with 5\% fetal bovine serum and $2 \mathrm{mM}$ glutamine. Antibiotics added to the medium were $100 \mathrm{U} / \mathrm{mL}$ penicillin and 100 $\mu \mathrm{g} / \mathrm{mL}$ streptomycin. Cell cultures were maintained in a humidified atmosphere of 
$95 \%$ air and $5 \% \mathrm{CO}_{2}$ at $37{ }^{\circ} \mathrm{C}$. Cells were passaged at preconfluent densities by the use of a solution containing $0.05 \%$ trypsin and $0.5 \mathrm{mM}$ EDTA.

Busulfan and $\gamma$-E-THT-AG, in the concentration 0-400 $\mu \mathrm{g} / \mathrm{mL}$, were incubated with NCI-H460 cells for 24. Busulfan was dissolved in DMSO while the sulfonium ion conjugate of busulfan was dissolved in phosphate buffer $(\mathrm{pH}$ 7.4). Apoptosis was quantified by assessing the characteristic morphological changed in the apoptotic cells using Hoechst 33342 staining. Hoechst 33342 binds specifically to the A-T base region of DNA and emits the fluorescence. At the end of the incubation, cells were washed twice with PBS (pH 7.4), stained with Hoechst $33342(10 \mu \mathrm{g} / \mathrm{ml}$ in PBS) for $3 \mathrm{~min}$, and then photographs were taken at X200 magnification under a fluorescent microscope (Olympus, Tokyo, Japan). The number of attained cells per more than 200 cells was counted to assess the proportion of cells with nuclear fragmentation. The experiment was repeated three times.

\subsubsection{Effect of $\boldsymbol{\gamma}$-E-THT-AG on glutathione-S-transferase (GST)}

The effect of $\gamma$-E-THT-AG on the enzymatic activity of glutathione-Stransferases was determined at room temperature in $1 \mathrm{~mL}$ (final volume) of 100 $\mathrm{mM}$ Trzma ${ }^{\circledR}$-HCl buffer (pH 7.4) containing $1 \mathrm{mM} \mathrm{GSH}, 100 \mathrm{mM}$ CDNB, human liver cytosol (final protein concentration of $0.08 \mathrm{mg}$ ), and $\gamma$-E-THT-AG (1-100 $\mu \mathrm{M})$. Reactions were initiated by the addition of human liver cytosol which was omitted in control incubations. Ethacrynic acid $(2.5-200 \mu \mathrm{M})$ was used as a 
positive control. Both ethacrynic acid and CDNB were dissolved in methanol and the total methanol concentration was less than $1.0 \%$. The formation of GS-DNB adduct was followed spectrophotometerically and the apparent reaction velocity was determined as described above.

\subsection{Busulfan-Cysteine Sulfonium Ion Conjugate}

\subsubsection{Synthesis of S- $\beta$-Alanyltetrahydrothiophenium (THT-A)}

The busulfan-cysteine sulfonium conjugate was prepared according to the method of Roberts et al (37) with some modifications. 1-bromo-4-chlorobutane was used instead of dibromobutane. Briefly, 1-bromo-4-chloro butane (2.16 g) were added to ethanol: water (70: 30, v: v) solution. Five $\mathrm{mL}$ of $4 \mathrm{~N} \mathrm{NaOH}$ containing $1.57 \mathrm{~g}$ of cysteine were then added, and the reaction was allowed to stand at room temperature over night. The reaction mixture was then filtered and the filtrate was discarded. The product was crystallized using $0.5 \mathrm{~L}$ of acetone. THT-A was characterized by MS, MS/MS, and NMR as described above for $\gamma$-ETHT-AG. Elemental analysis showed that the THT-A product contained one equivalent of $\mathrm{Cl}^{-}$, one equivalent of $\mathrm{Br}^{-}$and one equivalent of $\mathrm{H}_{2} \mathrm{O}$. Product (1.0 g); ${ }^{1} \mathrm{H}$ NMR $\left(\mathrm{D}_{2} \mathrm{O}\right): \delta$ 2.30-2.52 (m, 4H), 3.52-3.64 (m, 4H), 3.68-3.80 (m, 2H), and $3.96 \mathrm{ppm}$ (t, 1H). ESI-MS; $\mathrm{M}^{+} \mathrm{m} / \mathrm{z} 176$ (positive ion mode); MS/MS: m/z 88, $\mathrm{M}^{+}$- tetrahydrothiophene. 


\subsubsection{Chemical Stability of THT-A}

The chemical stability of THT-A at pH 7.4 and 8.0 was determined by measuring its rate of disappearance. Stock solutions were made in distilled water $(2.0 \mathrm{mg} / \mathrm{mL})$, and further diluted in $100 \mathrm{mM}$ potassium phosphate buffer $(\mathrm{pH} 7.4$ or $\mathrm{pH} 8.0$ ) to produce a final concentration of $100 \mu \mathrm{g} / \mathrm{mL}$. Both solutions were incubated in a shaking water bath at $37^{\circ} \mathrm{C}$. Aliquots $(6 \mu \mathrm{L})$ taken at $0,0.25,0.5$, $0.75,1.0,1.5,2,3,4,5$, and $6 \mathrm{~h}$, were diluted in $1.5 \mathrm{~mL}$ distilled water and $50 \mu \mathrm{L}$ aliquots were injected into the LC/UV/MS system. The photodiode array detector was programmed to scan between 200 and $300 \mathrm{~nm}$, and the mass spectrometer was programmed to utilize electrospray ionization in a positive ion mode with selected ion recording of $m / z$ 176. The mobile phase consisted of methanol-water (50:50, $\mathrm{v} / \mathrm{v}$ ) pumped at $0.4 \mathrm{~mL} / \mathrm{min}$ through an Agilent Zorbax SB-NC $\mathrm{C}_{18} 150 \times 4.6 \mathrm{~mm}$ reversed phase column. Ion optics (ESP+) were as follows: capillary, $3.0 \mathrm{kV}$; sample cone, $21 \mathrm{~V}$; and extraction cone, $3.0 \mathrm{~V}$. The source block temperature was set at $120^{\circ} \mathrm{C}$ and desolvation gas temperature was set at $300^{\circ} \mathrm{C}$. The desolvation gas flow and cone gas flow (both $\mathrm{N}_{2}$ ) were $473 \mathrm{~L} / \mathrm{h}$ and $117 \mathrm{~L} / \mathrm{h}$, respectively.

\subsubsection{Reaction of cysteine with busulfan.}

Aliquots $(50 \mu \mathrm{L})$ of busulfan stock solution $(200 \mu \mathrm{g} / \mathrm{mL}$ in acetonitrile $)$ were mixed with $4.9 \mathrm{~mL}$ of $100 \mathrm{mM}$ potassium phosphate buffer ( $\mathrm{pH} 8.0$ ), then 50 $\mu \mathrm{L}$ of cysteine stock solution ( $40 \mathrm{mg} / \mathrm{mL}$ in water) were added. The mixture was vortexed for one minute and incubated at $37^{\circ} \mathrm{C}$. Aliquots $(100 \mu \mathrm{L})$ taken at 0,30 , $60,90,120$, and 180 minutes, were diluted with $100 \mu \mathrm{L}$ acetonitrile containing $\mathrm{d}_{8^{-}}$ 
busulfan $(5 \mu \mathrm{g} / \mathrm{mL})$, and transferred to HPLC vials. Busulfan was assayed as described earlier.

\subsubsection{Enzymatic Conversion of THT-A to Pyruvate and Ammonium}

THT-A contains a good leaving group and could undergo a $\beta$-elimination reaction to produce pyruvate and ammonium. To evaluate the potential for a $\beta$ elimination reaction, THT-A was incubated with rat liver, brain and kidney homogenate, and purified cystathionine- $\gamma$-lyase. All experiment procedures in this section were done by Dr. Arthur Coopers' group at Weill Medical College of Cornell University.

Preparation of rat tissue homogenates: All experimental procedures were approved by the Weill Medical College of Cornell University Institutional Animal Care and Use Committee (Protocol 0505-367A). Six-month old male Fisher x Brown Norway $F_{1}$ rats were used. The animals were fed ad libitum and had full access to water. Rats were sacrificed by decapitation. Liver, kidneys and forebrains were removed and separately immersed in $50 \mathrm{~mL}$ of ice-cold isolation buffer containing $300 \mathrm{mM}$ sucrose, $10 \mathrm{mM}$ HEPES, $0.5 \mathrm{mM}$ EGTA, and 0.5\% (w/v) fatty acids-free bovine serum albumin ( $\mathrm{pH}$ adjusted to 7.4 with Tris base). The tissues were pre-chilled for $\sim 5-6$ minute. Each tissue sample was separately cut into small pieces with scissors and homogenized in a $\sim 10$-fold volume of isolation buffer supplemented with protease-inhibitor cocktail (1/100 dilution). Liver and kidney tissues were homogenized using a Potter homogenizer. The 
brains were homogenized using a Dounce homogenizer. All steps were carried out at $0-4{ }^{\circ} \mathrm{C}$. The homogenates were divided into several aliquots and stored at -20 ${ }^{\circ} \mathrm{C}$. In some experiments, the liver homogenate was fractionated into cytosolic and mitochondrial fractions and stored at $-20^{\circ} \mathrm{C}(77)$. All tissue samples were freezethawed several times. In other experiments, aliquots of the tissue preparations were centrifuged at $1,000 \mathrm{~g}$ for $5 \mathrm{~min}$ and $0.1 \mathrm{~mL}$ of each supernatant was filtered through a centrifugal filter device with a 10-KDa cut-off membrane (Microcon Ultracel YM-10, Millipore Corporation, Bedford, MA). The pass through is not expected to contain PLP-dependent enzymes, but is expected to possess free PLP and free pyridoxal.

Protein measurements: Protein concentrations were determined using a microBiuret assay kit obtained from Sigma Chemical Company (St. Louis, MO). Bovine serum albumin was used as a standard.

Purifcation of Cystathionine $\gamma$-lyase ( $\gamma$-cystathionase; $2.4 \mathrm{U} / \mathrm{mg} ; 1.32 \mathrm{U} / \mathrm{mL}$ ) was purified from rat liver cytosol by a method modified from that of Hargrove and Wichman (78) as described by Pinto et al. (79) and stored frozen at $-20^{\circ} \mathrm{C}$. Bovine liver glutamate dehydrogenase (GDH) (40 U/mg in 40\% glycerol) was obtained from Boehringer Mannheim (Mannheim, Germany). Rat liver mitochondrial aspartate aminotransferase [mitAspAT; $1.35 \mathrm{mg} / \mathrm{mL}$ in $20 \mathrm{mM}$ Tris- $\mathrm{HCl}$ buffer, $\mathrm{pH} 8.3$, containing $0.1 \mathrm{mM}$ EDTA, $150 \mathrm{mM} \mathrm{NaCl}$ and $0.2 \%(\mathrm{w} / \mathrm{v})$ sodium azide; $410 \mathrm{U} / \mathrm{mg}$ of protein at $37^{\circ} \mathrm{C}$ ] was a generous gift from Dr. Ana Iriarte, University of Missouri-Kansas, Kansas City, MO. Rat kidney glutamine transaminase K 
(GTK; $5 \mathrm{U} / \mathrm{mg}$ in $20 \%$ glycerol; $0.18 \mathrm{U} / \mathrm{mL}$ ) was purified from the cytosolic fraction of rat kidneys as described previously (80).

Enzyme assays. Cystathionine $\gamma$-lyase activity was assayed by a slight modification of the procedure of Cooper and Pinto (81) in which $\alpha$-ketobutyrate formed from L-homoserine was measured as its 2,4-dinitrophenylhydrazone. The standard reaction mixture $(20 \mu \mathrm{L})$ contained $100 \mathrm{mM}$ potassium phosphate buffer (pH 7.4), $20 \mathrm{mM}$ L-homoserine and enzyme. The blank contained enzyme but no L-homoserine. After incubation at $37^{\circ} \mathrm{C}$, the reaction was terminated by the addition of $10 \mu \mathrm{L}$ of $5 \mathrm{mM}$ 2,4-dinitrophenylhydrazine in $2 \mathrm{M} \mathrm{HCl}$. After a further 10 minutes incubation, $170 \mu \mathrm{L}$ of $1 \mathrm{M} \mathrm{NaOH}$ was added and the absorbance at $430 \mathrm{~nm}$ was read within 2 minutes of addition of alkali against a blank carried through the same procedure. The extinction coefficient of $\alpha$-ketobutyrate 2,4dinitrophenylhydrazone under these conditions is $15,000 \mathrm{M}^{-1} \mathrm{~cm}^{-1}$. L-Homoserine is a convenient $\gamma$-lyase substrate of cystathionine $\gamma$-lyase (82) that is less expensive than L-cystathionine.

$\beta$-Lyase reactions with THT-A were measured in a reaction mixture (20 $\mu \mathrm{L}$ ) containing $100 \mathrm{mM}$ potassium phosphate buffer (pH 7.4), $5 \mathrm{mM}$ THT-A and enzyme. After incubation at $37^{\circ} \mathrm{C}$ the reaction was stopped by addition of $10 \mu \mathrm{L}$ of $5 \mathrm{mM}$ 2,4-dinitrophenylhydrazine in $2 \mathrm{M} \mathrm{HCl}$. After a further 10 minutes incubation, $170 \mu \mathrm{L}$ of $1.0 \mathrm{M} \mathrm{NaOH}$ was added and the absorbance at $430 \mathrm{~nm}$ was read within 2 minutes. The extinction coefficient of pyruvate 2,4- 
dinitrophenylhydrazone under these conditions is $16,000 \mathrm{M}^{-1} \mathrm{~cm}^{-1}$. The blank contained no enzyme or enzyme source added just before addition of 2,4dinitrophenylhydrazine reagent. A blank containing no enzyme takes into account the small amount of pyruvate generated non-enzymatically from $5 \mathrm{mM}$ THT-A. Most cysteine $S$-conjugate $\beta$-lyases that catalyze a non-physiological $\beta$ elimination reaction if a strong electron-withdrawing group is attached at the sulfur of the cysteine $S$-conjugate are aminotransferases $(49,83)$. For these enzymes, a transamination reaction usually competes with the $\beta$-lyase reaction. A half transamination results in the formation of the pyridoxamine 5'-phosphate form of the coenzyme. The enzyme in the pyridoxamine 5'-phosphate form cannot support a $\beta$-lyase reaction. For the enzyme to catalyze an uninterrupted $\beta$-lyase reaction an $\alpha$-keto acid substrate (or PLP) must be present in the assay mixture to ensure continuous presence of the PLP form of the enzyme $(52,84)$. To determine whether $\beta$-lyase-catalyzed reactions with THT-A are dependent on $\alpha$-keto acids, in some experiments the $\beta$-lyase reaction mixture was supplemented with $0.5 \mathrm{mM}$ $\mathrm{KMB}$ or $0.5 \mathrm{mM} \mathrm{KG}$. KMB is good $\alpha$-keto acid substrate of glutamine transaminase K (GTK), an enzyme that catalyzes a strong $\beta$-lyase reaction with the cysteine $S$-conjugates $S$-(1,1,2,2-tetrafluoroethyl)-L-cysteine (TFEC) and S-(1,2dichlorovinyl)-L-cysteine (DCVC) $(49,83,85) . \mathrm{KG}$ is a good $\alpha$-keto acid substrate of most other mammalian aminotransferases, including mitAspAT, an enzyme that 
also exhibits $\beta$-lyase activity toward TFEC and DCVC (56). GTK and mitAspAT activities were measured as described by Cooper (80).

Ammonium was measured with GDH. To the solution containing ammonium $(20 \mu \mathrm{L})$ was added $180 \mu \mathrm{L}$ of a reaction mixture containing $100 \mathrm{mM}$ potassium phosphate buffer (pH 7.4), $0.1 \mathrm{mM}$ EDTA, $10 \mathrm{mM} \mathrm{KG}, 0.25 \mathrm{mM}$ $\mathrm{NADH}, 0.01 \mathrm{mM}$ ADP and $4 \mathrm{U}$ of GDH. The decrease in absorbance at $340 \mathrm{~nm}$ $\left(\varepsilon=6.22 \times 10^{3} \mathrm{M}^{-1} \mathrm{~cm}^{-1}\right)$ due to oxidation of NADH to $\mathrm{NAD}^{+}$was continuously measured at $37^{\circ} \mathrm{C}$. The reaction was complete in 20 minutes.

All spectrophotometric measurements were carried out with a SpectraMax 96-well plate spectrophotometer (Molecular Devices, Sunnyvale, CA, USA). A unit of enzyme activity $(\mathrm{U})$ is defined as the amount of enzyme that catalyzes the formation of $1 \mu \mathrm{mol}$ of product per min at $37^{\circ} \mathrm{C}$.

\section{$2.6 \gamma$-Glutamyldehydroalanylglycine (dehydroglutathione)}

\subsubsection{Synthesis of dehydroglutathione}

Dehydroglutathione was synthesized through the elimination of 2,4dinitrothiophenolate from $S$-(2,4-dinitrophenyl)glutathione as described by Carthew et al (86). S-(2,4-Dinitrophenyl)glutathione was synthesized with minor modification of the method of Patchornik et al (87). Briefly, $2.02 \mathrm{mg}(10 \mathrm{mmol})$ of 1-chloro-2,4-dinitrobenzene were dissolved in $20 \mathrm{~mL}$ of methanol and added drop wise over 30 minutes to a solution containing $3.07 \mathrm{~g}(10 \mathrm{mmol})$ reduced glutathione dissolved in $40 \mathrm{~mL}$ of $1 \mathrm{~N} \mathrm{NaHCO}_{3}$. The solution was then stirred at 
room temperature for one hour, filtered, and the product was precipitated by the addition of $1 \mathrm{M} \mathrm{HCl}$. The yellow precipitate was collected by vacuum filtration and dried. S-(2,4-Dinitrophenyl)glutathione was recrystallized from hot water. The yellow crystals were characterized by MS, MS/MS, and ${ }^{1} \mathrm{H}$ NMR. Product (2.0 g) had m.p. $189-191{ }^{\circ} \mathrm{C} .{ }^{1} \mathrm{H}$ NMR (DMSO-d $\left.{ }_{6}\right): \delta 1.84(\mathrm{~m}, 1 \mathrm{H}), 1.95(\mathrm{~m}, 1 \mathrm{H}), 2.32(\mathrm{~m}$, 2H), 3.31-3.38 (m, 2H), 3.60-3.65 (m, 1), $3.73(\mathrm{~m}, 1 \mathrm{H}), 4.61(\mathrm{~m}, 1 \mathrm{H}), 7.97(\mathrm{~d}$, $1 \mathrm{H}), 8.46(\mathrm{~d}, 1 \mathrm{H}), 8.71(\mathrm{~d}, 1 \mathrm{H})$, and $8.87 \mathrm{ppm}(\mathrm{m}, 2 \mathrm{H})$. ESI-MS; $\mathrm{MH}^{+} \mathrm{m} / \mathrm{z} 474$ (positive ion mode); MS/MS: m/z 399, $\mathrm{MH}^{+}$- glycine; $\mathrm{m} / \mathrm{z} 345, \mathrm{MH}^{+}$pyroglutamic acid.

S-(2,4-Dinitrophenyl)glutathione was then used to prepare dehydroglutathione. One gram of S-(2,4-dinitrophenyl)glutathione was dissolved in $50 \mathrm{~mL}$ of $0.5 \mathrm{M} \mathrm{NaOH}$, and the solution was stirred at room temperature for 30 minutes. The solution was then extracted five times with butanol $(20 \mathrm{~mL}$ each), the organic layers were discarded and the aqueous layer was mixed with 3 grams of Dowex ${ }^{\circledR}-50 \mathrm{~W}$ ion exchange resin (hydrogen form) to remove $\mathrm{Na}^{+}$. The $\mathrm{pH}$ of the solution dropped from 12.4 to $\sim 4.0$. The aqueous solution was evaporated, and a light brown solid was collected (yield 60.4\%). Unlike the method of Carthew et al, the obtained product was neither decolorized by charcoal nor recrystallized from ethanol. The product was characterized by mass spectrometry and ${ }^{1} \mathrm{H}$ NMR spectrometry, and its purity was determined by quantitative ${ }^{13} \mathrm{C}$ NMR. Product (0.51 g). ${ }^{1} \mathrm{H}$ NMR $\left(\mathrm{D}_{2} \mathrm{O}\right): \delta 2.06(\mathrm{~m}, 2 \mathrm{H}), 2.48(\mathrm{~m}, 2 \mathrm{H}), 3.69(\mathrm{~m}, 1 \mathrm{H}), 3.81(\mathrm{~s}, 2 \mathrm{H})$, 
and $5.62 \mathrm{ppm}(\mathrm{d}, 2 \mathrm{H})$. ESI-MS; $\mathrm{MH}^{+} \mathrm{m} / \mathrm{z} 274$ (positive ion mode); MS/MS: $\mathrm{m} / \mathrm{z}$ 256, $\mathrm{MH}^{+}$- water; $\mathrm{m} / \mathrm{z}$ 199, $\mathrm{MH}^{+}$- glycine.

\subsubsection{Reactivity of Dehydroglutathione Toward Nucleophiles}

The ability of dehydroglutathione to react in the body with nucleophiles such as cysteine and glutathione was evaluated. The adduct structure was elucidated by mass spectrometry and the rate of adduct formation was determined by ${ }^{1} \mathrm{H}$ NMR.

Cysteine-dehydroglutathione adduct: A solution of dehydroglutathione in water $(10 \mu \mathrm{mol}, 0.5 \mathrm{~mL})$ was mixed with a solution of cysteine in $1 \% \mathrm{NH}_{4} \mathrm{OH}(10 \mu \mathrm{mol}$, $0.5 \mathrm{~mL}$ ), and the mixture was held overnight at $37^{\circ} \mathrm{C}$ in a water bath. The mixture was further diluted 200 fold in a solution of $1 \% \mathrm{FA}$ in methanol/water $(50 / 50$, $\mathrm{v} / \mathrm{v}$ ), and analyzed by mass spectrometry. The rate of the reaction was determined by ${ }^{1} \mathrm{H}$ NMR through following the disappearance of the vinylic proton doublet (between 5-6 ppm) of the dehydroglutathione upon the addition of cysteine.

Dehydroglutathione $(0.05 \mathrm{mmol})$ and cysteine $(0.05 \mathrm{mmol})$ were dissolved in 100 $\mathrm{mM}$ potassium phosphate buffer prepared in $\mathrm{D}_{2} \mathrm{O}(\mathrm{pD}$ 8.0). Both solutions were incubated at $37{ }^{\circ} \mathrm{C}$ for 30 minutes, then $0.5 \mathrm{~mL}$ of each solution was mixed and transferred to NMR tube. The NMR probe was set at $37{ }^{\circ} \mathrm{C}$, the first ${ }^{1} \mathrm{H}$ NMR spectrum recorded was designated as time zero, and a new spectrum was recorded every 5 minutes for 30 minutes.

Glutathione-dehydroglutathione adduct: $0.5 \mathrm{~mL}$ of a solution of glutathione in $1 \%$ $\mathrm{NH}_{4} \mathrm{OH}(18.3 \mathrm{mmol})$ were mixed with $0.5 \mathrm{~mL}$ of dehydroglutathione in water 
(36.6 mmol), the mixture was incubated at $37^{\circ} \mathrm{C}$ for 12 hours. The solution was diluted 1000 fold in a solution of methanol/water (50/50, v/v, 1\% formic acid). Structure elucidation of the adduct was performed in MS, MS/MS, and $\mathrm{MS}^{3}$.

\subsubsection{In Vitro Cytotoxicity of Dehydroglutathione}

C6 rat glioma cells were obtained from the American Type Culture Collection (Manassas, VA), and maintained in DMEM-F12 (1:1) medium (Gibco, Grand Island, NY) supplemented with $1 \%$ of antibiotic-antimycotic mixture (Gibco, Grand Island, NY) and 10\% fetal calf serum (FCS; Sigma, St. Louis, MO) at $37^{\circ} \mathrm{C}$ under an atmosphere of $5 \% \mathrm{CO}_{2}-95 \%$ air. For toxicity experiments $5 \times 10^{4}$ cells per well were seeded into Primaria 12-well cluster dishes in $0.5 \mathrm{ml}$ of DMEM-F12/FCS medium, and allowed to attach to the substratum overnight.

Subsequently, the cells were exposed to busulfan and dehydroglutathione for $24 \mathrm{~h}$. Busulfan was added as DMSO (1\% final concentration) solution and cultures treated with DMSO alone served as controls. Dehydroglutathione was added as aqueous solution. Cell viability was assessed by the trypan blue exclusion test. Briefly, the medium was removed, the adhering cells were trypsinized and stained with trypan blue. Viable, dye excluding cells were counted in a hemocytometer.

\subsection{Effect of N,N-Dimethylacetamide (DMA) on the Catalytic Activity of CYP450 3A4, 2B6, and 2C9 in Human Liver Microsomes}

The effect of DMA on CYP450 3A4, 2B6, and 2C9 isoforms in human liver microsomes was determined by studying its ability to inhibit the metabolism of known substrate markers for each isoform. 


\subsubsection{CYP450 3A4 Assay}

Testosterone $6 \beta$-hydroxylation was measured to determine the inhibitory effect of DMA on CYP450 3A4. A typical incubation consisted of human liver microsomes $(0.2 \mathrm{mg})$, testosterone $(40 \mu \mathrm{M})$, DMA $(0-25 \mathrm{mM})$, NADPH $(1 \mathrm{mM})$ in a total volume of $500 \mu \mathrm{L}$ of $50 \mathrm{mM}$ potassium phosphate buffer (total methanol $<2 \%$ ). The incubations were done in a shaking water bath maintained at $37^{\circ} \mathrm{C}$. For control incubations, NADPH was omitted. Reactions were started by the addition of NADPH, and were stopped after 10 minutes by the addition of $2.0 \mathrm{~mL}$ of methylene chloride. Each sample was then vortexed for 1 minute and centrifuged for 10 minutes at 3,000 rpm. The aqueous layer (upper layer) was discarded, and $1.8 \mathrm{~mL}$ of the organic layer was transferred to a clean culture tube. The organic layer was evaporated under a gentle stream of nitrogen, and the residue was reconstituted in $200 \mu \mathrm{L}$ of $50 \%$ methanol, and $10 \mu \mathrm{L}$ were injected into the HPLC.

Testosterone and $6 \beta$-hydroxytestosterne were resolved using an Agilent Zorbax SB-NC $5 \mu \mathrm{m} \mathrm{C}_{18}$ HPLC column $(4.6 \times 150 \mathrm{~mm}) \mathrm{kept}$ at $40^{\circ} \mathrm{C}$, and a binary linear gradient elution. The method used was described by Naritomi et al $(87,88)$, the mobile phase consisted of solvent A (methanol: water, 20:80, v:v) and solvent B (methanol: acetonitrile, 91:9, v:v). The solvent program was as follows: 30\% B 0-1 min, 30-38\% B 1-18 min, 38-100\% B 18-18.1 min, 100\% B 18.1-20 $\min$. The flow rate was $1.0 \mathrm{~mL} / \mathrm{min}$, and elution was detected at $238 \mathrm{~nm} .6 \beta-$ 
Hydroxytestosterne formation was quantified by comparison of its peak intensity with that of authentic standard.

\subsubsection{CYP450 2B6 Assay}

Bupropion hydroxylation was used to evaluate the inhibitory effect of DMA on CYP450 2B6. Concentrated stock solution of bupropion was prepared and diluted in methanol. The incubation mixture consisted of human liver microsomes $(0.2 \mathrm{~g})$, bupropion $(500 \mu \mathrm{M})$, DMA $(0-25 \mathrm{mM})$, and NADPH $(1 \mathrm{mM})$ in a final volume of $500 \mu \mathrm{L}$ of $50 \mathrm{mM}$ potassium phosphate buffer. The incubation was carried out in a shaking water bath maintained at $37^{\circ} \mathrm{C}$ for 30 minutes. For controls NADPH was omitted, and for positive control DMA was replaced by thio-TEPA $(50 \mu \mathrm{M})$. Reactions were started by the addition of NADPH, and were stopped by the addition of $100 \mu \mathrm{L}$ of ethyl acetate. Sample handling and LC/MS analysis was carried out as described by Arellano et al (89). Briefly, $100 \mu \mathrm{L}$ of $0.25 \mathrm{~N} \mathrm{NaOH}$ were added to each sample. After mixing for one minute, $900 \mu \mathrm{L}$ of ethyl acetate were added, samples were then vortexed and centrifuged at 3,000 rpm for two minutes. After centrifugation, $850 \mu \mathrm{L}$ of the organic layer were transferred to a clean culture tube containing $850 \mu \mathrm{L}$ of $0.5 \%$ formic acid. Samples were mixed vigorously and centrifuged at 3,000 rpm for two minutes. The organic layer was discarded and $50 \mu \mathrm{L}$ of the aqueous layer were transferred to an HPLC vial for analysis.

LC/MS analysis was performed on Water SymmetrySheild ${ }^{\mathrm{TM}} 5 \mu \mathrm{m} \mathrm{C}_{18}(3.9$ $\mathrm{x} 150 \mathrm{~mm}$ ). The mobile phase consisted of a mixture of $0.1 \%$ formic acid: 
methanol (75: 25, v: v), the flow rate was set at $0.2 \mathrm{~mL} / \mathrm{min}$, and the injection volume was $5 \mu \mathrm{L}$. The mass spectrometer was programmed in a positive ion mode with a selective ion recording of $m / z 256$ for hyroxybupropion. Ion optics (ESP+) were as follows: capillary, $1.98 \mathrm{KV}$; sample cone, $13 \mathrm{~V}$; and extraction cone, 7.0 $\mathrm{V}$. The source block temperature was set at $120^{\circ} \mathrm{C}$. The desolvation gas flow and cone gas flow (both $\mathrm{N}_{2}$ ) were $353.5 \mathrm{~L} / \mathrm{h}$ and $192.6 \mathrm{~L} / \mathrm{h}$, respectively.

\subsubsection{CYP450 2C9 Assay}

Tolbutamide 4-methylhydroxylation was used to evaluate the inhibitory effect of DMA on CYP450 2C9. Human liver microsomes ( $0.2 \mathrm{~g})$ were incubated at $37^{\circ} \mathrm{C}$ in $500 \mu \mathrm{L}$ (final volume) containing $50 \mathrm{mM}$ potassium phosphate buffer (pH 7.4), tolbutamide (1 mM), DMA (0-25 mM), and NADPH (1 mM). The reactions were started with the addition of NADPH and stopped after 40 minutes by the addition of $100 \mu \mathrm{L}$ of ice cold $4.0 \mathrm{~N} \mathrm{HCl}$. NADPH was omitted in control incubations and sulfaphenazole $(50 \mu \mathrm{M})$ was used as a positive control. Tolbutamide and sulfaphenazole solution were prepared and diluted in methanol. Samples were handled as described by Lasker et al (90). After the reaction was stopped, $1.5 \mathrm{~mL}$ of ethyl acetate were added, the samples were then vortexed and centrifuged for 5 minutes at 3,000 rpm. One $\mathrm{mL}$ of the organic layer was evaporated to dryness in a Savant SC100 Speed Vac Concentrator (Farmingdale, NY), and the residue was reconstituted in $200 \mu \mathrm{L}$ methanol.

A semiquantitative LC/MS method was developed for the detection of 4methylhydroxytolbutamide. Elution was carried on a $\mathrm{YMC}^{\mathrm{TM}} \operatorname{Pro~}_{18}(2.0 \times 50$ 
$\mathrm{mm})$ column, using a mixture the $0.1 \%$ formic acid: methanol $(60: 40, \mathrm{v}: \mathrm{v})$ at 0.2 $\mathrm{mL} / \mathrm{min}$, with $5 \mu \mathrm{L}$ injection volume. The mass spectrometer was programmed in a positive ion mode with a selective ion recording $\mathrm{m} / \mathrm{z} 286$ for 4-methylhyroxy tolbutamide. Ion optics (ESP+) were as follows: capillary, 1.75 KV; sample cone, $17 \mathrm{~V}$; and extraction cone, $7.0 \mathrm{~V}$. The source block temperature was set at $120^{\circ} \mathrm{C}$. The desolvation gas flow and cone gas flow (both $\mathrm{N}_{2}$ ) were $719.5 \mathrm{~L} / \mathrm{h}$ and 101.4 $\mathrm{L} / \mathrm{h}$, respectively. 


\section{Chapter 3: Results}




\subsection{In Vitro Metabolism of Busulfan by Liver Microsomes}

Incubation of busulfan with human liver microsomes did not result in the appearance of detectable busulfan metabolites as determined by LC/MS analysis. In substrate disappearance studies, busulfan $(1,2$, and $4 \mu \mathrm{M})$ was incubated with both human liver microsomes and Aroclor-1254 induced rat liver microsomes. The obtained results, which are depicted in Figure 3.1, did not show significant reduction in busulfan concentration in the incubation mixture compared to the control (no NADPH).

Apparent Michaelis-Menton kinetics was calculated $(\mathrm{Km}=752 \mu \mathrm{M}$ and $\mathrm{Vmax}=1652 \mathrm{nmole} / \mathrm{min} / \mathrm{mg}$ protein) for the conversion of 1-chloro-2,4dinitrobenzene to 2,4-dinitrophenyl-S-glutathione in the presence of human liver cytosol and glutathione (Figure 3.2). Ethacrynic acid as a positive control showed strong inhibitory effect on GST activity toward 1-chloro-2,4-dinitrobenzene. Ketoconazole showed a slight inhibitory effect on the activity of GST toward 1chloro-2,4-dinitrobenzene with $\mathrm{Ki}=141.3 \mu \mathrm{M}$ (Figure 3.3). 


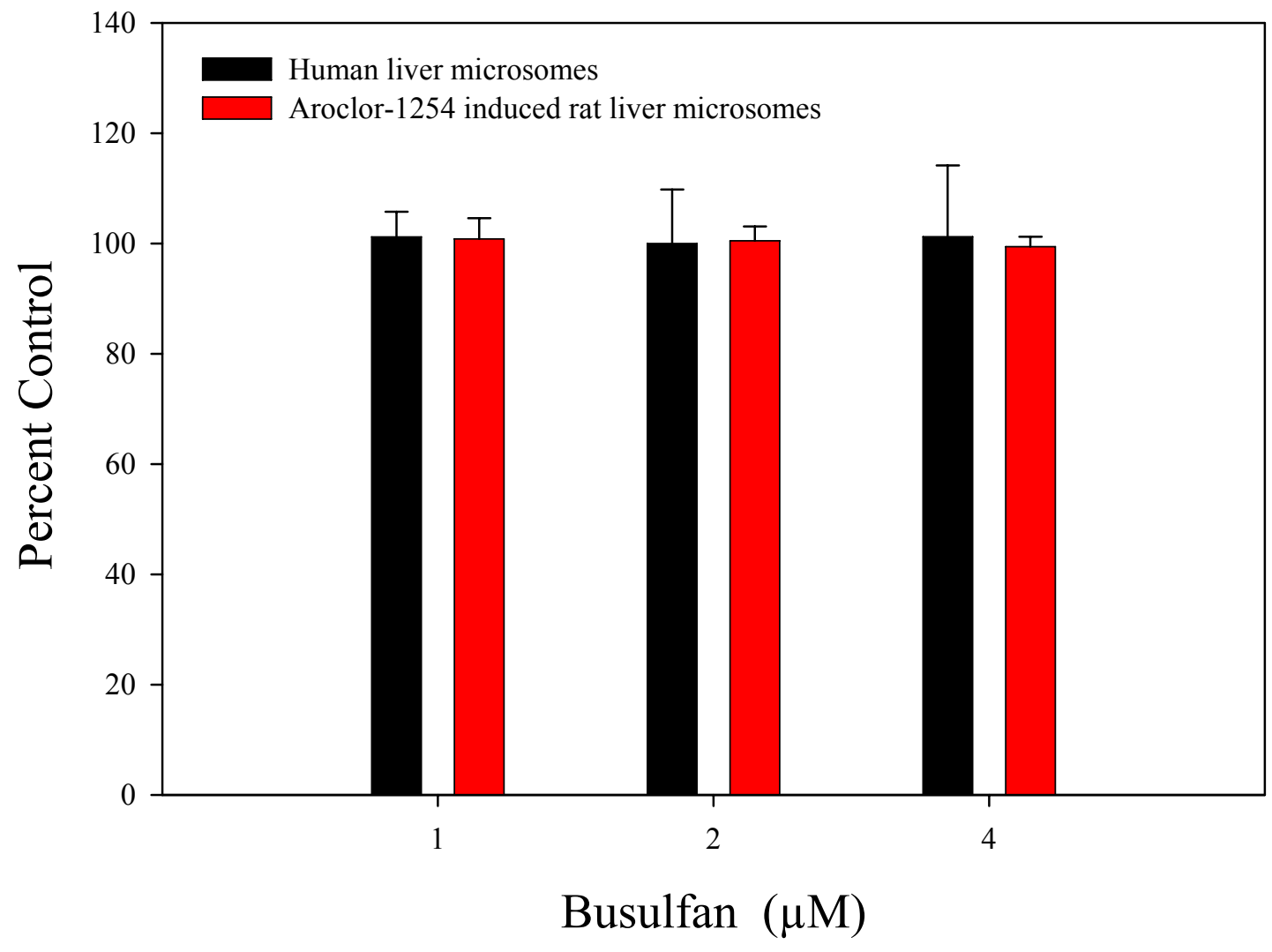

Figure 3.1. Busulfan substrate disappearance studies. Each bar represents the ratio between busulfan concentration in the incubation mixture to its concentration in the control incubations (no NADPH). Values represent triplicate runs and error bars represent standard deviation. 


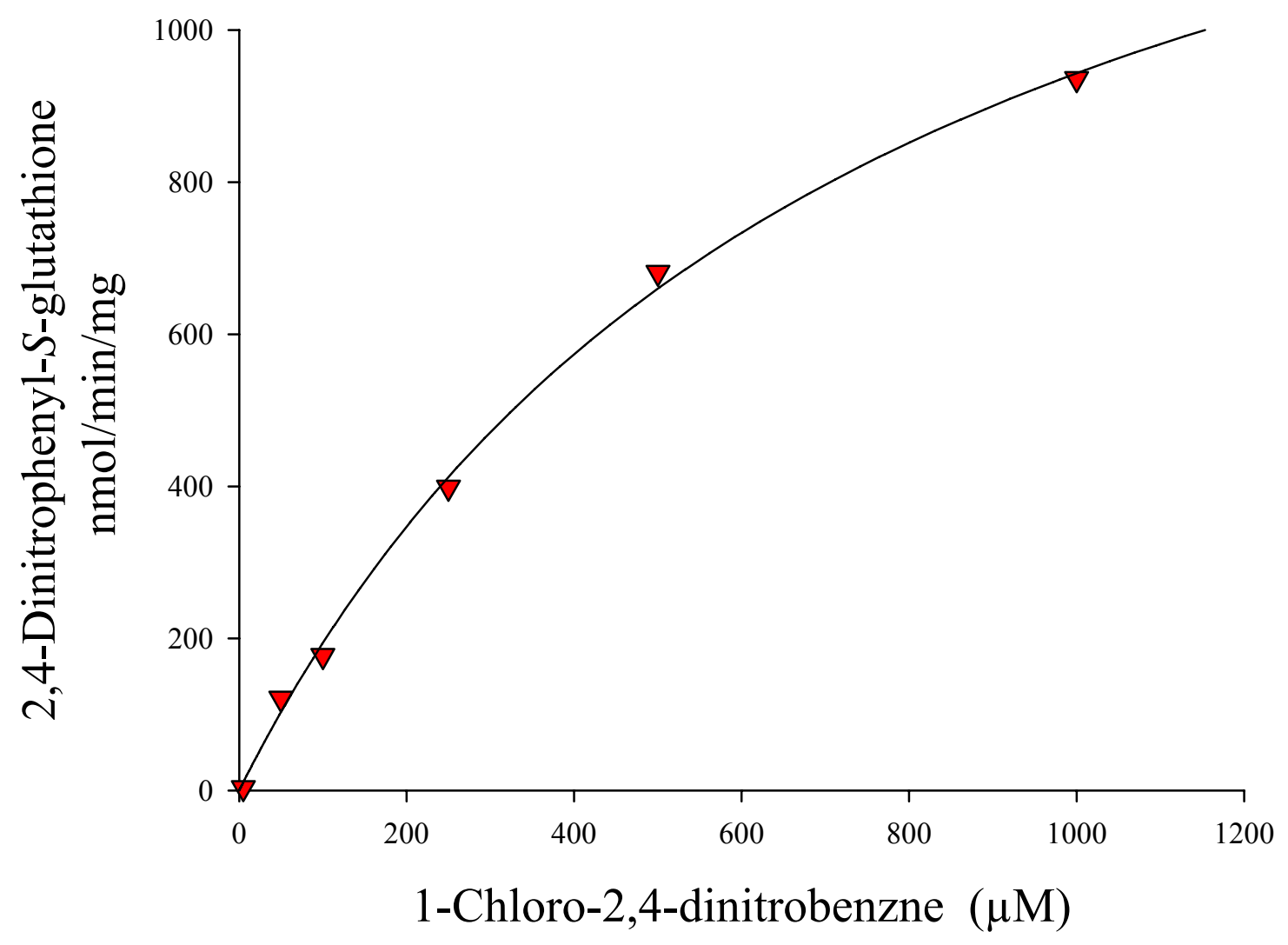

Figure 3.2. Enzymatic conversion of 1-chloro-2,4-dinitrobenzene to 2,4dinitrophenyl-S-glutathione in human liver cytosol. Each point represents the average of duplicate runs 


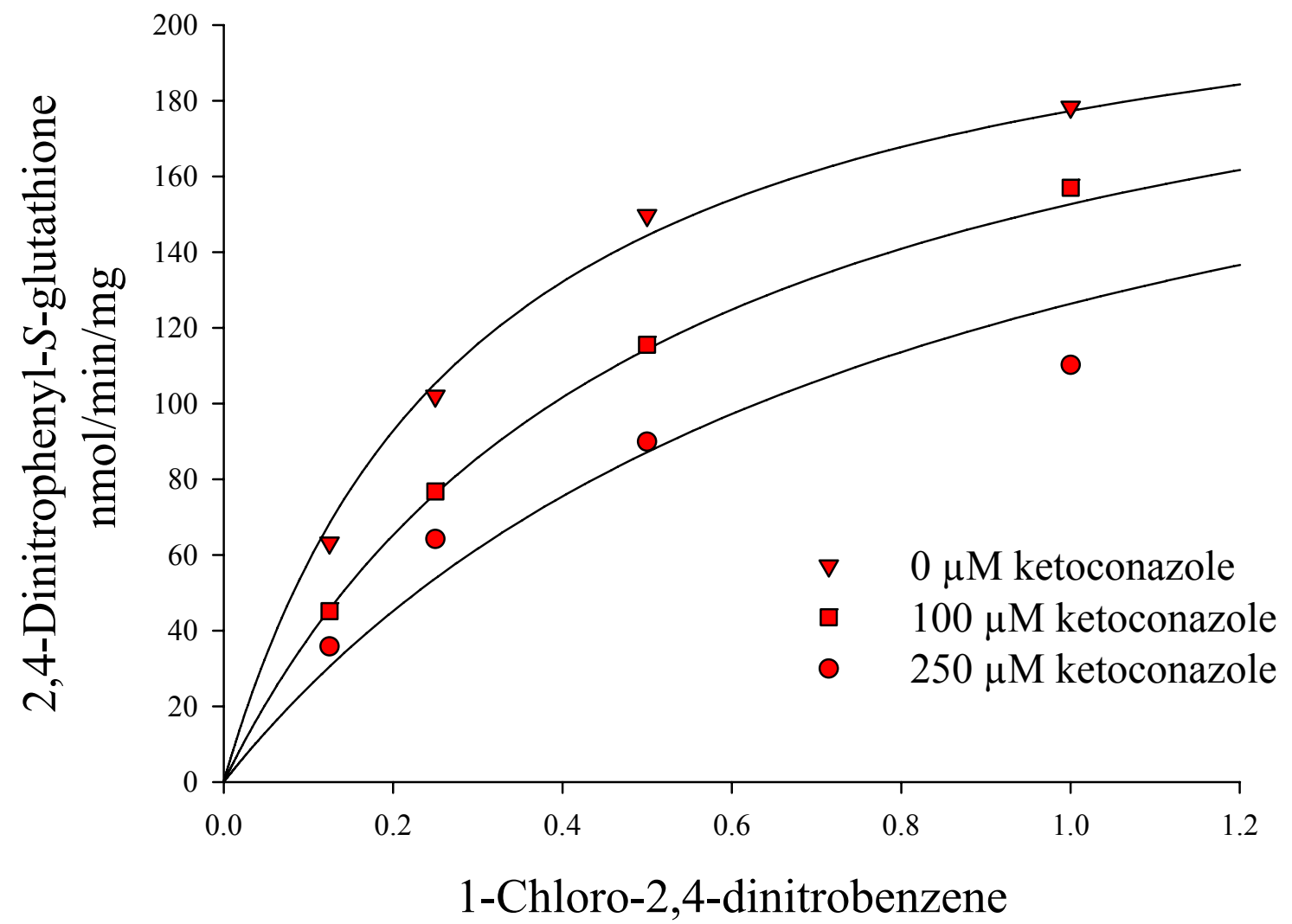

Figure 3.3. Inhibition of glutathione-S-transferase in human liver cytosol by ketoconazole. Each point represents the average of duplicate runs. 


\subsection{Sulfonium Ion Conjugate of Busulfan}

\subsubsection{Synthesis of $\gamma$-Glutamyl- $\beta$-(S-tetrahydrothiophenium)alanylglycine ( $\gamma$-E-}

THT-AG)

The glutathione sulfonium conjugate was synthesized and subsequently purified by semi-preparative HPLC (percent yield $=11.1 \%$ ). An ESI-MS scan of the purified product showed an $\mathrm{M}^{+}$ion with $\mathrm{m} / \mathrm{z}$ 362. MS/MS produced two daughter ions $\mathrm{m} / \mathrm{z} 274.1$ corresponding to the loss of tetrahydrothiophene, and $\mathrm{m} / \mathrm{z} 145.2$ consistent with the neutral loss of tetrahydrothiophene and pyroglutamic acid (Figure 3.4). The NMR spectrum and proton assignments were consistent with those reported in the literature (40).

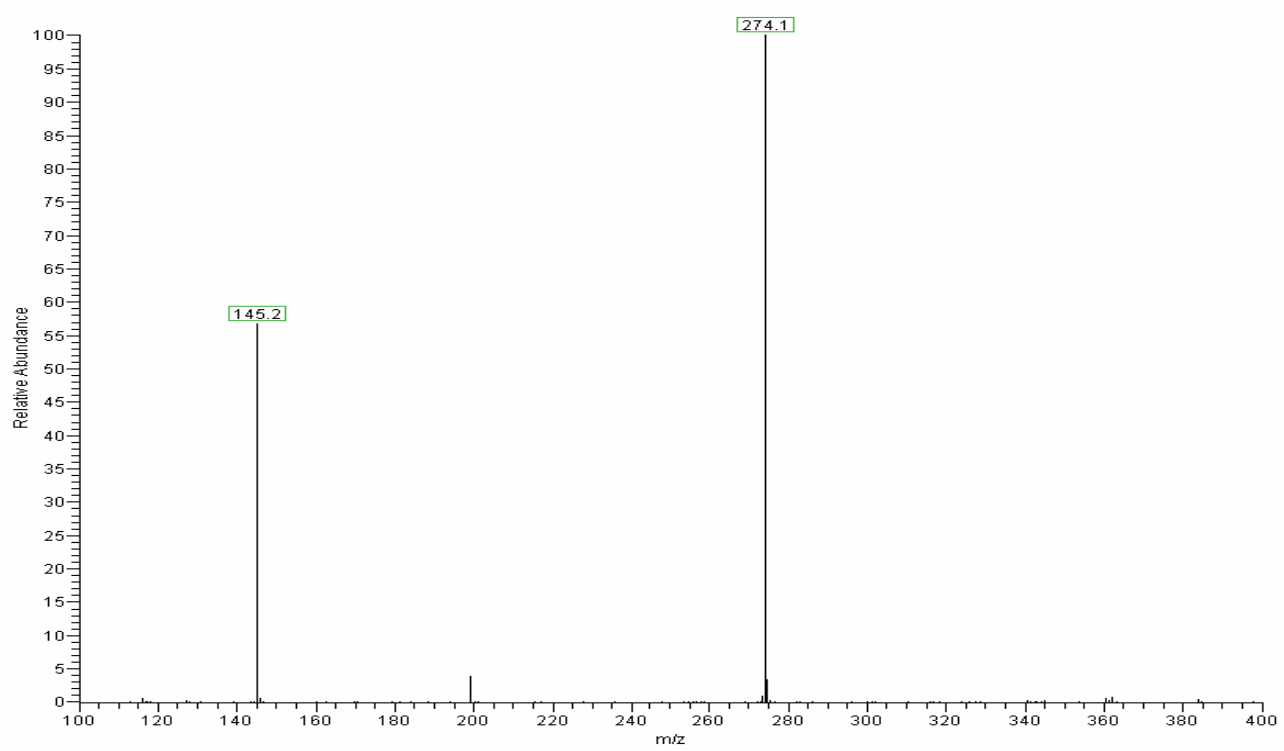

Figure 3.4. MS/MS of $\gamma$-glutamyl- $\beta$-(S-tetrahydrothiophenium)alanylglycine. Loss of tetrahydrothiophene $(\mathrm{m} / \mathrm{z} 274.1)$, loss of glycine and tetrahydrothiophene $(\mathrm{m} / \mathrm{z}$ 199.1), loss of tetrahydrothiophene and pyroglutamic acid ( $m / z$ 145.2). 


\subsubsection{Stability of $\gamma$-E-THT-AG}

$\gamma$-E-THT-AG undergoes a facile non-enzymatic $\beta$-elimination reaction which is expected to generate a glutathione analogue in which a cysteine moiety is replaced by a dehydroalanine residue. In agreement with this expectation, incubation of $\gamma$-E-THT-AG in $100 \mathrm{mM}$ potassium phosphate buffer ( $\mathrm{pH} 7.4$ and 8.0) for $6 \mathrm{~h}$ at $37^{\circ} \mathrm{C}$ resulted in the disappearance of the conjugate (Figure 3.5). The loss of $\gamma$-E-THT-AG was more pronounced at $\mathrm{pH} 8.0$ than at $\mathrm{pH}$ 7.4. In another experiment, $\gamma$-E-THT-AG $(57 \mathrm{mM})$ was incubated in $\mathrm{D}_{2} \mathrm{O}-100 \mathrm{mM}$ phosphate buffer $(\mathrm{pD} \sim 8.0)$ for 12 hours at $37^{\circ} \mathrm{C}$. The formation of $\gamma$ glutamyldehydroalanylglycine as a degradation product of $\gamma$-E-THTP-AG was confirmed by the appearance of vinylic protons as a doublet at 5.76 and $5.80 \mathrm{ppm}$ in the ${ }^{1} \mathrm{H}$ NMR spectrum. This instability of $\gamma$-E-THT-AG was verified by Dr. Arthur Cooper group by measuring the appearance of THT. Thus, when $75 \mu \mathrm{M} \gamma$ E-THT-AG was incubated at $37{ }^{\circ} \mathrm{C}$ in $1 \mathrm{~mL}$ of potassium phosphate buffer $(\mathrm{pH}$ 7.4) or phosphate buffer ( $\mathrm{pH} 8.0)$ in 1.5-mL screw cap septum vials, the amount of THT present in solution at $6 \mathrm{~h}$ as measured by the HPLC-CoulArray procedure was $27.8 \pm 0.8$ and $41.0 \pm 0.3 \mathrm{nmol} / \mathrm{mL}$, respectively $(\mathrm{n}=3)$. The data show that by $6 \mathrm{~h} \sim 50 \%$ and $>90 \%$ of $\gamma$-E-THT-AG were converted to THT at $\mathrm{pH} 7.4$ and $\mathrm{pH}$ 8.0, respectively. This estimate agrees well with the amount of $\gamma$-E-THT-AG remaining at $6 \mathrm{~h}$ as estimated by LC/MS/UV detection. These findings verify the previous findings $(37,91)$ that $\gamma$-E-THT-AG is unstable, especially at alkaline $\mathrm{pH}$. 


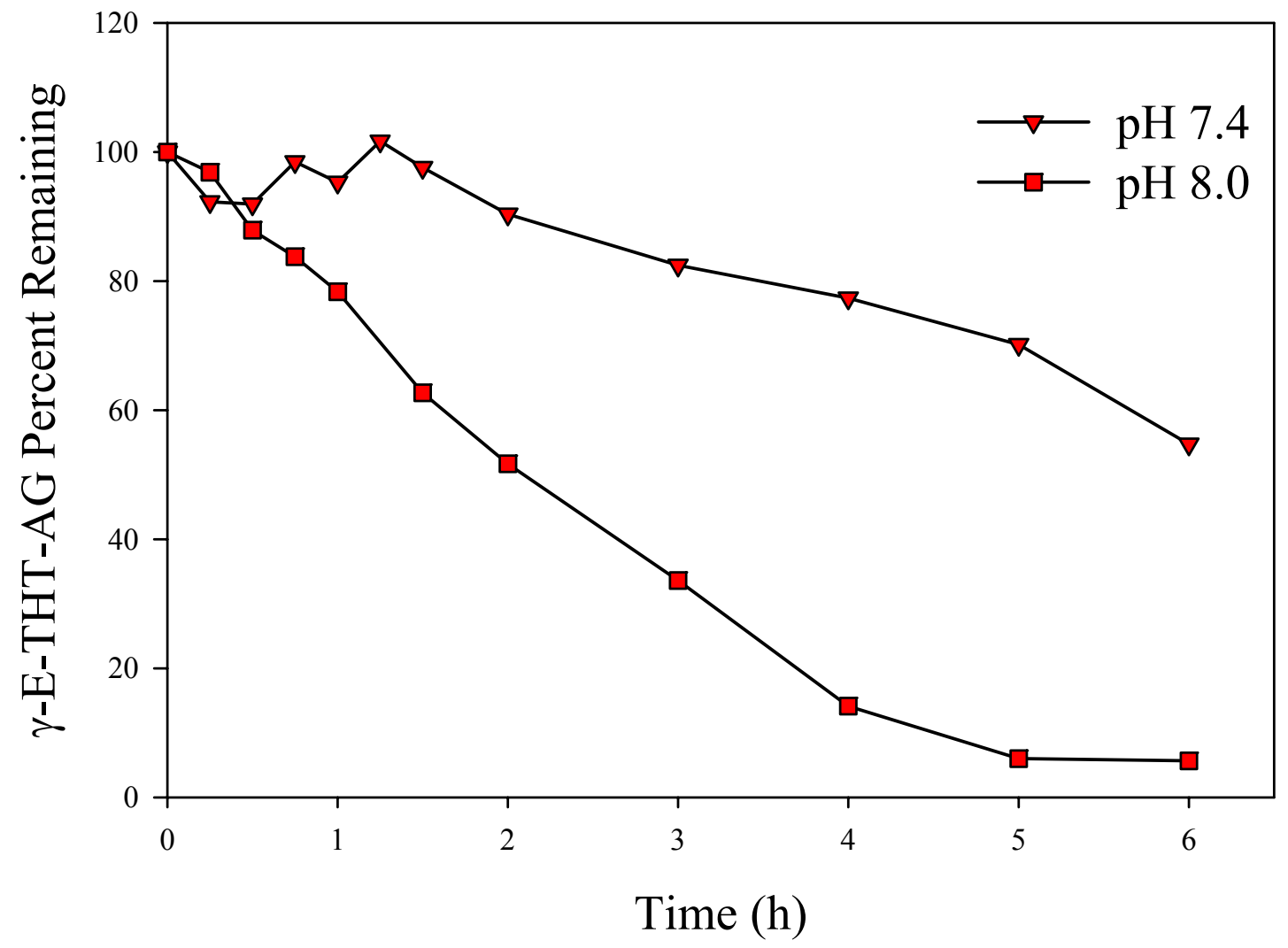

Figure 3.5. Stability of $\gamma$-glutamyl- $\beta$-(S-tetrahydrothiophenium)alanylglycine ( $\gamma$-ETHT-AG) at $\mathrm{pH} 7.4$ and $\mathrm{pH}$ 8.0. The data points are the average of two determinations. 


\subsubsection{Relative Alkylation Reactivity of $\gamma$-E-THT-AG}

The alkylating reactivity of $\gamma$-E-THT-AG, in the concentration range of

0.25-10 mg/mL, was compared to that of busulfan using 4-(4-nitrobenzyl)pyridine (NBP). Thio-TEPA was used as a positive control. Upon alkalinization, the alkylated NBP product that was formed generated a purple colored complex, which was quantified spectrophotometerically at $580 \mathrm{~nm}$. $\gamma$-E-THT-AG did not react with NBP and no color formation was observed. On the other hand, busulfan produced a purple color and the intensity of the color increased with increasing concentration of busulfan (Figure 3.6). The intensity of the color produced by thioTEPA was 10 fold higher than that produced by busulfan at the same concentration (data not shown).

\subsubsection{Cytotoxicity of $\gamma$-E-THT-AG}

The ability of $\gamma$-E-THT-AG to induce apoptosis was assessed using human liver cancer epithelial NCI-H460 cells. In addition, the percent apoptosis induced by $\gamma$-E-THT-AG was compared to that induced by the parent drug busulfan. $\gamma$-ETHT-AG ion induced $5 \%$ apoptosis at $400 \mu \mathrm{g} / \mathrm{mL}$ compared to the control while busulfan induced 30\% apoptosis at the same concentration. The percent induction of apoptosis was increased with increasing the busulfan concentration; on the other hand, increasing $\gamma$-E-THT-AG concentration did not significantly increase the percent of apoptosis induction (Figure 3.7). 


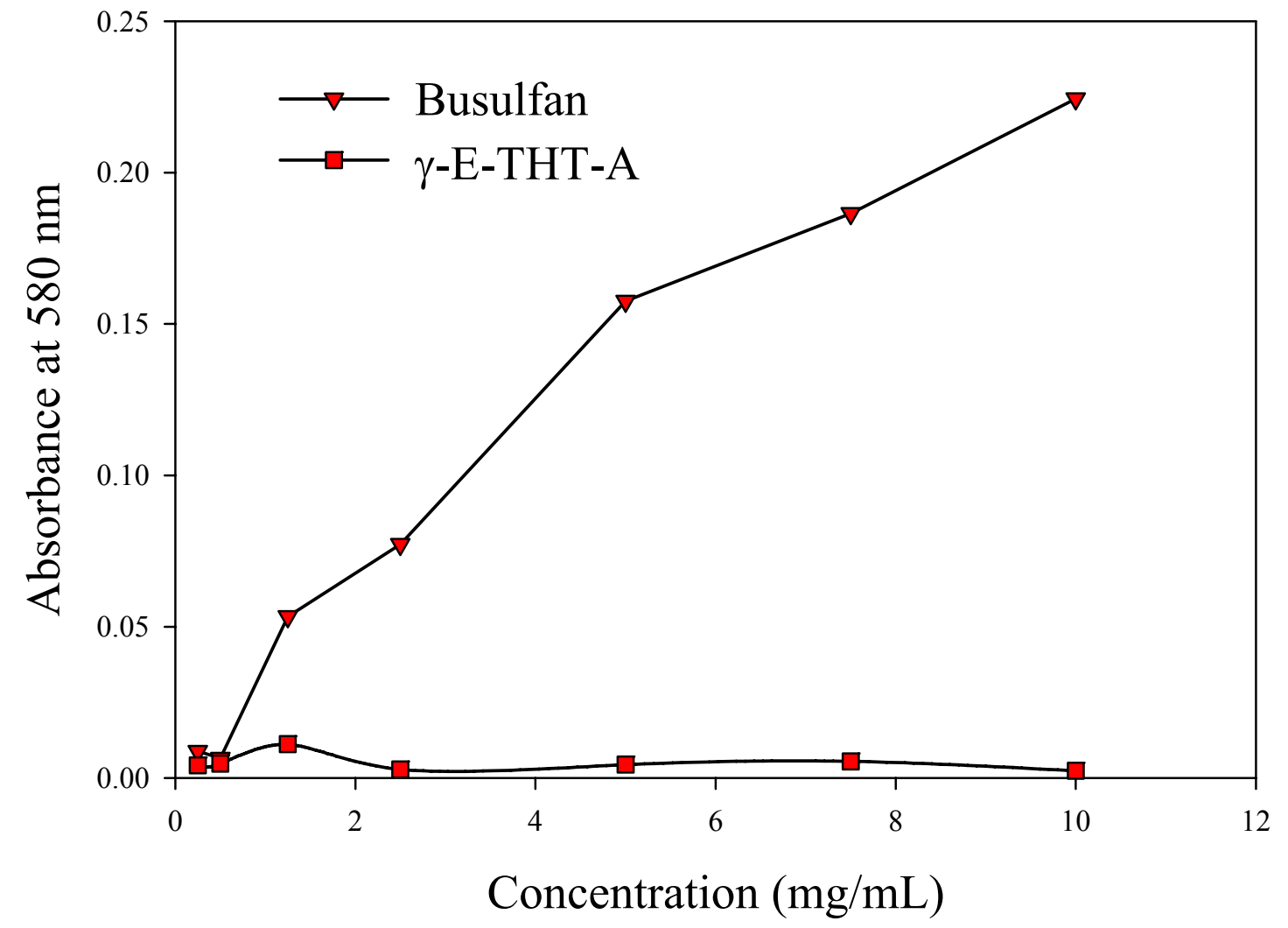

Figure 3.6. Reactivity of busulfan and $\gamma$-E-THT-AG with 4-(4-nitrobenzyl)pyridine. Each point represents the average of two determinations. 


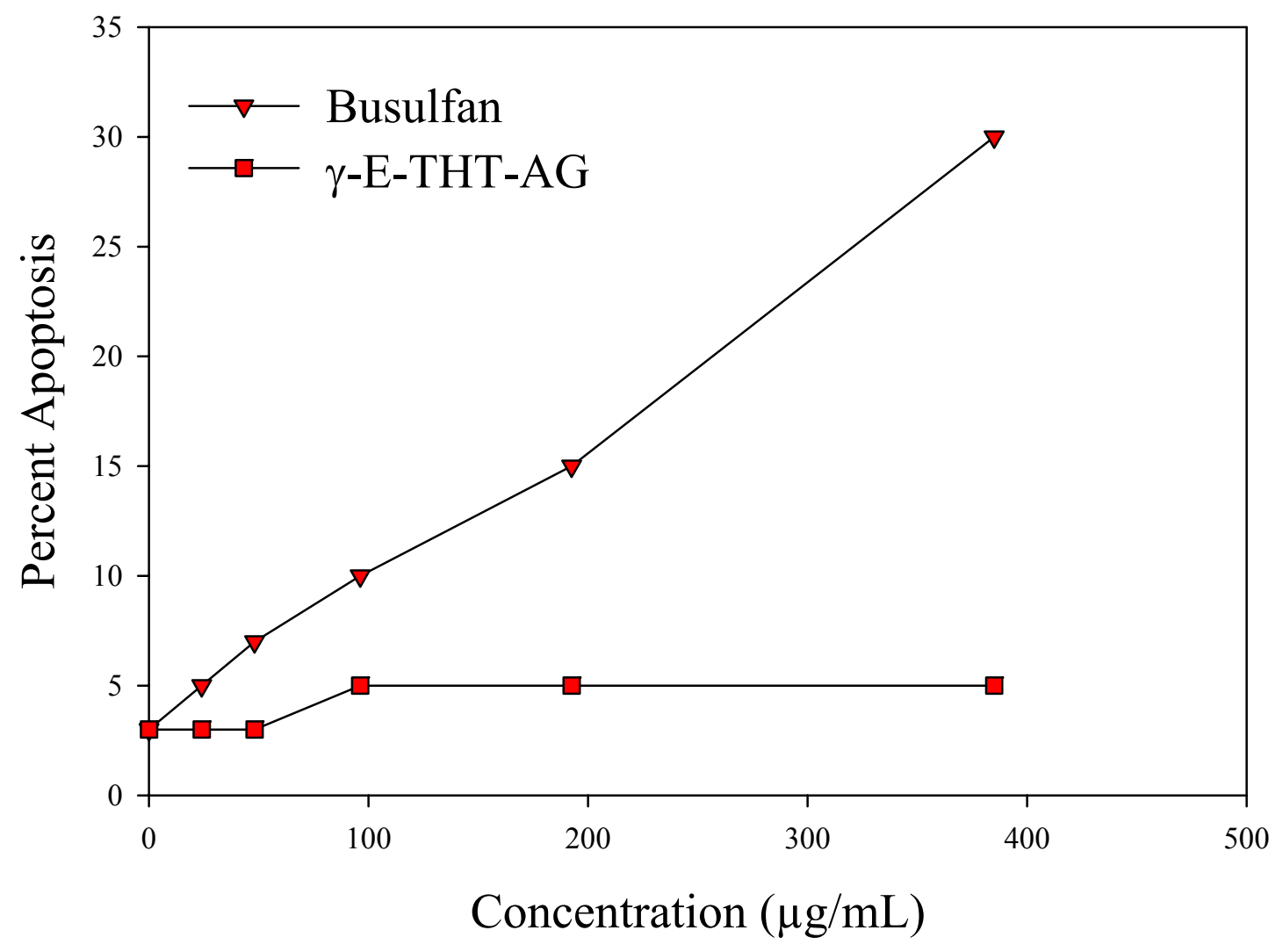

Figure 3.7. Percent apoptosis induced by busulfan and $\gamma$-E-THT-AG in NCI-H460 cells. 


\subsubsection{Effect of $\boldsymbol{\gamma}$-E-THT-AG on glutathione-S-transferase (GST)}

.As depicted in Figure 3.8, $\gamma$-E-THT-AG in the concentration range (1-100

$\mu \mathrm{M})$, did not inhibit glutathione-S-transferase catalytic activity measured by assessing the rate of formation of 2,4-dintrophenyl-S-glutathione adduct in the presence of human liver cytosol. Ethacrynic acid (2.5-100 $\mu \mathrm{M})$ was used as a positive control and showed concentration dependent inhibition of the glutathione$S$-transferase activity.

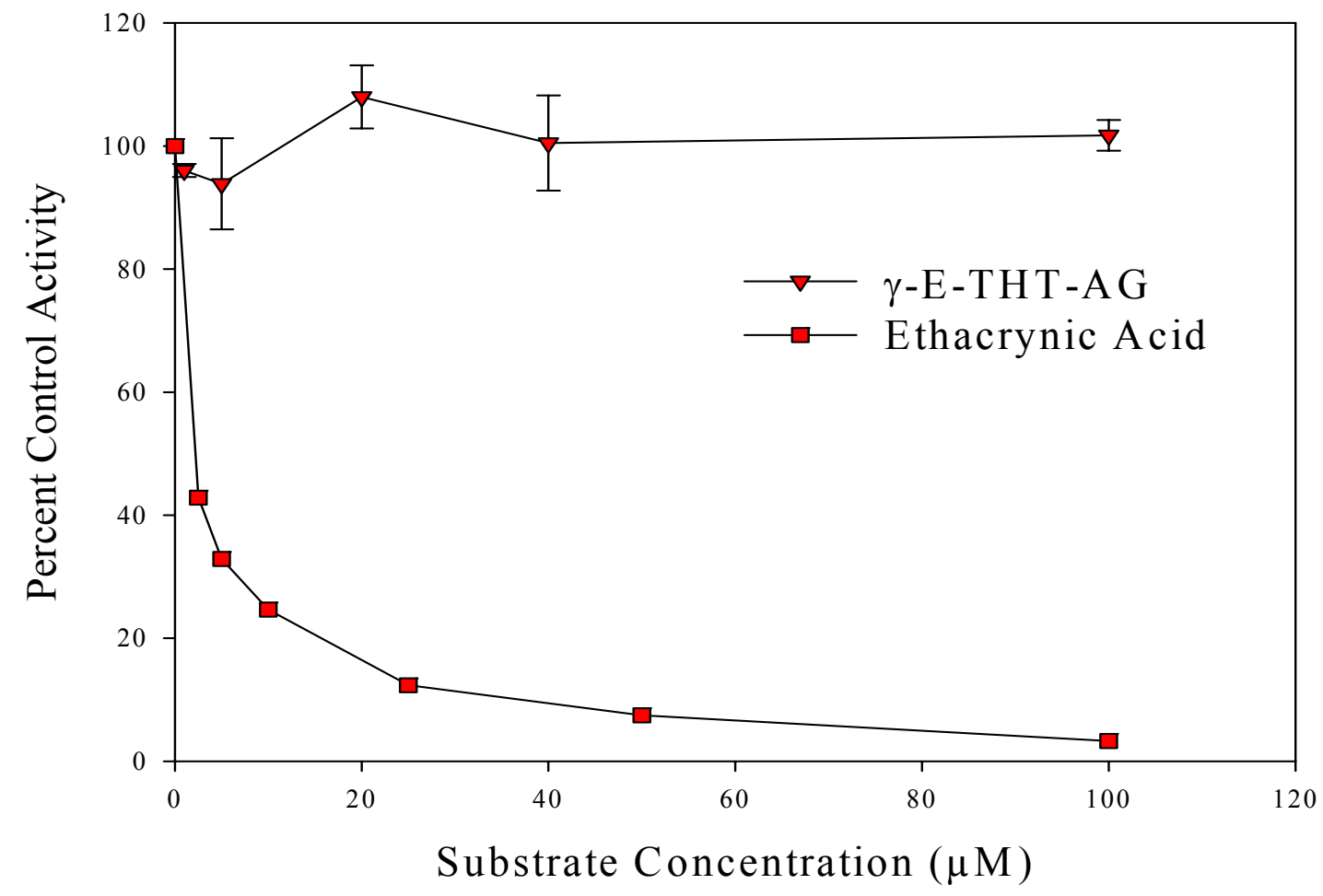

Figure 3.8. Inhibitory effect of $\gamma$-E-THT-AG on the catalytic activity of glutathione-Stransferase in human liver cytosol. Each point of $\gamma$-E-THT-AG curve represents the mean of triplicate determinations, and the error bars represent standard deviations. Ethacrynic acid was used a positive control, each point represent the average of two determinations. 


\subsection{Busulfan-Cysteine Sulfonium Ion Conjugate}

\subsubsection{Synthesis of S-( $\beta$-alanyl)tetrahydrothiophenium (THT-A)}

THT-A was synthesized by the reaction of cysteine and 1-bromo-4-

chlorobutane. The product was crystallized from acetone (percent yield $=47.8 \%$ ).

The full scan spectrum of conjugate shows only a high intensity ion peak $\mathrm{M}^{+}$with $\mathrm{m} / \mathrm{z}$ of 176 corresponding to the mass of THT-A, suggesting that the final product was pure, which was verified by ${ }^{1} \mathrm{H}$ NMR spectral analysis.

The ESI- MS/MS spectrum of THT-A (Figure 3.9) showed one daughter ion with $\mathrm{m} / \mathrm{z}$ of 88 consistent with the neutral loss of tetrahydrothiophene.

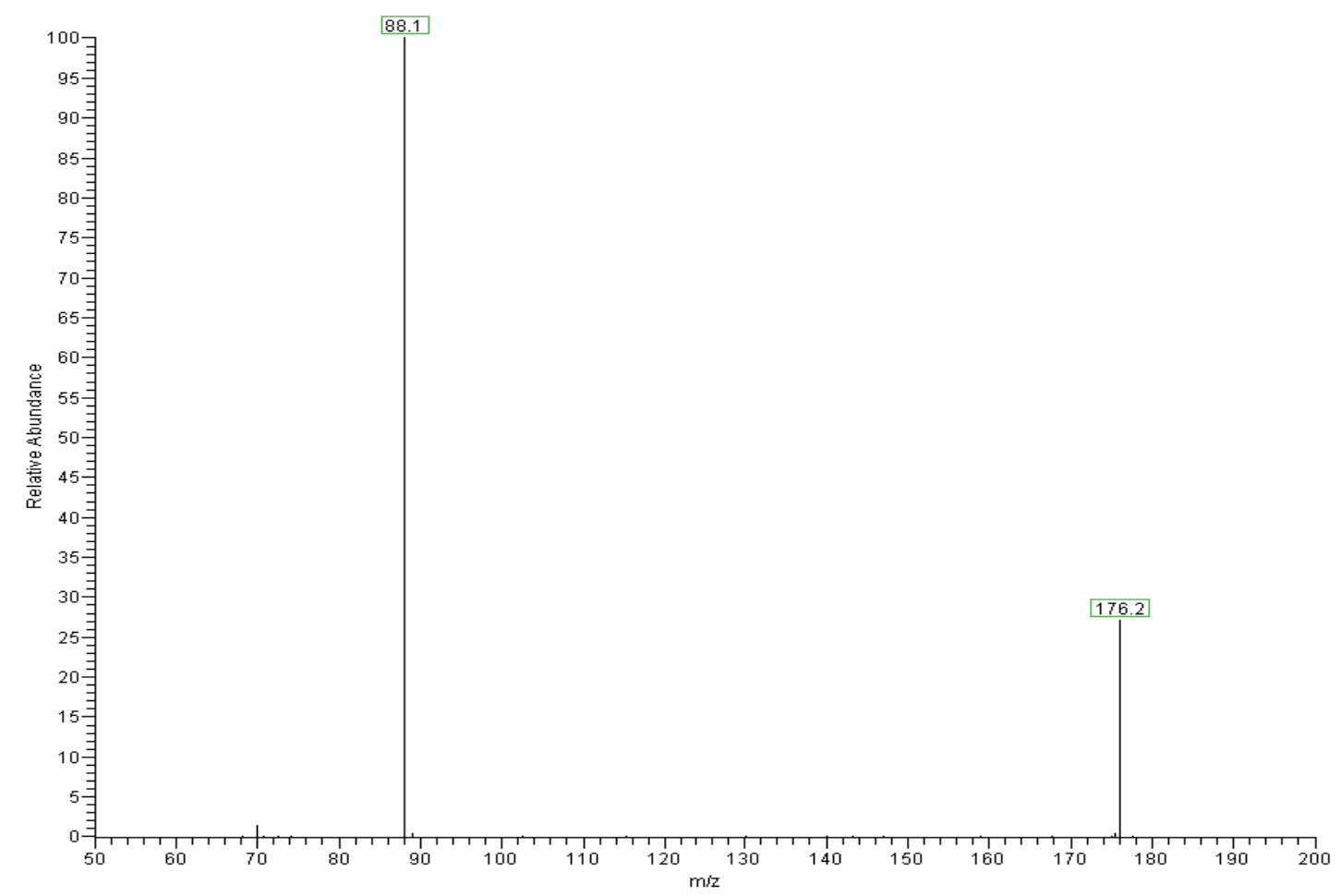

Figure 3.9. MS/MS of S- $\beta$-alanyltetrahydrothiophenium (THT-A); $m / z 176$ consistent with the molecular mass of THT-A; $\mathrm{m} / \mathrm{z} 88$ consistent with the loss of tetrahydrothiophene. 


\subsubsection{Chemical Stability of THT-A}

To determine if THT-A undergoes a facile non-enzymatic $\beta$-elimination reaction to yield tetrahydrothiophene and dehydroalanine, THT-A was incubated at $37^{\circ} \mathrm{C}$ in $100 \mathrm{mM}$ potassium phosphate buffer (pH 7.4 and 8.0) for 6 hours. The conjugate did decompose over 6 hours at both pH by less than $5 \%$ (Figure 3.10 ). This small amount of decomposition was observed by Dr. Cooper group through detecting the amount of THT formed. Thus, when $1 \mathrm{mM}$ THT-A was incubated in $1 \mathrm{~mL}$ of $100 \mathrm{mM}$ potassium phosphate buffer at $\mathrm{pH} 7.4$ or $8.0\left(37^{\circ} \mathrm{C}\right)$ in $1.5-\mathrm{mL}$ screw cap septum vials, the average percent of THT formed from THT-A at 0,3 , and $6 \mathrm{~h}$ was $3.77 \%, 4.95 \%$, and $5.79 \%(\mathrm{pH} 7.4)$ and $4.09 \%, 5.01 \%$, and $5.79 \%$ ( $\mathrm{pH} 8.0)$, respectively ( $\mathrm{n}=3$ separate incubations). Thus, at $\mathrm{pH} 7.4$, the initial rate of conversion of THT-A to THT is about $3 \%$ per $6 \mathrm{~h}$ at $\mathrm{pH} 7.4\left(37^{\circ} \mathrm{C}\right)$. This value is in excellent agreement with the $2-4 \%$ loss per $6 \mathrm{~h}$ estimated from production of pyruvate and ammonium (control in Figure 3.14). Interestingly, the conversion of THT-A to THT at $\mathrm{pH} 8.0$ is also quite slow ( $3 \%$ per $6 \mathrm{~h})$. By comparing these data with data in Figure 3.5, it appears that $\gamma$-E-THT-AG decomposes to THT about 20 to 50 times faster than THT-A at $\mathrm{pH} 7.4$ and 8.0. 


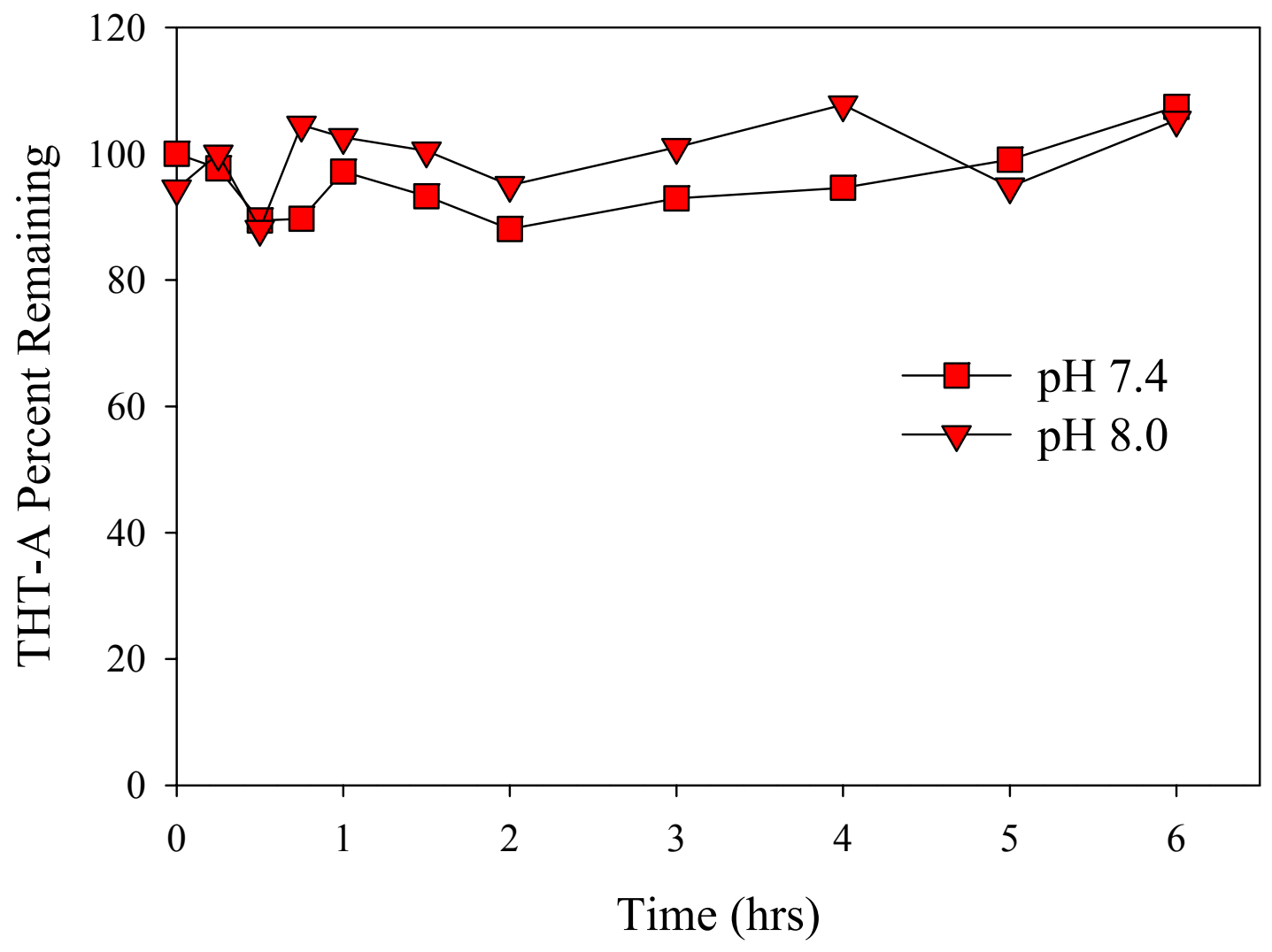

Figure 3.10. Stability of $S$ - $\beta$-alanyltetrahydrothiophenium (THT-A) at pH 7.4 and $\mathrm{pH} 8.0$ at $37^{\circ} \mathrm{C}$. The data points are the average of two determinations. 


\subsubsection{Reaction of cysteine with busulfan.}

The chemical reactivity of busulfan with cysteine was determined by following the disappearance of busulfan with time in an incubation mixture containing a 400-fold molar excess of cysteine over busulfan in $100 \mathrm{mM}$ potassium phosphate buffer $\left(\mathrm{pH} 8.0 ; 37^{\circ} \mathrm{C}\right)$. The results which are depicted in

Figure 3.11 showed that busulfan disappeared slowly $\left(\mathrm{K}_{1 \text { pseudo }}=0.0014 \mathrm{~min}^{-1}\right)$ from the solution by a combination of hydrolysis and adduct formation $\left(\mathrm{k}_{\mathrm{hydolysis}}=\right.$ $0.0007 \mathrm{~min}^{-1}$ ). Busulfan degradation is independent on the $\mathrm{pH}$ and decomposes at $37^{\circ} \mathrm{C}$ in 0.05 phosphate buffer $(\mathrm{pH} 7.0)$ to tertrahydrofuran and methanesulfonic acid with an apparent first order rate constant of $0.00072 \mathrm{~min}^{-1}$ (92). Our result is in conjugation with the reported value for the first order rate constant of busulfan degradation. The rate of disappearance of busulfan was doubled in the presence of cysteine which indicates that some of the busulfan reacted with cysteine to from THT-A. 


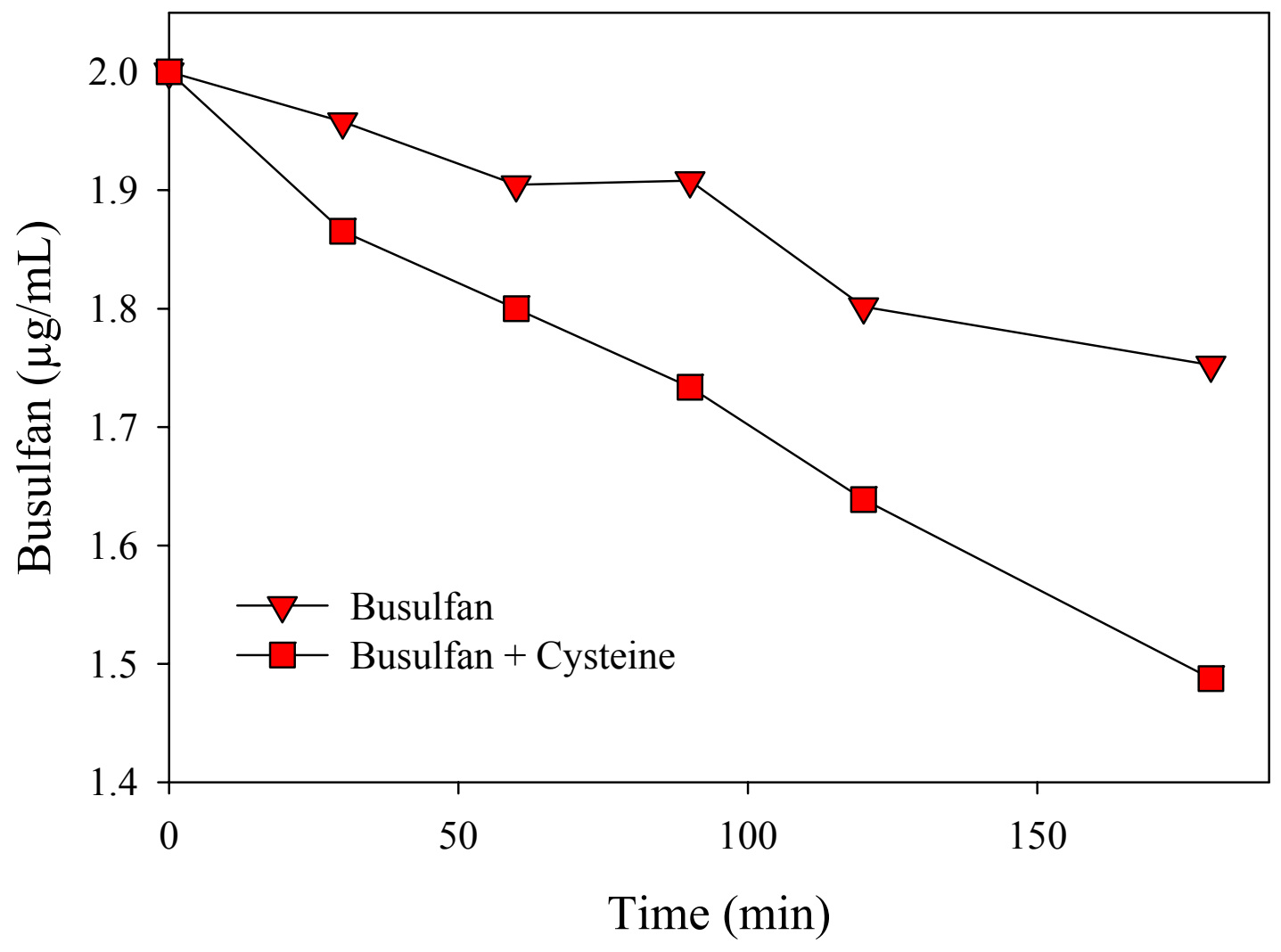

Figure 3.11. Reaction of busulfan with cysteine in $100 \mathrm{mM}$ potassium phosphate buffer ( $\mathrm{pH} 8.0$ ) at $37^{\circ} \mathrm{C}$. Each point is the average of duplicate runs. 


\subsubsection{Enzymatic Conversion of THT-A to Pyruvate and Ammonium}

Dr. Cooper and his coworkers evaluated the ability of two highly purified PLP-containing enzymes, namely glutamine transaminase K (GTK) and mitochondrial aspartate aminotransferase (AspAT), to catalyze a $\beta$-elimination reaction with THT-A. These enzymes are known to catalyze effective $\beta$-lyase reactions with halogenated cysteine $S$-conjugates such as DCVC and TFEC (83), and served as well-established reference cysteine $S$-conjugate $\beta$-lyases. However, no $\beta$-lyase activity toward THT-A with either GTK or mitAspAT was detected.

Substantial $\beta$-lyase activity toward THT-A was found to be present in the liver homogenate, liver cytosol and liver mitochondrial fraction as measured by pyruvate formation (Figure 3.12). Clearly, the ability of kidney and brain homogenates to catalyze a $\beta$-lyase reaction with THT-A is much greater than that of the liver homogenate. This finding indicates that kidney and brain possess more enzymes that are capable of catalyzing $\beta$-elimination reactions with THT-A.

The $\beta$-lyase activity toward THT-A was strongly, but not totally, inhibited by D,L-propargylglycine in the rat liver homogenate and cytosolic fraction. D,LPropargylglycine also significantly inhibited the $\beta$-lyase activity in the mitochondrial fraction, but proportionately less so than in the cytosol and homogenate (Figure 3.13). Since D,L-propargylglycine completely inhibits cystathionine $\gamma$-lyase, the data hypothesize that the enzymes cystathionine $\gamma$-lyase plus other $\beta$-lyases contribute to $\beta$-lyase activity with THT-A in rat liver fractions. 
Figure 3.14 displays the ability of purified cystathionine- $\gamma$-lyase to catalyze a $\beta$-elimination reaction toward THT-A. The rate of formation of pyruvate and ammonium was significantly enhanced when THT-A was incubated with purified cystathionine- $\gamma$-lyase compared to the control (no enzyme). The effectiveness of the liver cytosol in catalyzing a $\beta$-elimination reaction with $5 \mathrm{mM}$ THT-A relative to the rate at which the cytosol catalyzes a $\gamma$-elimination reaction with $20 \mathrm{mM} \mathrm{L}$ homoserine is about 1.20: 100. As noted above, this ratio for the purified enzyme is about 1.55:100. Therefore, within the experimental error of the procedures, the data indicate that cystathionine $\gamma$-lyase is the major $\beta$-lyase in rat liver cytosol acting on THT-A. However, a small fraction $(\sim 30 \%)$ of the $\beta$-lyase activity toward THT-A in the liver cytosol must be due to enzymes other than cystathionine $\gamma$-lyase as evidenced by activity that is propargylglycine-insensitive.

The specific activity of the purified rat liver cystathionine $\gamma$-lyase $(0.55$ $\mathrm{mg} / \mathrm{mL}$ ) toward $20 \mathrm{mM} \mathrm{L}$-homoserine is $2,400 \mathrm{nmol} / \mathrm{min} / \mathrm{mg}$ of protein. The specific activity of this enzyme as a $\beta$-lyase with $5 \mathrm{mM}$ THT-A as substrate was found to be $37.1 \pm 0.37 \mathrm{nmol} / \mathrm{min} / \mathrm{mg}$ of protein $(\mathrm{n}=4)$. Thus, the rate at which cystathionine $\gamma$-lyase catalyzes a $\beta$-elimination reaction with $5 \mathrm{mM}$ THT-A is about $1.55 \%$ the rate at which the enzyme catalyzes a $\gamma$-elimination reaction with 20 mM L-homoserine. 


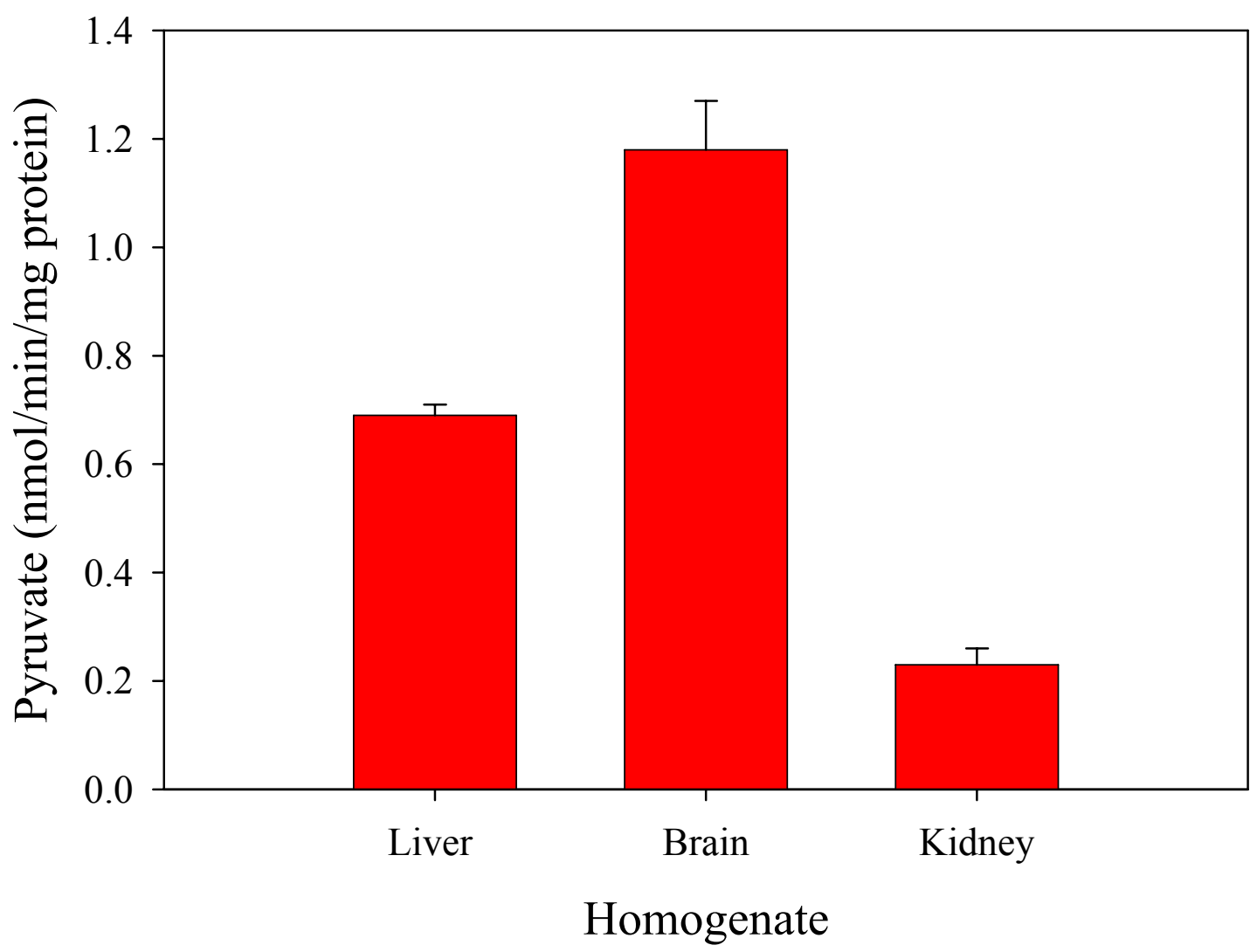

Figure 3.12. $\beta$-lyase activity toward S- $\beta$-alanyltetrahydrothiophenium (THT-A) in rat liver, brain, and kidney homogenates. Each bar represents the average of triplicate runs, and the error bars represent standard deviation. 


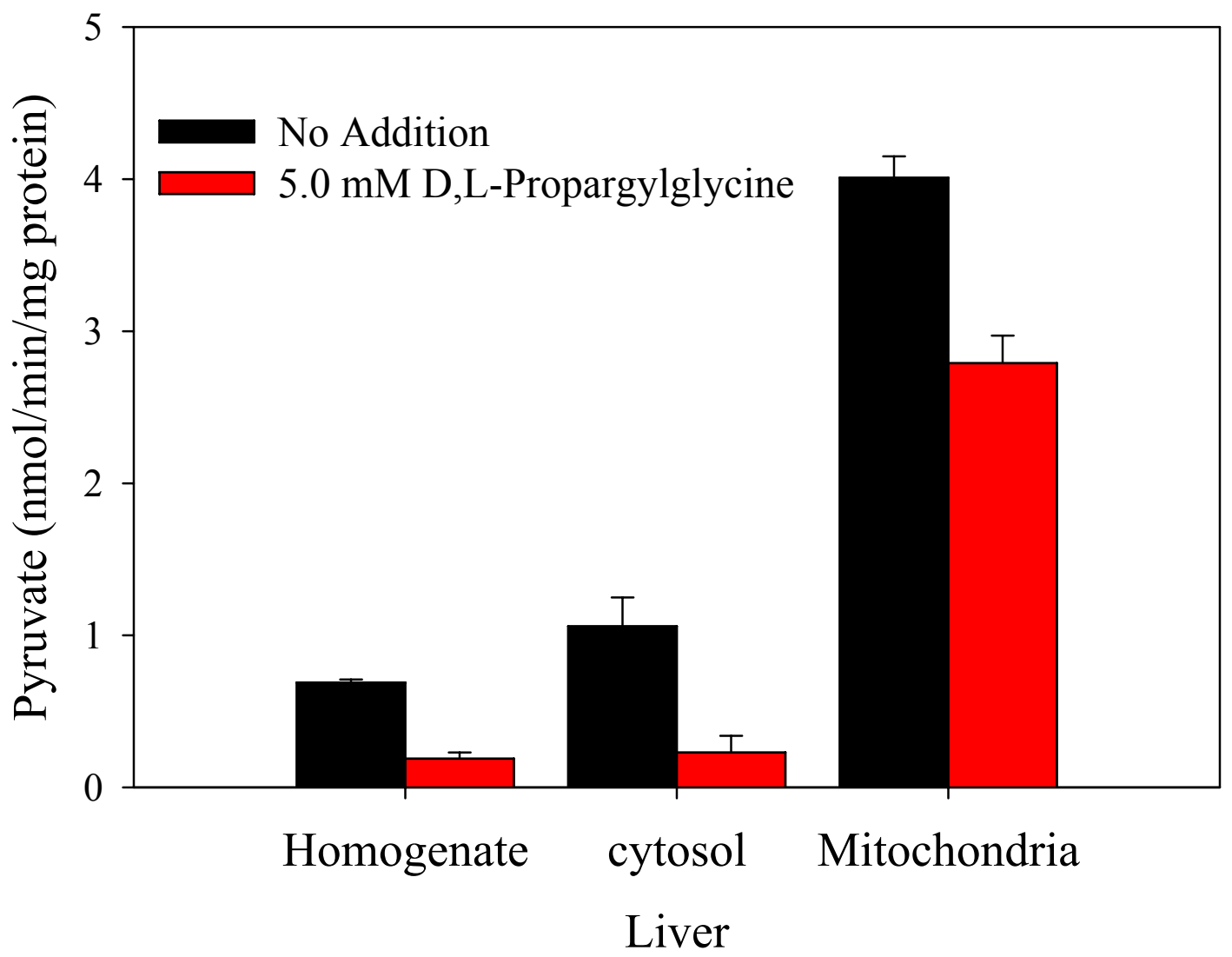

Figure 3.13. $\beta$-lyase activity toward $S$ - $\beta$-alanyltetrahydrothiophenium (THT-A) in rat liver homogenate, cytosol, and mitochondria. The activity is measured in the presence and absence of D,L-propargylglycine, a potent inhibitor of the enzyme cystathionine- $\gamma$-lyase. Each bar represents the average of three determinations, with the error bars representing standard deviation. 

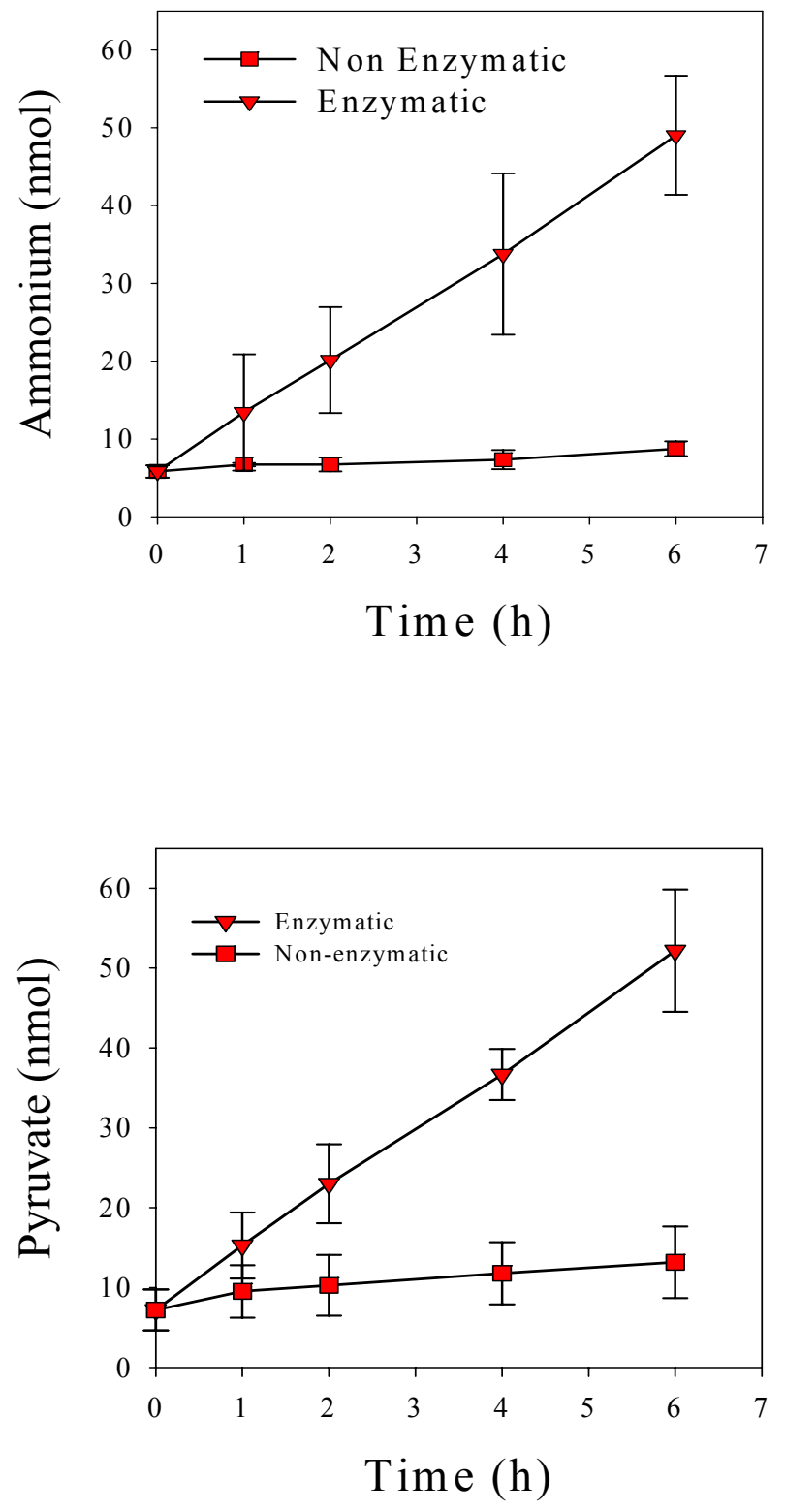

Figure 3.14. Non-enzymatic and enzymatic degradation of THT-A. Ammonium (top panel) and pyruvate (bottom panel) formation via $\beta$-elimination reactions with THT-A. Each point represents the average of three determinations, with error bars representing standard deviation. 


\section{4 $\gamma$-Glutamyldehydroalanylglycine (dehydroglutathione)}

\subsubsection{Synthesis of dehydroglutathione}

The synthesis of dehydroglutathione was carried in two steps; the first step was the synthesis of the precursor 2,4-dinitrophenyl-S-glutathione, which was prepared through the reaction of 1-chloro-2,4-dinitrobenzene with reduced glutathione. After recrystallization from hot water, a yellow crystalline material was obtained (yield 42.5\%). The structure of the compound was confirmed by ${ }^{1} \mathrm{H}$ NMR spectroscopy, and mass spectrometry. ESI-MS of the compound gave a molecular ion species $\left(\mathrm{MH}^{+}\right)$with $\mathrm{m} / \mathrm{z} 473$ consistent with the molecular mass of the product. The structure of the compound was further confirmed by multistage mass spectrometry. MS/MS of the molecular species of the compound produced a protonated daughter ion with $\mathrm{m} / \mathrm{z}$ of 345 consistent with the neutral loss of pyroglutamic acid. ${ }^{1} \mathrm{H}$ and COSY NMR spectra of the product are depicted in Figures 3.15 and 3.16, respectively. The proton assignments and the structure of the product are shown in Table 1.

Dehydroglutathione was synthesized through the base-catalyzed elimination of thiophenolate ion form 2,4-dinitrophenyl-S-glutathione. It is worth noting that increasing the time of mixing of the starting material in base produced many impurities that are difficult to remove, mixing for thirty minutes resulted in a relatively good yield and limited the impurities in the final product. Multiple extractions with sec-butanol were necessary to remove colored impurities. Passage through cation exchange resin was performed to remove sodium ions. After 
evaporating the aqueous layer, a gold colored precipitate was obtained (yield 60.4\%). The ESI-MS full spectrum of the compound gave a high intensity ion peak $\left(\mathrm{MH}^{+}\right)$with $\mathrm{m} / \mathrm{z}$ of 274 . The formation of dehydroglutathione was further confirmed by ${ }^{1} \mathrm{H}$ NMR (Figure 3.17), which shows the doublet of the vinylic protons centered at $5.62 \mathrm{ppm}$. The integration of the peaks in the spectrum shows that the obtained product is $\sim 90 \%$ pure, which was confirmed by a quantitative ${ }^{13} \mathrm{C}$ NMR experiment. Further purification of the product using charcoal and/or crystallization with ethanol did not improve the purity of the compound. The data obtained from HETCOR NMR spectrum (Figure 3.18) suggested that the impurities are not carbon based.

\begin{tabular}{|c|c|c|}
\hline \multirow{2}{*}{ Position } & \multicolumn{2}{|c|}{ Chemical Shift (ppm) } \\
\hline & $\mathrm{DNPGSH}^{*}$ & dehydroGSH ${ }^{¥}$ \\
\hline 2 & 3.73 & 3.93 \\
\hline 4 & 4.46 & \\
\hline 5 & 3.35 & 5.6 \\
\hline 7 & 2.3 & 2.48 \\
\hline 8 & 1.85 & 2.08 \\
\hline 9 & 3.63 & 3.46 \\
\hline 11 & 8.86 & \\
\hline 12 & 7.79 & \\
\hline 13 & 8.47 & \\
\hline
\end{tabular}

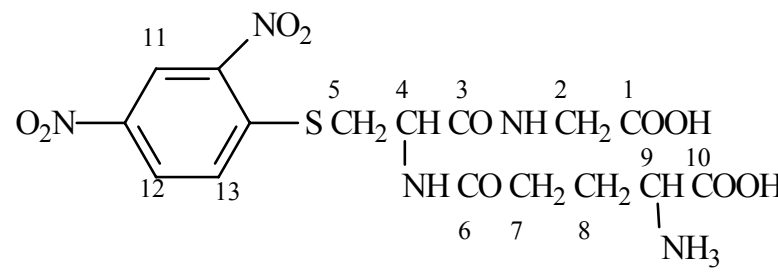

S-2,4-dinitrophenylglutathione (DNPGSH)

$$
\begin{aligned}
& \begin{array}{llll}
5 & 4 & 2 & 1
\end{array} \\
& \mathrm{CH}_{2}=\underset{l}{\mathrm{CCONHCH}} \mathrm{COOH}_{9} \\
& \mathrm{NHCO} \mathrm{CH} \mathrm{CH}_{2} \underset{\mathrm{C}}{\mathrm{C}} \mathrm{H} \mathrm{COOH} \\
& \begin{array}{llll}
6 & 7 & 8 & \text { I } \\
& & \mathrm{NH}_{3}
\end{array}
\end{aligned}
$$

$\gamma$-glutamyldehydroalanylglycine (dehydroGSH)

Table 3.1. NMR spectral proton assignments of 2,4-dinitrophenyl-S-glutathione (DNPGSH), and $\gamma$-glutamyldehydroalanylglycine (dehydroGSH). DNPGSH was dissolved in $\mathrm{d}_{6}$-DMOS, $¥$ dehydroGSH was dissolved in $\mathrm{D}_{2} \mathrm{O}$. 


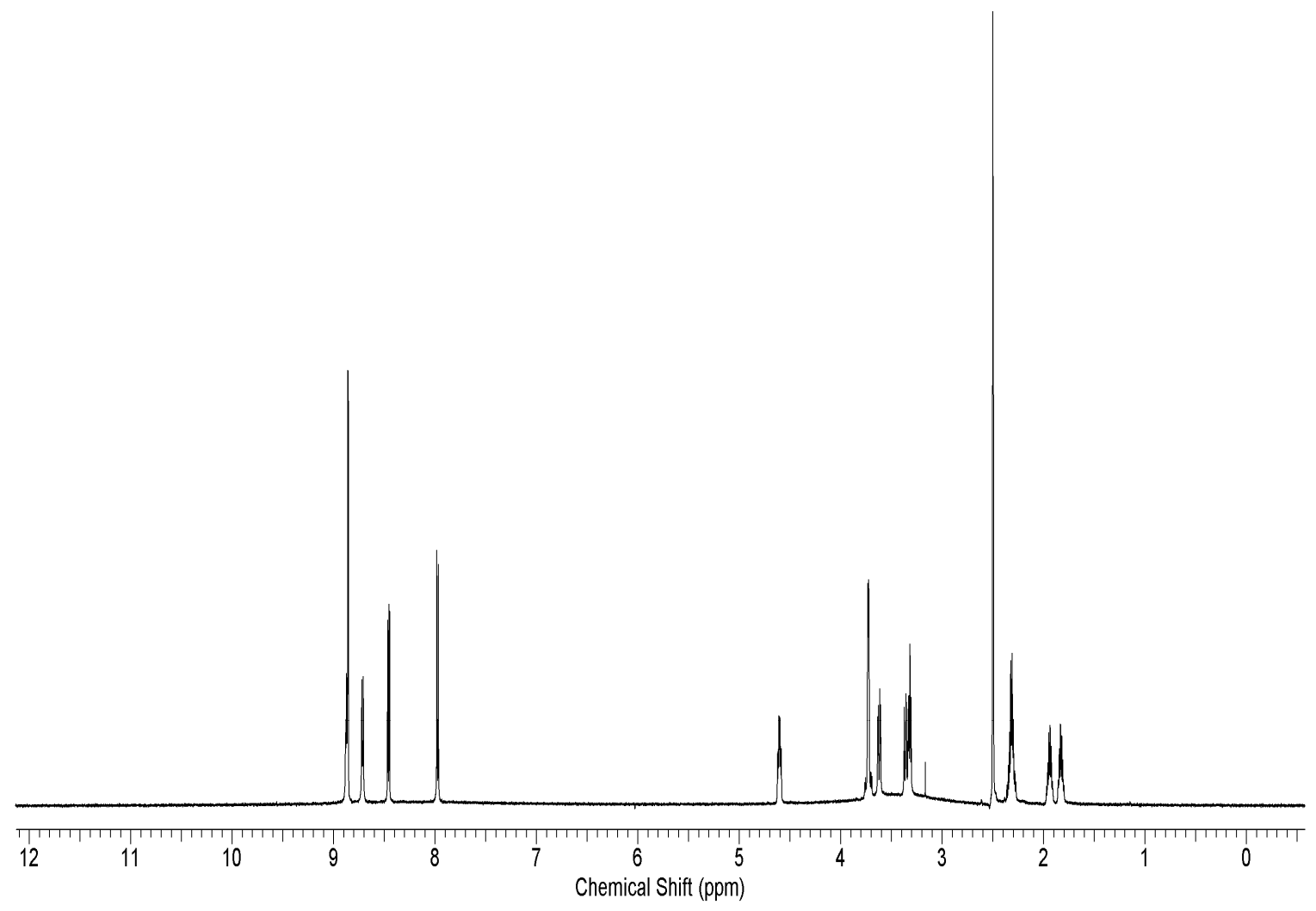

Figure 3.15. ${ }^{1} \mathrm{H}$ NMR spectrum of 2,4-dinitrophenyl-S-glutathione. 


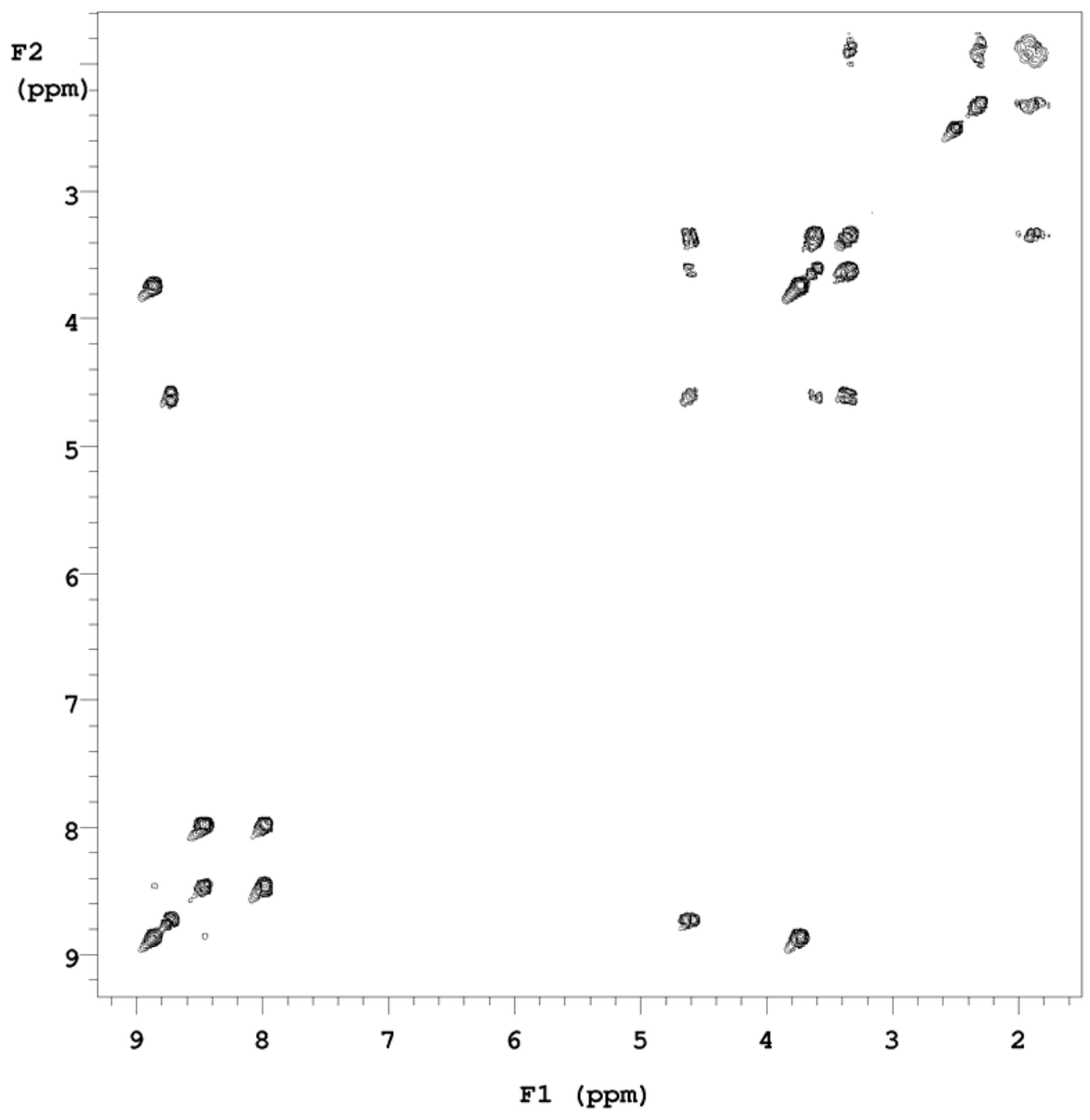

Figure 3.16. COSY NMR spectrum of 2,4-dinitrophenyl-S-glutathione. 


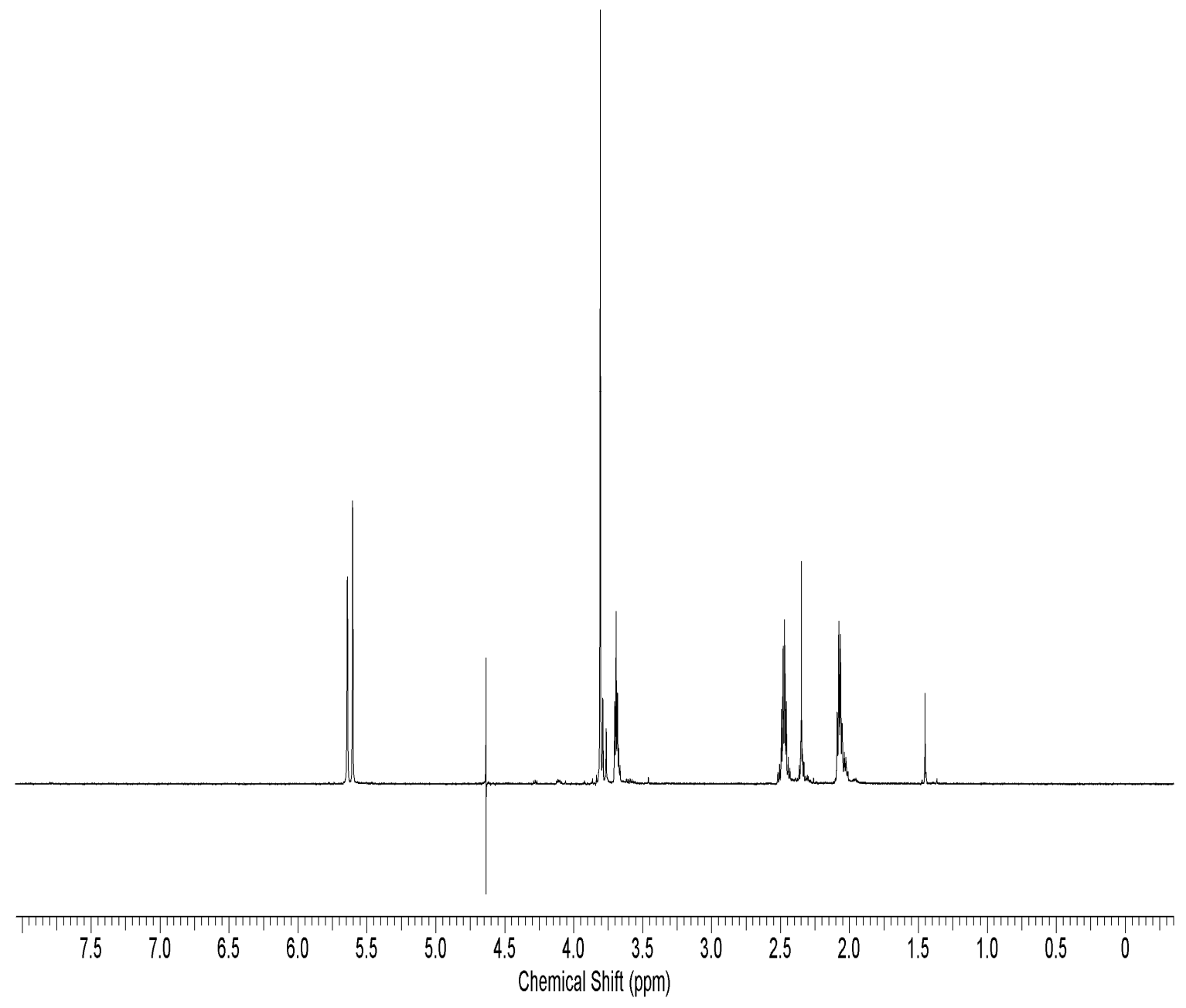

Figure 3.17. $\quad{ }^{1} \mathrm{H} \quad$ NMR $\quad$ spectrum of $\quad \gamma$-glutamyldehydroalanylglycine (dehydroglutathione). The compound is characterized by the vinylic protons doublet at $5.62 \mathrm{ppm}$ which is consistent with reported literature value of $5.72 \mathrm{ppm}$ $(86,92)$. 


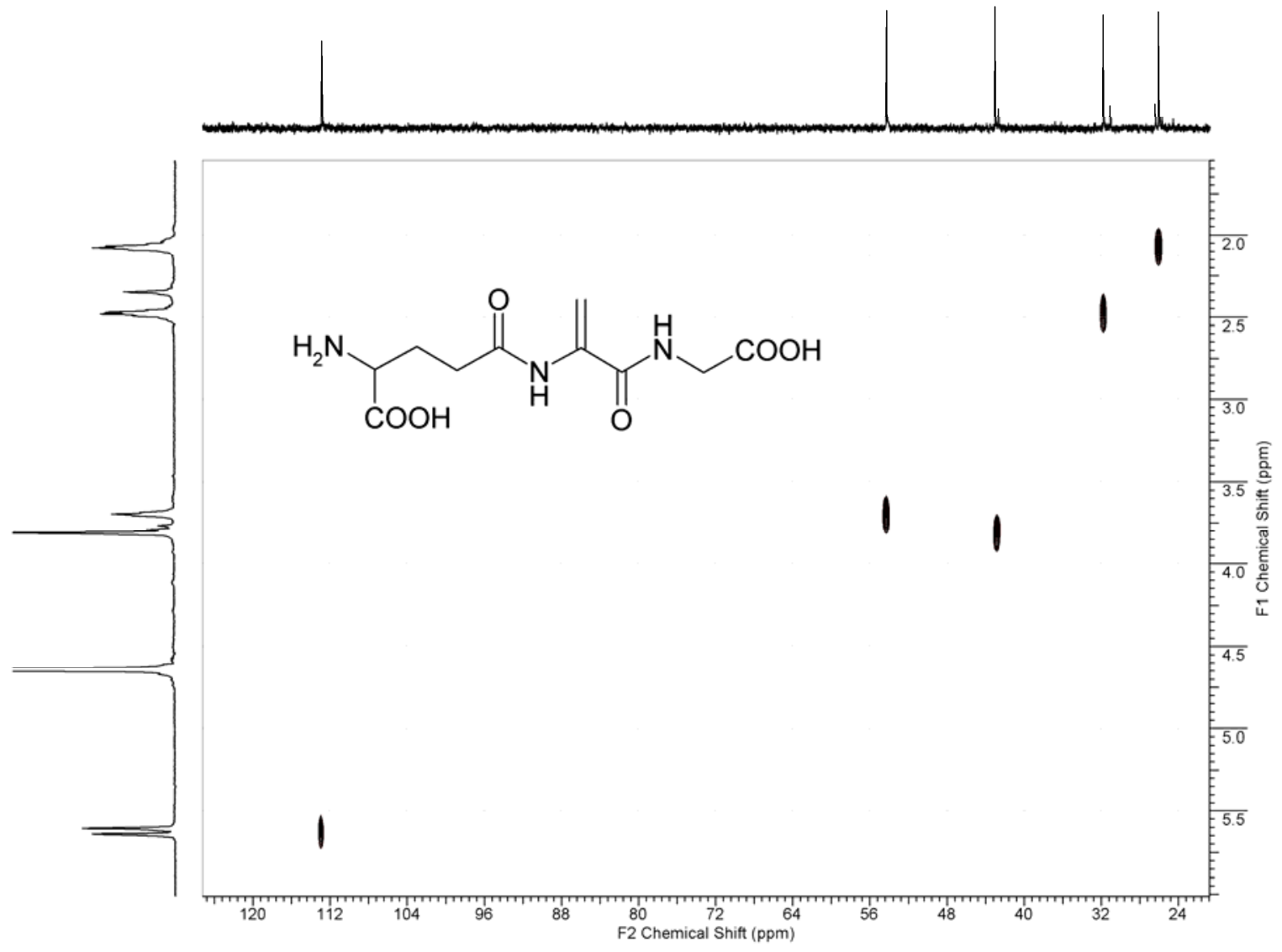

Figure 3.18. HETCOR NMR spectrum of $\gamma$-glutamyldehydroalanylglycine (dehydroglutathione). 


\subsubsection{Reactivity of Dehydroglutathione Toward Nucleophiles}

Dehydroglutathione contains an $\alpha, \beta$-unsaturated system which makes it a Michael acceptor. Michael acceptor is generally referred to as the electrophile which reacts with a nucleophile to form a conjugate or adduct. We tested the ability of dehydroglutathione to form adducts with cellular nucleophiles such as glutathione and cysteine. Dehydroglutathione was incubated with cysteine in 1\% $\mathrm{NH}_{4} \mathrm{OH}$ overnight and the crude reaction mixture was analyzed by mass spectrometry. The ESI-MS full scan of the mixture showed a protonated molecular species $\left(\mathrm{MH}^{+}\right)$with $\mathrm{m} / \mathrm{z}$ of 396 consistent with molecular mass of the cysteinedehydroglutathione adduct. Fragmentation of the adduct by MS/MS produced a daughter ion with $\mathrm{m} / \mathrm{z} 267$ consistent with the neutral loss of pyroglutamic acid (data not shown). Further fragmentation of the daughter ion produced protonated molecular species with $\mathrm{m} / \mathrm{z} 249$ and $\mathrm{m} / \mathrm{z} 192$ corresponding to the loss of water and glycine, respectively (data not shown).

The observed second order reaction rate constant for the formation of the cysteine-dehydroglutathione adduct was determined by following the disappearance of the vinylic proton doublet in the ${ }^{1} \mathrm{H}$ NMR spectrum. Cysteine and dehydroglutathione solution, prepared in $100 \mathrm{mM}$ potassium phosphate buffer in deuterium oxide ( $\mathrm{pD} 8.0$ ), were mixed in equal molar concentrations and the reaction was carried out in NMR tube maintained at $37^{\circ} \mathrm{C}$ in the NMR probe. Figure 3.19 shows the plot of the reciprocal of the dehydroglutathione 
concentration versus time. The slope of this curve which represents the observed second order rate reaction constant was determined to be $2.9 \mathrm{mM}^{-1} \mathrm{~min}^{-1}$.

The formation of glutathione-dehydroglutathione adduct (lanthionylglutathione) was studied in the same manner as for the cysteinedehydroglutathione adduct described above. Structure elucidation of the adduct was obtained by single stage and multistage mass spectrometry. The full spectrum of the reaction mixture produced a protonated molecular species $\left(\mathrm{MH}^{+}\right)$with $\mathrm{m} / \mathrm{z}$ 581 , which is consistent with molecular mass of the adduct. MS/MS of the adduct produced three daughter ions with $\mathrm{m} / \mathrm{z} 563, \mathrm{~m} / \mathrm{z} 452$, and $\mathrm{m} / \mathrm{z} 323$ consistent with the neutral loss of water, pyroglutamic acid, and two molecules of pyroglutamic acid, respectively (Figure 3.20). The daughter ion $\mathrm{m} / \mathrm{z} 323$ was also obtained upon the fragmentation of the daughter ion $\mathrm{m} / \mathrm{z} 452$, which also produced a weak ion $\mathrm{m} / \mathrm{z} 248$ consistent with the neutral loss of glycine.

\subsubsection{In Vitro Cytotoxicity of Dehydroglutathione}

C6 cell exposed to $0.25 \mathrm{mM}-2.0 \mathrm{mM}$ of dehydroglutathione for $24 \mathrm{~h}$ displayed abnormal cell morphology characterized by cell shrinkage and the loss of cell processes. No such morphological changes were observed in C6 cells not treated with dehydroglutathione. Following $24 \mathrm{~h}$ of exposure to dehydroglutathione, there was a profound decrease in the number of viable cells. When compared to busulfan, dehydroglutathione produced less cytotoxicity ( $50 \%$ ) at the same molar concentration (Figure 3.21). The $\mathrm{LD}_{50}$ values were 
approximately $460 \mu \mathrm{M}$ and $880 \mu \mathrm{M}$ for busulfan and dehydroglutathione, respectively.

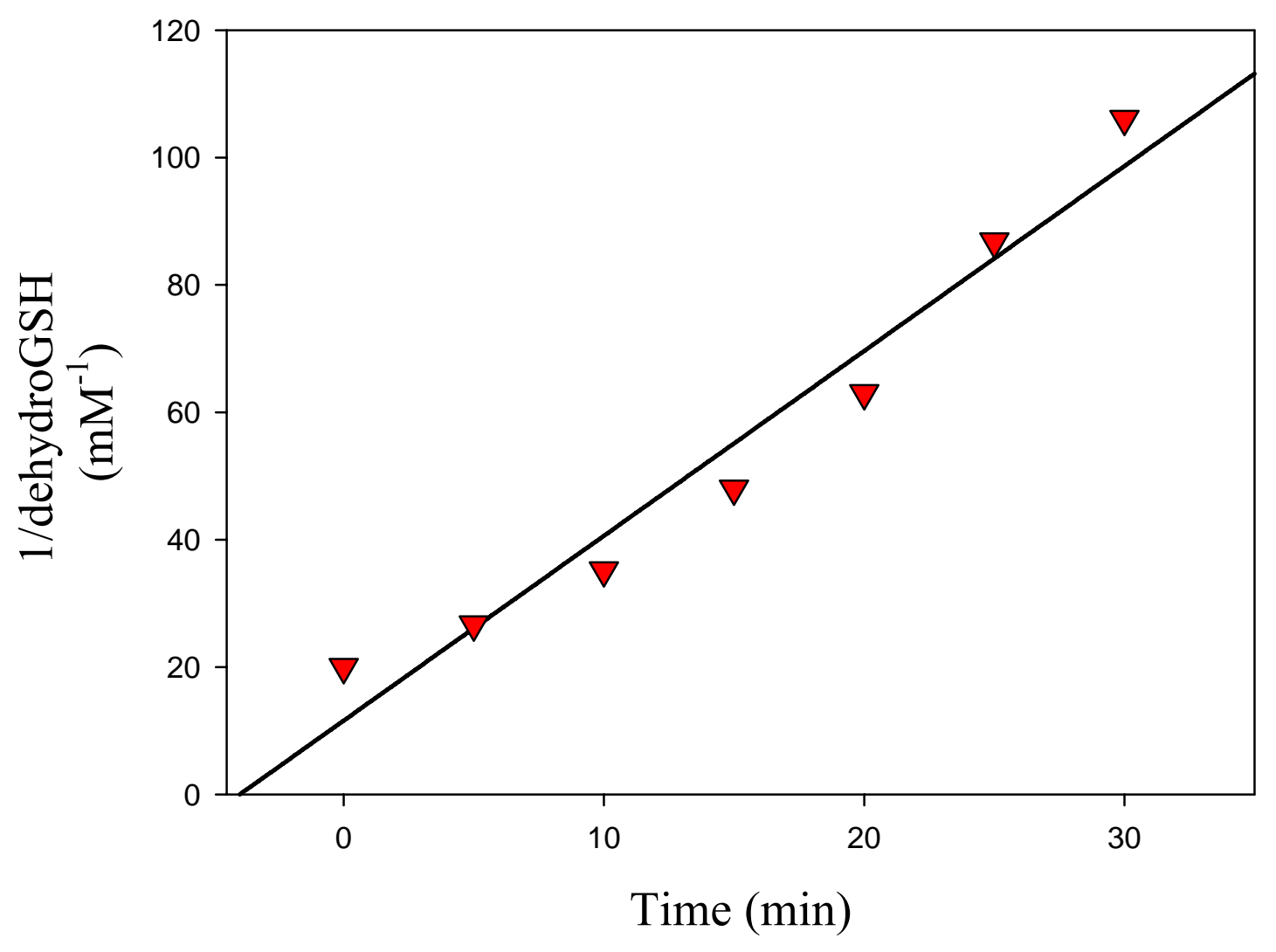

Figure 3.19. The second order reaction between cysteine and $\gamma$ glutamyldehydroalanylglycine (dehydroglutathione) in $100 \mathrm{mM}$ potassium phosphate buffer ( $\mathrm{pH} 8.0)$. Each point represents the average of duplicate runs ( $\mathrm{n}=$ 2). 


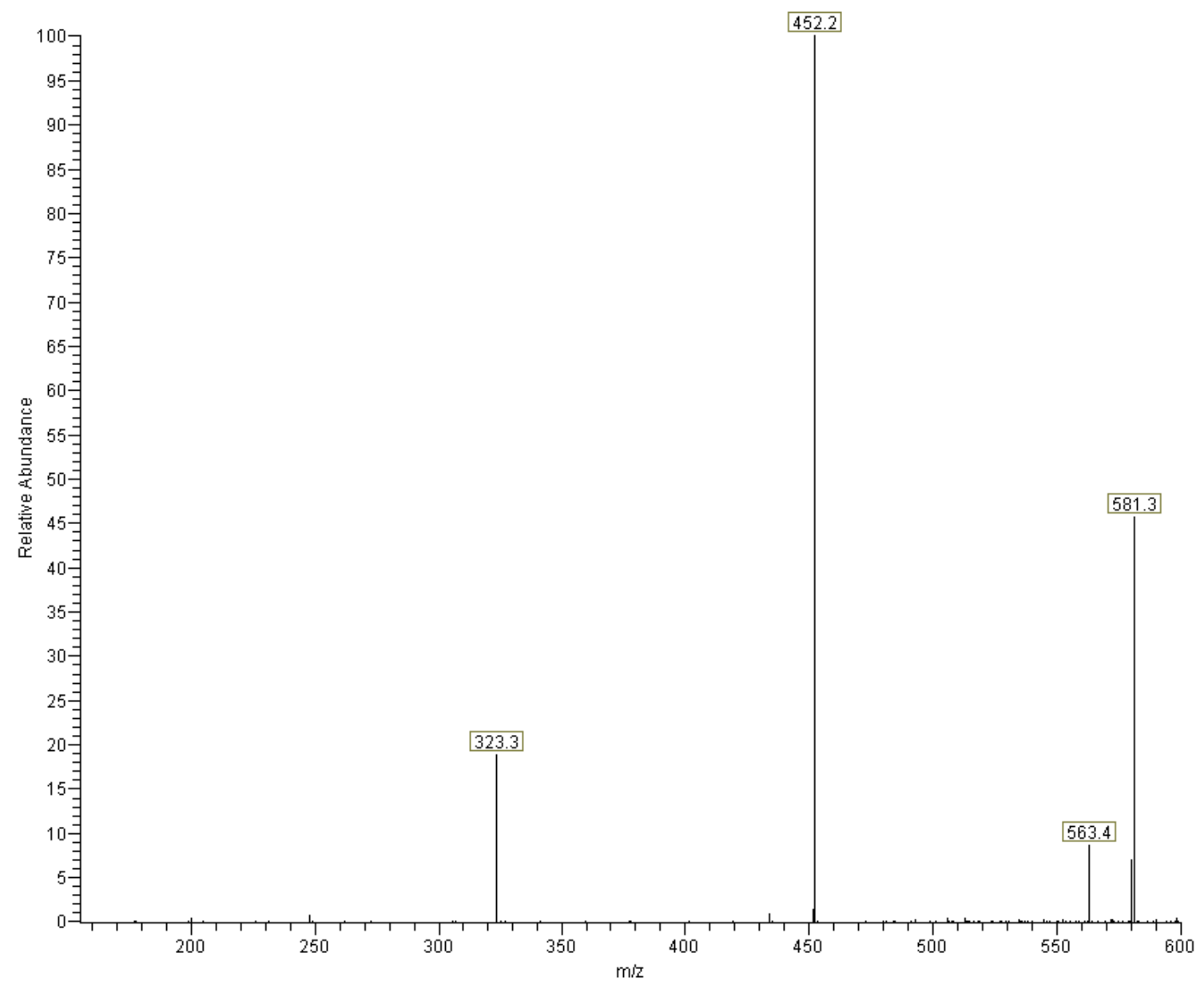

Figure 3.20. MS/MS of the glutathione- dehydroglutathione adduct. The adduct $\mathrm{m} / \mathrm{z} 581$, loss of water $\mathrm{m} / \mathrm{z} 563$, loss of pyroglutamic acid $\mathrm{m} / \mathrm{z} 452$, loss of two molecules of pyroglutamic acid $\mathrm{m} / \mathrm{z} 323$. 


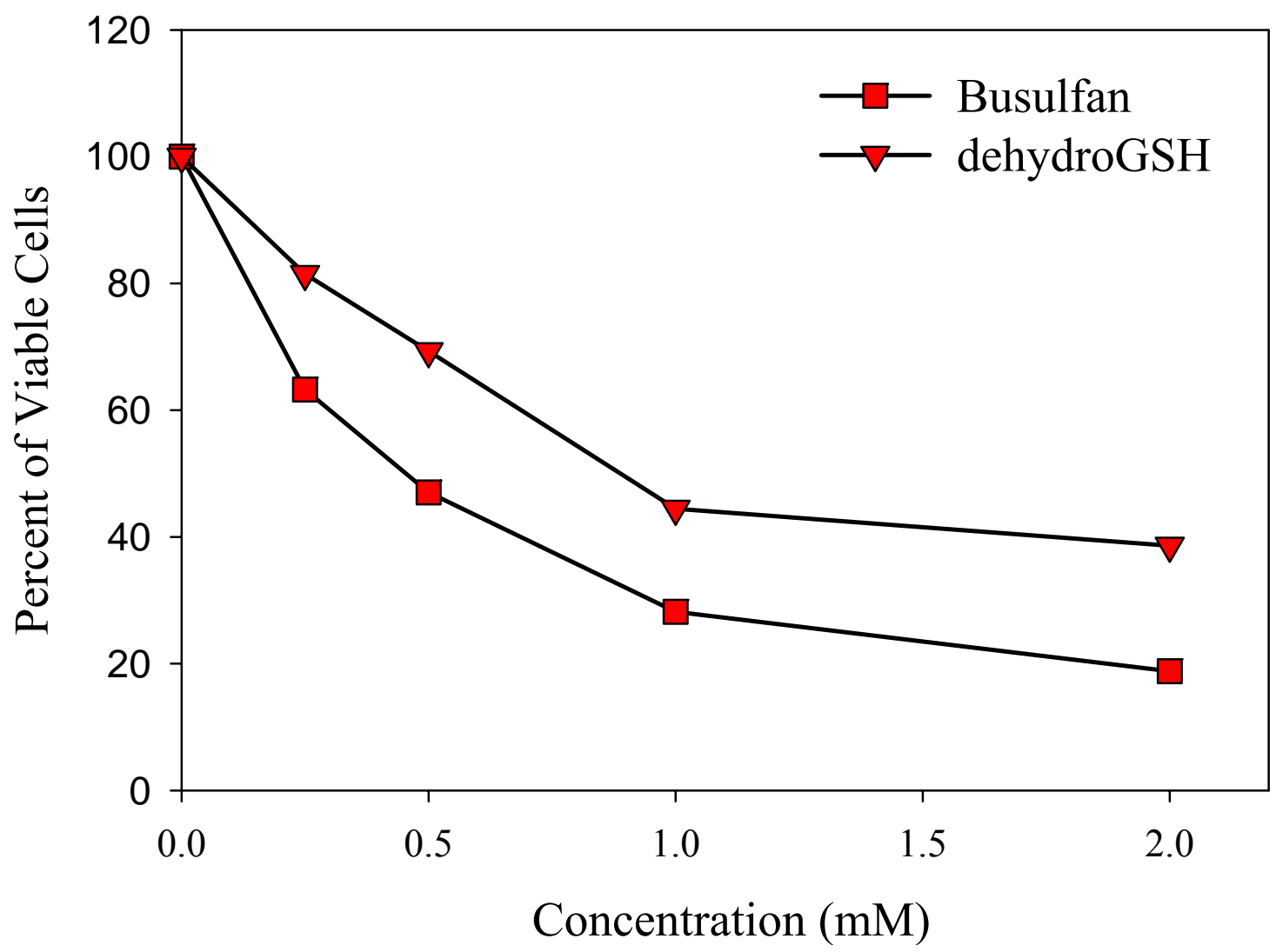

Figure 3.21. Busulfan and $\gamma$-glutamyldehydroalanylglycine (dehydroglutathione) cytotoxicity against $\mathrm{C} 6$ cells. Each point represents the average of three determinations. The $\mathrm{LD}_{50}$ values were approximately $460 \mu \mathrm{M}$ and $880 \mu \mathrm{M}$ for busulfan and dehydroglutathione, respectively. 


\subsection{Effect of N,N-Dimethylacetamide (DMA) on the Catalytic Activity of CYP450 3A4, 2B6, and 2C9 in Human Liver Microsomes}

\subsubsection{CYP3A4 Assay}

Testosterone $6 \beta$-hydroxylation was measured to determine the catalytic activity of the CYP3A4 enzyme in human liver microsomes (93). The formation of $6 \beta$-hydroxytestosterone did not vary from the control when the microsomes were co-incubated with DMA (Figure 3.22, panel A). The results suggested that DMA is not a competitive inhibitor of CYP3A4.

\subsubsection{CYP2B6 Assay}

Bupropion hydroxylation has previously been shown to be a marker for CYP2B6 activity in humans (94). The rate of hydroxylbupropion formation was not affected when DMA $(0-25 \mathrm{mM})$ was added to the incubation mixture (Figure 3.22, panel B). When compared to thio-TEPA, a known CYP2B6 specific inhibitor (95), DMA did not produce significant inhibition on the catalytic activity of CYP2B6.

\subsubsection{CYP2C9 Assay}

Tolbutamide methylhydroxylation was measured to determine the effect of DMA on the catalytic activity of CYP2C9 (96). As depicted in panel C of Figure 3.22, DMA did not inhibit CYP2C9 catalytic activity in the concentration range 0 $25 \mathrm{mM}$. 

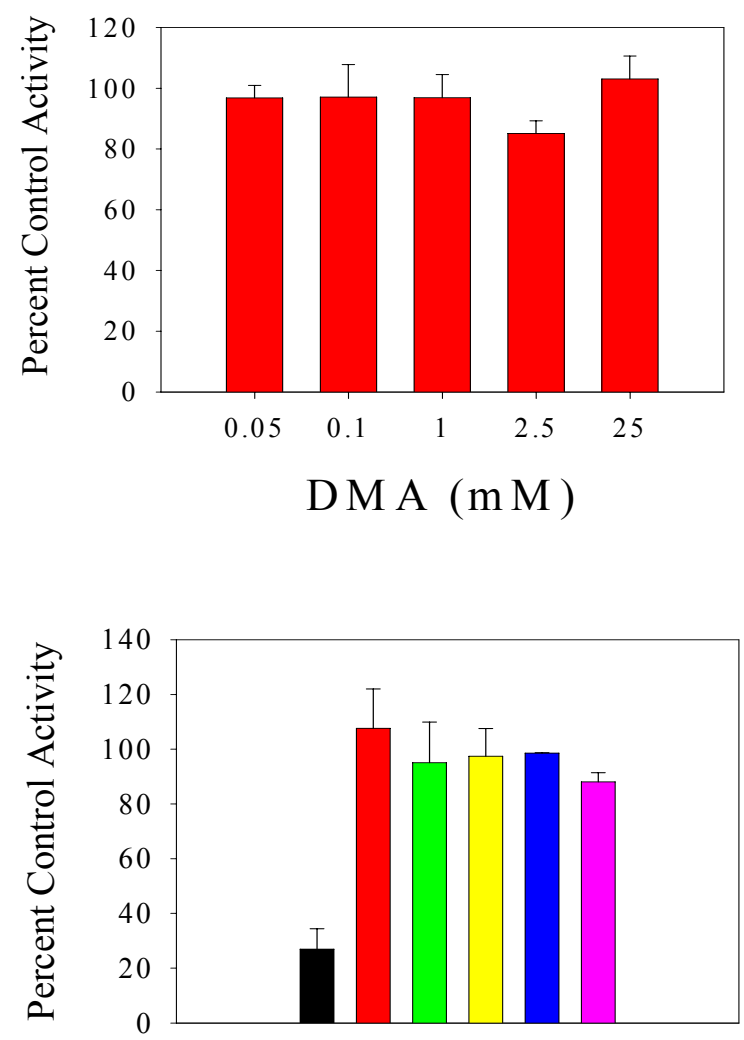

$$
\begin{aligned}
& 50 \mu \mathrm{M} \text { thio-TEPA } \\
& \square \quad 5 \mu \mathrm{MMA} \\
& \square \quad 100 \mu \mathrm{M} \text { DMA } \\
& \square \quad 1 \mathrm{mM} \mathrm{DMA} \\
& \square \quad 2.5 \mathrm{mM} \mathrm{DMA} \\
& \square \mathrm{mM} \mathrm{DMA}
\end{aligned}
$$

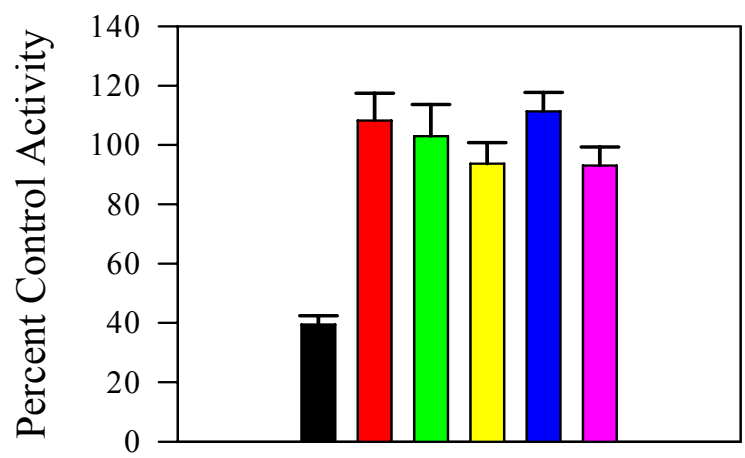

- $50 \mu \mathrm{M}$ sulfaphenazole

$\square \quad 5 \mu \mathrm{M}$ DMA

$\square \quad 100 \mu \mathrm{M}$ DMA

$\square \quad 1 \mathrm{mM}$ DMA

— $2.5 \mathrm{mM}$ DMA

$\square \quad 25 \mathrm{mM}$ DMA

Figure 3.22. Effect of DMA on the catalytic activity of CYP40 in human liver microsomes. Panel A testosterone 6 $\beta$-hydroxylation (CYP3A4); panel B, bupropion hydroxylation (CYP2B6); panel C, tolbutamide 4-methylhydroxylation (CYP2C9). The results represent the average value $(n=3)$, and the error bars represent standard deviation. 
Chapter 4: Discussion 
Metabolism of busulfan: The major elimination pathway of busulfan is through conjugation with glutathione. Some literature data suggested a possible involvement of CYP450 in the metabolism of busulfan $(23-25,97)$. Our results clearly showed that busulfan is not a substrate for CYP450. The observed increase in busulfan clearance upon the co-administration of drugs that are known to induce CYP450 is more likely caused by increased elimination of busulfan by pathways other than CYP450 mediated metabolism. Fitzsimmons et al reported that anticonvulsants such as phenytoin and phenobarbital protect from the acute neurotoxicity, and increase the survival rate from myelotoxicity caused by busulfan(97). Phenytoin induces $\gamma$-glutamyltransferase (44), this enzyme has a wide substrate specificity and can convert the glutathione $S$-conjugate of busulfan to its corresponding cysteinylglycine $S$-conjugate. It is also possible that these enzyme inducers induce microsomal GST which provides protection against busulfan toxicity (98). On the other hand, our results suggest that the slight reduction in busulfan clearance ( $20 \%)$ observed upon using ketoconazole along with busulfan, can be attributed in part to the weak inhibitory effect of ketoconazole on GST activity. The obtained results support the idea that glutathione conjugation is the only pathway for busulfan clearance, and that observed changes in busulfan clearance can be attributed to changes in this pathway. It should be noted that one can not rule out the substrate inhibition of CYP450 in the liver microsomes at $1 \mu \mathrm{M}$ of busulfan. Hassan et al reported that busulfan significantly reduced the clearance, increased the elimination half-life, 
and reduced the exposure to the cytotoxic metabolites of cyclophosphamide (99). These findings suggest the ability of busulfan to inhibit CYP450 3A4, 2C9, and 2B6 which are necessary for the bioactivation of cyclophosphamide.

Busulfan is converted to the glutathione S-conjugate (L- $\gamma$-glutamyl- $\beta-(S-$ tetrahydrothiophenium)-L-alanylglycine ( $\gamma$-E-THT-AG) non-enzymatically(100) and by GST, especially GSTA-1 $(41,42,100)$. Several studies have shown that major urinary metabolites of busulfan are sulfolane [tetrahydrothiophene 1,1dioxide], 2-hydroxysulfolane, 3-hydroxysulfolane, and tetrahydrothiophene 1oxide $(26,37,91,101)$. These findings indicate that busulfan is metabolized to tetrahydrothiophene (THT), which is subsequently readily oxidized in vivo at the sulfur, and at the 2- and 3-positions of the ring. $\gamma$-E-THT-AG has been shown to undergo a non-enzymatic $\beta$-elimination reaction yielding THT under alkaline conditions (91) (Figure 1.1).

Two possible mechanisms for non-enzymatic production of THT from $\gamma$-ETHT-AG; one would be through $\mathrm{SN}_{2}$ hydrolysis by direct attack at the acyclic methylene attached to the sulfur to produce THT and $\gamma$-glutamylserinylglycine (Figure 4.1, A) and the other would be through E1 type reaction ( $\beta$-elimination) that is a base catalyzed elimination of THT by the abstraction of the $\alpha$ proton, which will lead to the formation of THT and $\gamma$-glutamyldehydroalanylglycine (Figure 4.1, B). Our data show that in addition to THT, a product observed by NMR in the non-enzymatic $\beta$-elimination reaction of 


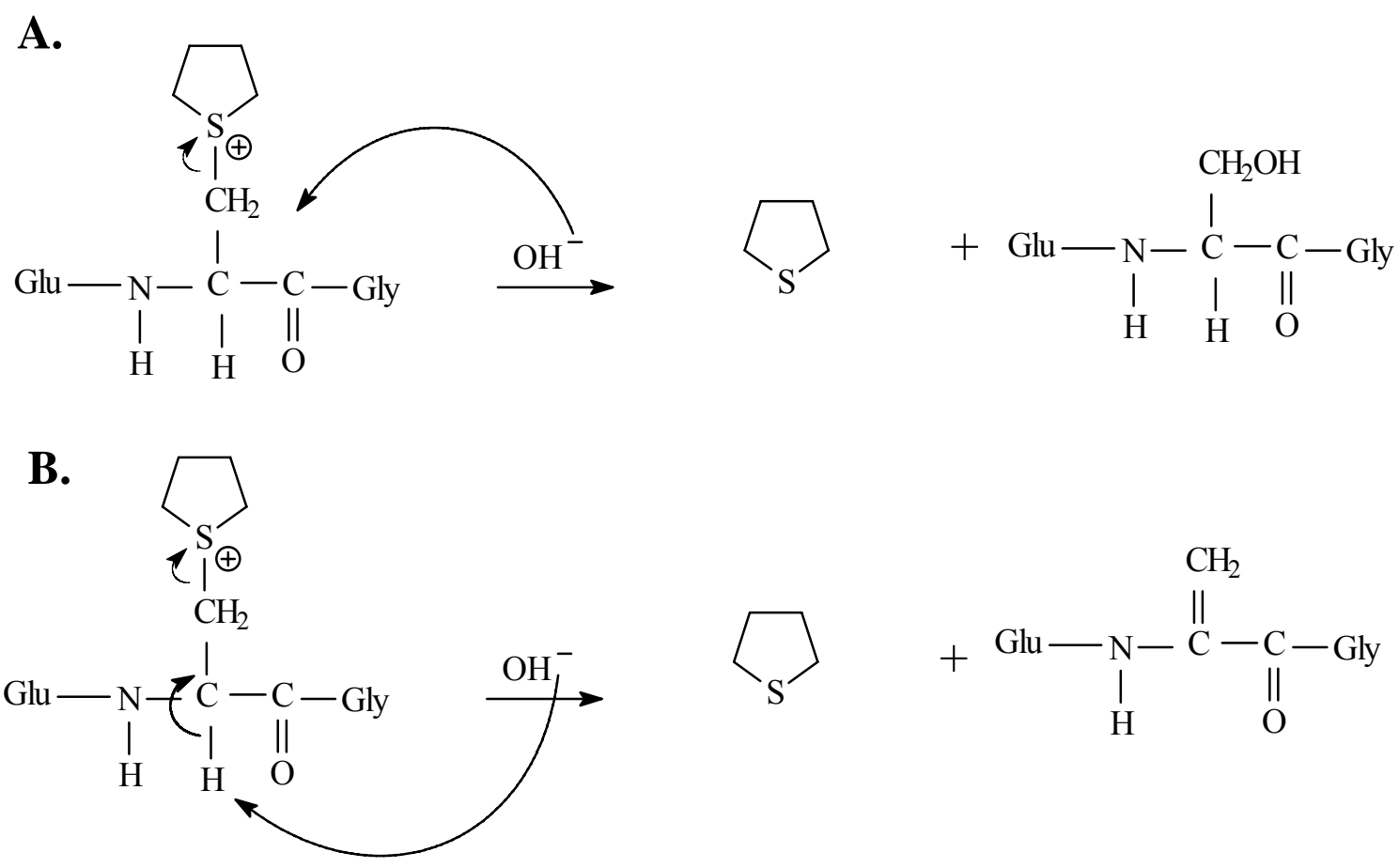

Figure 4.1. Proposed mechanisms of non-enzymatic degradation of L- $\gamma$-glutamyl$\beta$-(S-tetrahydrothiophenium)-L-alanylglycine ( $\gamma$-E-THT-AG), $\mathrm{SN}_{2}$ hydrolysis (A), $\beta$-elimination (B).

$\gamma$-E-THT-AG is $\gamma$-glutamyldehydroalanylglycine. This non-enzymatic reaction takes place at a slow but measurable rate under physiological conditions $(\mathrm{pH} 7.4$ and $37^{\circ} \mathrm{C}$ ). Thus, there seems little doubt that THT can be formed nonenzymatically in vivo from $\gamma$-E-THT-AG. The question remains as to which enzymes such as $\beta$-lyases, also contribute to THT formation from $\gamma$-E-THT-AG in vivo. Ritter et al (100) stated "the sulfonium product can be cleaved to THT either enzymatically, for example, by $\beta$-lyases or chemically by alkalization". We are 
unaware of precedence for GST or other enzymes catalyzing $\beta$-elimination reactions with glutathione $S$-conjugates. A more likely substrate for an enzymecatalyzed $\beta$-lyase reaction in the busulfan metabolic pathway is the cysteine $S$ conjugate (THT-A) rather than the glutathione $S$-conjugate $(\gamma$-E-THT-AG).

Since the enzymes that convert glutathione $S$-conjugates to cysteine $S$ conjugates (i.e. $\gamma$-glutamyltransferase and dipeptidase/cysteinylglycinase) have a wide substrate specificity $(85,102)$, it is probable that $\gamma$-E-THT-AG will be converted in vivo to the corresponding cysteine $S$-conjugate $[\beta-(S-$ tetrahydrothiophenium)-L-alanine, THT-A] by these enzymes. THT-A can be either converted to an $\mathrm{N}$-acetylcysteine conjugate or undergo a $\beta$-elimination reaction. The identification of the $\mathrm{N}$-acetylcysteine conjugate of busulfan in rat urine treated with busulfan confirms the existence of this pathway in vivo (39). It should also be noted that THT-A may also be formed non-enzymatically. Our reasoning is based on the nucleophilic reactivity of sulfhydryl compounds with busulfan. GSH reacts with busulfan at $\mathrm{pH} 7.4$ (84). Because the $\mathrm{p} K_{\mathrm{a}}$ value of the $\mathrm{SH}$ group in cysteine is lower than that of the -SH group in GSH (8.2-8.5 versus 9.2) (103), the cysteine sulfhydryl is a more reactive nucleophile than is the GSH sulfhydryl at physiological $\mathrm{pH}$ values.

Our data showed that cysteine can react non-enzymatically with busulfan to generate THT-A at $\mathrm{pH} 8$ and $37^{\circ} \mathrm{C}$. Thus, some THT-A is probably formed in vivo by the non-enzymatic reaction of endogenous cysteine with busulfan. However, 
the predominant route for formation of THT-A in vivo is likely to be enzyme catalyzed. We hypothesize that although a portion of $\gamma$-E-THT-AG is converted non-enzymatically to THT and $\gamma$-glutamyldehydroalanylglycine, the major metabolic fate of $\gamma$-E-THT-AG in liver and other organs in vivo is conversion to THT-A by the consecutive action of $\gamma$-glutamyltranspeptidase and dipeptidase/cysteinylglycinase. We further hypothesize that THT-A is then converted to THT in part non-enzymatically, but for the most part by cysteine $S$ conjugate $\beta$-lyases.

The $V_{\max }$ and $K_{\mathrm{m}}$ values for human liver cytosol-catalyzed formation of THT from busulfan in the presence of $0.7 \mathrm{mM}$ GSH were reported to be $134 \mathrm{pmol}$ mg protein ${ }^{-1} \min ^{-1}$ and $2.74 \mathrm{mM}$, respectively (100). In the present work, we showed that the rate at which rat liver cytosol catalyzes a $\beta$-lyase reaction with 5 mM THT-A $\left(\sim 1.06 \mathrm{nmol} \mathrm{mg}\right.$ protein $\left.{ }^{-1} \mathrm{~min}^{-1}\right)$ is considerably faster than the rate at which human liver cytosol can maximally convert busulfan to THT. We also showed that rat liver mitochondria and homogenates of rat brain and kidney also catalyze a $\beta$-lyase reaction with THT-A. Busulfan is capable of crossing the brain blood barrier (104). Thus, the potential exists for prominent metabolism of busulfan via cysteine $S$-conjugate $\beta$-lyase reactions in multiple organs including the brain. Furthermore, we have identified a major $\beta$-lyase acting on THT-A in rat liver cytosol as cystathionine $\gamma$-lyase. Our data also suggest that other enzymes are also capable of catalyzing this reaction in rat liver mitochondria, brain and kidney. 
The identity of these enzymes must await further study. However, two PLPcontaining enzymes that catalyze prominent $\beta$-lyase reactions with halogenated cysteine S-conjugates, namely GTK and mitAspAT were ruled out as candidates. Toxicity of busulfan and its metabolites: Conditioning therapy with cytotoxic drugs, such as busulfan and cyclophosphamide, in patients undergoing bone marrow transplant is the most important factor leading to the development of hepatic venoocclusive disease (HVOD) (105-109). HVOD is caused by the destruction of sinusoidal endothelial cells and the surrounding centriobular hepatocytes $(110,111)$. This effect is observed more often in patients with high systemic exposure to the parent drug, whereas efficacy may be compromised in those with low systemic exposure $(107,112)$. Monitoring of the prospective busulfan plasma disposition and dose individualization may reduce the frequency of HVOD in some, but not all, patients (113). It was proposed that HVOD associated with conditioning regimens of busulfan in bone transplant patients is related to the metabolites of busulfan rather than the parent compound (114). DeLeve et al suggested that this complication can be caused either directly through oxidative stress or indirectly through glutathione depletion (115). We hypothesize that these conditions are related in part to the non-enzymatic decomposition of the glutathione $S$-conjugate $\gamma$-E-THT-AG to $\gamma$-glutamyldehydroalanylglycine.

Dehydroalanine-containing peptides are well known in nature and have been recognized as excellent Michael acceptors that can link biologically active molecules to a variety of cellular targets. For example, dehydroalanine is present 
in lantibiotics, a class of ribosomally synthesized peptide antibacterial agents. Michael addition of a sulfhydryl to the double bond of a dehydroalanine residue can occur readily. In fact, many of the lantibiotics possess lanthionine residues, that are formed though Michael addition of a cysteine sulfhydryl group to the double bond of a dehydroalanine residue (reviewed in (116)). A similar addition reaction to a Michael acceptor is hypothesized to occur in the human lens. Thus, lanthionine residues are associated with aging of the human lens and cataractogenesis (117). These lanthionine residues appear to be due in part to nonreducible thioethers formed from glutathione. Linetsky and LeGrand (117) reasonably considered that the non-reducible glutathionylation is due to Michael addition of the sulfhydryl moiety of GSH to dehydroalanine residues formed within lens proteins. Our data suggest, however, that non-reducible glutathionylation could also occur through addition of $\gamma-$ glutamyldehydroalanylglycine to the cysteine moiety of a susceptible protein.

Presumably, $\gamma$-glutamyldehydroalanylglycine formation is not of primary significance during normal physiological aging. However, formation of $\gamma$ glutamyldehydroalanylglycine may be a critical factor/toxicant in individuals treated with busulfan, not only in regard to the lens, but also to the circulatory system in general. Interestingly, it has recently been shown that busulfan treatment of mice resulted in upregulation of glutathione synthesis and increased toxicity of busulfan (118). We suggest that higher GSH levels lead to higher concentrations 
of $\gamma$-E-THT-AG. An increase in $\gamma$-E-THT-AG would lead to increased nonenzymatic formation of $\gamma$-glutamyldehydroalanylglycine, which in turn, would lead to non-reducible glutathionylation of proteins associated with the circulatory system. This could be confirmed by the observed reduction in the neurotoxicity and myelotoxicity of busulfan when it is co-administered with phenytoin (97). Phenytoin induces $\gamma$-glutamyltransferase (44) which in turn will reduce the amount of $\gamma$-glutamyldehydroalanylglycine formed. Our data shows the ability of $\gamma$-glutamyldehydroalanylglycine to undergo Michael additions with free cysteine and with GSH. It is possible that the Michael adducts of $\gamma$ glutamyldehydroalanylglycine with cysteine and GSH will interfere with enzymes that utilize GSH/glutathione disulfide as substrates. We suggest that increased non-reducible glutathionylation of proteins and Michael adducts with GSH and free cysteine may contribute to busulfan-induced cataract formation and HVOD. If that is the case, then regimens or strategies designed to either deplete endogenous GSH levels with co-administration of ethacrynic acid (cf.(41)) or accelerate the conversion of the glutathione $S$-conjugate to the cysteine $S$-conjugate should be protective. Detoxification would be complete when the cysteine $S$-conjugate is converted to the relatively harmless products pyruvate, THT and ammonium via $\beta$-lyase reactions catalyzed by cystathionine $\gamma$-lyase and/or other PLP-containing enzymes. It is also possible that high doses of vitamin $\mathrm{B}_{6}$ might be beneficial in 
promoting the conversion of THT-A to THT in patients undergoing treatment with busulfan.

Harkey et al. (98) recently showed that overexpression of a microsomal GST (MGSTII) in HEK human kidney fibroblasts confers protection against busulfan and melphalan. At first glance, this finding is not in agreement with our hypothesis. Indeed, the authors suggested that formation of the glutathione $S$ conjugate is protective against busulfan toxicity. However, the authors showed that overexpression of GSTA1 and GSTP1 in these cells is not protective, yet as noted above, these GST catalyze the formation of $\gamma$-E-THT-AG from busulfan. Moreover, MGSTII does not have the ability to conjugate GSH to busulfan (41). Harkey et al. (98) discuss the possibility of involvement of other enzymes and the $\mathrm{ABC}$ transporter MRP1 (a major transporter of glutathione conjugates from cells) in contributing to protection against busulfan. It would be interesting to determine whether overexpression of MGSTII also leads to increased levels of $\gamma$ glutamyltranspeptidase and dipeptidase/cysteinylglycinase. Safety of busulfan parenteral formulation: N,N-Dimethylacetamide (DMA) is a constituent of the solvent system used to solubilize busulfan in IV formulation. As a result, patients receiving high dose of busulfan are also exposed to high dose of DMA. We evaluated the effect of DMA on the catalytic activity of CYP450 2B6, 2C9, and 3A4 using human liver microsomes and substrate markers. Bupropion, tolbutamide, and testosterone were used as substrate marker to assess the catalytic activity of CYP450 2B6, 2C9, and 3A4, respectively. These three isoform were 
chosen cause of their role in the activation of cyclophosphamide, an anti-cancer agent used along with busulfan in high doses for conditioning patients prior to bone marrow transplant.

.The DMA concentration range used $(5 \mu \mathrm{M}-25 \mathrm{mM})$ took into account the minimum amount of DMA detected in the urine of workers occupationally exposed to the solvent (119), and the maximum amount of DMA delivered to the body in busulfan IV formulation. Our results indicated no inhibitory effect of DMA on the catalytic activity of CYP450 2B6, 2C9, 3A4. This supports the safety of using DMA in busulfan formulation, and indicates no drug-drug interaction associated with DMA and cyclophosphamide. The obtained results are in agreement with the work of Andersson et al (120), where the safety of using IV busulfan along with cyclophosphamide as pretransplantation conditioning therapy was indicated.

Though the current work showed no inhibitory effect of DMA on the aforementioned CYP450 isoforms, DMA is known to inhibit CYP450 2E1 (72). DMA should not be used to solubilize drugs that are co-administered with CYP450 2E1 substrates such as the sevoflurane, isoflurane, and methoxyflurane (121). 


\section{Chapter 5: Summary and Conclusion}


The major biotransformation pathway in the metabolism of busulfan involves the glutathione-derived formation of THT. Although busulfan contains two sulfur atoms, the sulfur of THT is not derived from busulfan, but rather from GSH. The glutathione $S$-conjugate of busulfan ( $\gamma$-E-THT-AG) undergoes a non-enzymatic elimination reaction to generate THT and $\gamma$-glutamyldehydroalanylglycine. We hypothesize that $\gamma$-glutamyldehydroalanylglycine contributes to the toxicity of busulfan by forming Michael adducts with protein cysteinyl residues, free cysteine, GSH and Coenzyme A. Here we show that rat tissues contain enzymes, one of which was identified as cystathionine $\gamma$-lyase, that are capable of converting the cysteine $S$-conjugate of busulfan (THT-A) to pyruvate, THT and ammonium. The $\beta$ lyase reaction is likely a detoxification mechanism. The results suggest that THT either is formed non-enzymatically from $\gamma$-E-THT-AG or through the mercapturic acid pathway and $\beta$-lyase catalysis involving THT-A as an intermediate. Stimulation of this pathway may afford protection against busulfan toxicity.

We have constructed the most likely pathways for the metabolism of busulfan to THT in vivo (Figure 5.1). The strong electron-withdrawing properties of the $-\mathrm{OS}\left(\mathrm{O}_{2}\right) \mathrm{CH}_{3}$ group on busulfan (I) results in electron deficiency at each carbon adjacent to the two methanesulfonyl groups. This deficiency facilitates the nucleophilic attack of the sulfhydryl of glutathione at one of these carbons, resulting in elimination of methanesulfonate (II) and subsequent generation of adduct III. This step occurs non-enzymatically, but is accelerated by GST. The electron 
deficiency in the remaining carbon adjacent to the $-\mathrm{OS}\left(\mathrm{O}_{2}\right) \mathrm{CH}_{3}$ group in adduct III facilitates non-enzymatic intramolecular nucleophilic attack at this carbon by a pair of electrons on the sulfur of the thioether, generating the glutathione $S$-conjugate $\gamma$ E-THT-AG (V) and eliminating a second equivalent of methanesulfonate. The conversion of busulfan (I) to $\gamma$-E-THT-AG $(\mathbf{V})$ is shown as occurring by two consecutive steps but may occur by a concerted mechanism. The adduct $\gamma$-E-THTAG $(\mathbf{V})$ possesses a cyclic sulfonium group. Owing to the broad specificity of $\gamma$ glutamyltranspeptidase and dipeptidase, $\mathbf{V}$ is expected to be readily converted to the corresponding cysteine S-conjugate THT-A (VI) in vivo. The adduct THT-A (VI) may also arise by non-enzymatic nucleophilic attack of a cysteine sulfur on busulfan (I), which generates adduct IV and methanesulfonate, followed by intramolecular cyclization and elimination of a second equivalent of methanesulfonate. The adduct THT-A (VI) contains a leaving group and is therefore expected to undergo a facile $\beta$-elimination reaction to yield THT (VII), pyruvate (VIII) and ammonium (IX). This reaction occurs non-enzymatically at $\mathrm{pH}$ 7.4, but is accelerated by PLP and by rat liver cystathionine $\gamma$-lyase (and by other as yet unrecognized enzymes in rat tissues). THT (VII) may also be generated directly and non-enzymatically from $\gamma$-ETHT-AG $(\mathbf{V})$ by an elimination reaction that results in the formation of $\gamma$ glutamyldehydroalanylglycine $(\mathbf{X})$. Michael addition of RSH (where RSH = cysteine, GSH, Coenzyme A or a cysteinyl residue of a protein) to $\gamma$ - 
glutamyldehydroalanylglycine (X) may generate adducts that contain a lanthionine bridge. 

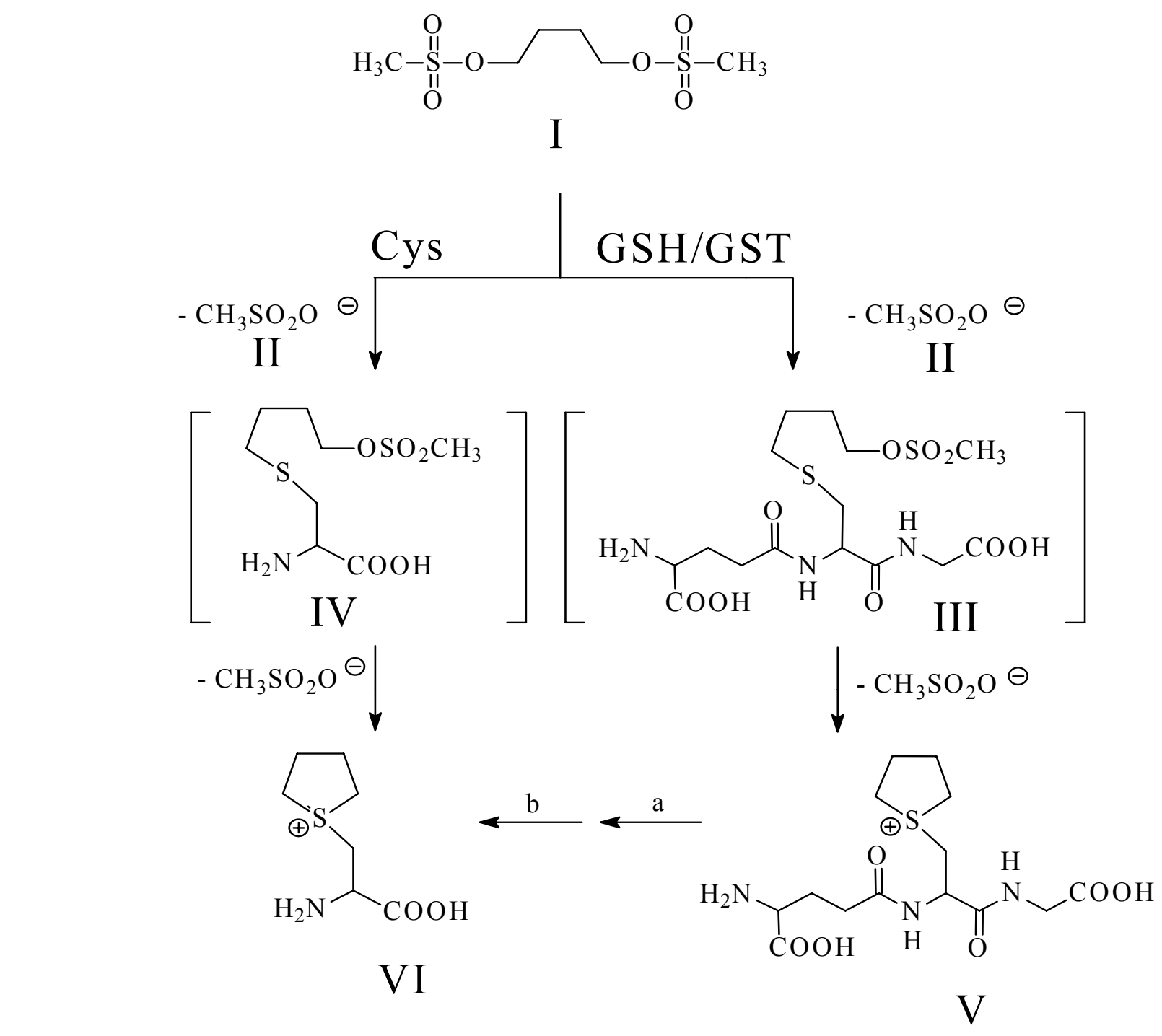

\section{cystathionine $\gamma$-lyase}<smiles>C=C(N)C(=O)O</smiles>

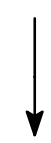

$$
\mathrm{NH}_{3}+{ }_{\mathrm{O}} \stackrel{-}{\mathrm{COOH}}_{\mathrm{C}}
$$

\section{IX}

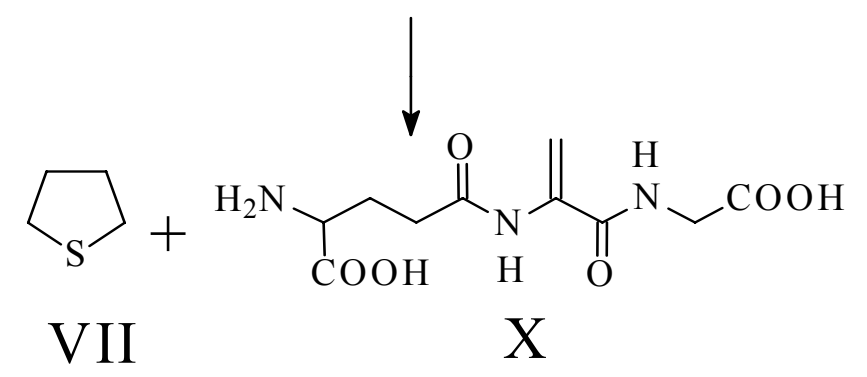

Figure 5.1. Proposed mechanism for the metabolic conversion of busulfan to THT 


\section{Reference List}

(1) Kohn KW. Beyond DNA cross-linking: history and prospects of DNA-targeted cancer treatment--fifteenth Bruce F. Cain Memorial Award Lecture. Cancer Res 1996 December 15;56(24):5533-46.

(2) Hurley LH. DNA and its associated processes as targets for cancer therapy. Nat Rev Cancer 2002 March;2(3):188-200.

(3) Dirven HA, van OB, van Bladeren PJ. Glutathione conjugation of alkylating cytostatic drugs with a nitrogen mustard group and the role of glutathione S-transferases. Chem Res Toxicol 1996 March;9(2):351-60.

(4) GALTON DA. Myleran in chronic myeloid leukaemia; results of treatment. Lancet 1953 January 31;264(6753):208-13.

(5) Silver RT. Chronic myeloid leukemia. Hematol Oncol Clin North Am 2003 October;17(5):1159-vii.

(6) Stone RM. Optimizing treatment of chronic myeloid leukemia: a rational approach. Oncologist 2004;9(3):259-70.

(7) Hasselbalch H, Berild D. Transition of myelofibrosis to polycythaemia vera. Scand J Haematol 1983 February;30(2):161-6.

(8) Anger B, Haug U, Seidler R, Heimpel H. Polycythemia vera. A clinical study of 141 patients. Blut 1989 December;59(6):493-500. 
(9) Brodsky I. Busulfan versus hydroxyurea in the treatment of polycythemia vera (PV) and essential thrombocythemia (ET). Am J Clin Oncol 1998 February;21(1):105-6.

(10) Barbui T, Finazzi G. Treatment indications and choice of a plateletlowering agent in essential thrombocythemia. Curr Hematol Rep 2003 May;2(3):248-56.

(11) Berrebi A, Shvidel L, Shtalrid M, Klepfish A. Short course of busulphan in essential thrombocythaemia: remodelling of an old strategy. $\mathrm{Br} J$ Haematol 2000 April;109(1):249-50.

(12) Hassan M. The role of busulfan in bone marrow transplantation. Med Oncol 1999 September;16(3):166-76.

(13) Iwamoto T, Hiraku Y, Oikawa S, Mizutani H, Kojima M, Kawanishi S. DNA intrastrand cross-link at the 5'-GA-3' sequence formed by busulfan and its role in the cytotoxic effect. Cancer Sci 2004 May;95(5):454-8.

(14) Ponti M, Souhami RL, Fox BW, Hartley JA. DNA interstrand crosslinking and sequence selectivity of dimethanesulphonates. Br J Cancer 1991 May;63(5):743-7.

(15) Buggia I, Locatelli F, Regazzi MB, Zecca M. Busulfan. Ann Pharmacother 1994 September;28(9):1055-62.

(16) Bertholle-Bonnet V, Bleyzac N, Galambrun C et al. Influence of underlying disease on busulfan disposition in pediatric bone marrow transplant 
recipients: a nonparametric population pharmacokinetic study. Ther Drug Monit 2007 April;29(2):177-84.

(17) Vassal G, Gouyette A, Hartmann O, Pico JL, Lemerle J. Pharmacokinetics of high-dose busulfan in children. Cancer Chemother Pharmacol 1989;24(6):386-90.

(18) Ehrsson H, Hassan M, Ehrnebo M, Beran M. Busulfan kinetics. Clin Pharmacol Ther 1983 July;34(1):86-9.

(19) Hassan M, Oberg G, Bekassy AN et al. Pharmacokinetics of highdose busulphan in relation to age and chronopharmacology. Cancer Chemother Pharmacol 1991;28(2):130-4.

(20) Grochow LB, Krivit W, Whitley CB, Blazar B. Busulfan disposition in children. Blood 1990 April 15;75(8):1723-7.

(21) Vassal G, Fischer A, Challine D et al. Busulfan disposition below the age of three: alteration in children with lysosomal storage disease. Blood 1993 August 1;82(3):1030-4.

(22) Hassan M, Fasth A, Gerritsen B et al. Busulphan kinetics and limited sampling model in children with leukemia and inherited disorders. Bone Marrow Transplant 1996 November;18(5):843-50.

(23) Fitzsimmons WE, Ghalie R, Kaizer H. Anticonvulsants and busulfan. Ann Intern Med 1990 April 1;112(7):552-3. 
(24) Hassan M, Oberg G, Bjorkholm M, Wallin I, Lindgren M. Influence of prophylactic anticonvulsant therapy on high-dose busulphan kinetics. Cancer Chemother Pharmacol 1993;33(3):181-6.

(25) Buggia I, Zecca M, Alessandrino EP et al. Itraconazole can increase systemic exposure to busulfan in patients given bone marrow transplantation. GITMO (Gruppo Italiano Trapianto di Midollo Osseo). Anticancer Res 1996 July;16(4A):2083-8.

(26) Hassan M, Ljungman P, Bolme P et al. Busulfan bioavailability. Blood 1994 October 1;84(7):2144-50.

(27) Sandstrom M, Karlsson MO, Ljungman P et al. Population pharmacokinetic analysis resulting in a tool for dose individualization of busulphan in bone marrow transplantation recipients. Bone Marrow Transplant 2001 October;28(7):657-64.

(28) Tran HT, Madden T, Petropoulos D et al. Individualizing high-dose oral busulfan: prospective dose adjustment in a pediatric population undergoing allogeneic stem cell transplantation for advanced hematologic malignancies. Bone Marrow Transplant 2000 September;26(5):463-70.

(29) Hassan M, Oberg G, Ericson $\mathrm{K}$ et al. In vivo distribution of [11C]busulfan in cynomolgus monkey and in the brain of a human patient. Cancer Chemother Pharmacol 1992;30(2):81-5. 
(30) Hassan M, Ehrsson H, Ljungman P. Aspects concerning busulfan pharmacokinetics and bioavailability. Leuk Lymphoma 1996 August;22(5-6):395407.

(31) Hassan M, Oberg G, Ehrsson H et al. Pharmacokinetic and metabolic studies of high-dose busulphan in adults. Eur J Clin Pharmacol 1989;36(5):525-30.

(32) Ehrsson H, Hassan M. Binding of busulfan to plasma proteins and blood cells. J Pharm Pharmacol 1984 October;36(10):694-6.

(33) Gibbs JP, Gooley T, Corneau B et al. The impact of obesity and disease on busulfan oral clearance in adults. Blood 1999 June 15;93(12):4436-40.

(34) Poonkuzhali B, Srivastava A, Quernin MH et al. Pharmacokinetics of oral busulphan in children with beta thalassaemia major undergoing allogeneic bone marrow transplantation. Bone Marrow Transplant 1999 July;24(1):5-11.

(35) Shaw PJ, Scharping CE, Brian RJ, Earl JW. Busulfan pharmacokinetics using a single daily high-dose regimen in children with acute leukemia. Blood 1994 October 1;84(7):2357-62.

(36) Vassal G, Deroussent A, Challine D et al. Is $600 \mathrm{mg} / \mathrm{m} 2$ the appropriate dosage of busulfan in children undergoing bone marrow transplantation? Blood 1992 May 1;79(9):2475-9.

(37) ROBERTS JJ, WARWICK GP. The mode of action of alkylating agents. II. Studies of the metabolism of myleran. The reaction of myleran with some naturally occurring thiols in vitro. Biochem Pharmacol 1961 June;6:205-16. 
(38) Hassan M, Ehrsson H. Metabolism of 14C-busulfan in isolated perfused rat liver. Eur J Drug Metab Pharmacokinet 1987 January;12(1):71-6.

(39) Hassan M, Ehrsson H. Urinary metabolites of busulfan in the rat. Drug Metab Dispos 1987 May;15(3):399-402.

(40) Marchand DH, Remmel RP, bdel-Monem MM. Biliary excretion of a glutathione conjugate of busulfan and 1,4-diiodobutane in the rat. Drug Metab Dispos 1988 January;16(1):85-92.

(41) Gibbs JP, Czerwinski M, Slattery JT. Busulfan-glutathione conjugation catalyzed by human liver cytosolic glutathione S-transferases. Cancer Res 1996 August 15;56(16):3678-81.

(42) Czerwinski M, Gibbs JP, Slattery JT. Busulfan conjugation by glutathione S-transferases alpha, mu, and pi. Drug Metab Dispos 1996 September;24(9):1015-9.

(43) Baumhakel M, Kasel D, Rao-Schymanski RA et al. Screening for inhibitory effects of antineoplastic agents on CYP3A4 in human liver microsomes. Int J Clin Pharmacol Ther 2001 December;39(12):517-28.

(44) Braide SA, Davies TJ. Factors that affect the induction of gamma glutamyltransferase in epileptic patients receiving anti-convulsant drugs. Ann Clin Biochem 1987 July;24 ( Pt 4):391-9.

(45) Wilce MC, Parker MW. Structure and function of glutathione Stransferases. Biochim Biophys Acta 1994 March 16;1205(1):1-18. 
(46) Ladner JE, Parsons JF, Rife CL, Gilliland GL, Armstrong RN. Parallel evolutionary pathways for glutathione transferases: structure and mechanism of the mitochondrial class kappa enzyme rGSTK1-1. Biochemistry 2004 January 20;43(2):352-61.

(47) Strange RC, Spiteri MA, Ramachandran S, Fryer AA. GlutathioneS-transferase family of enzymes. Mutat Res 2001 October 1;482(1-2):21-6.

(48) Jakobsson PJ, Morgenstern R, Mancini J, Ford-Hutchinson A, Persson B. Common structural features of MAPEG -- a widespread superfamily of membrane associated proteins with highly divergent functions in eicosanoid and glutathione metabolism. Protein Sci 1999 March;8(3):689-92.

(49) Commandeur JN, Stijntjes GJ, Vermeulen NP. Enzymes and transport systems involved in the formation and disposition of glutathione Sconjugates. Role in bioactivation and detoxication mechanisms of xenobiotics. Pharmacol Rev 1995 June;47(2):271-330.

(50) Anders MW. Formation and toxicity of anesthetic degradation products. Annu Rev Pharmacol Toxicol 2005;45:147-76.

(51) Stevens JL. Isolation and characterization of a rat liver enzyme with both cysteine conjugate beta-lyase and kynureninase activity. J Biol Chem 1985 July 5;260(13):7945-50.

(52) Stevens JL, Robbins JD, Byrd RA. A purified cysteine conjugate beta-lyase from rat kidney cytosol. Requirement for an alpha-keto acid or an 
amino acid oxidase for activity and identity with soluble glutamine transaminase K. J Biol Chem 1986 November 25;261(33):15529-37.

(53) Gaskin PJ, Adcock HJ, Buckberry LD, Teesdale-Spittle PH, Shaw PN. The C-S lysis of L-cysteine conjugates by aspartate and alanine aminotransferase enzymes. Hum Exp Toxicol 1995 May;14(5):422-7.

(54) Cooper AJ, Bruschi SA, Conway M, Hutson SM. Human mitochondrial and cytosolic branched-chain aminotransferases are cysteine Sconjugate beta-lyases, but turnover leads to inactivation. Biochem Pharmacol 2003 January 15;65(2):181-92.

(55) Ogasawara Y, Ishii K, Tanabe S. Enzymatic assay of gammacystathionase activity using pyruvate oxidase-peroxidase sequential reaction. $J$ Biochem Biophys Methods 2002 April 18;51(2):139-50.

(56) Cooper AJ, Bruschi SA, Iriarte A, Martinez-Carrion M. Mitochondrial aspartate aminotransferase catalyses cysteine S-conjugate betalyase reactions. Biochem J 2002 November 15;368(Pt 1):253-61.

(57) Amadasi A, Bertoldi M, Contestabile R et al. Pyridoxal 5'-phosphate enzymes as targets for therapeutic agents. Curr Med Chem 2007;14(12):1291-324.

(58) Abraham DG, Patel PP, Cooper AJ. Isolation from rat kidney of a cytosolic high molecular weight cysteine-S-conjugate beta-lyase with activity toward leukotriene E4. J Biol Chem 1995 January 6;270(1):180-8.

(59) Allen LV. Busulfan Oral Suspension. U S pharmacist 1990;November(29):94-5. 
(60) Partin JM, Poust RI, Cox FO. Stability of busulfan suspension. Phramaceutical Research 1988;5(10):S-74.

(61) Bhagwatwar HP, Phadungpojna S, Chow DS, Andersson BS. Formulation and stability of busulfan for intravenous administration in high-dose chemotherapy. Cancer Chemother Pharmacol 1996;37(5):401-8.

(62) Ehninger G, Schuler U, Renner U et al. Use of a water-soluble busulfan formulation--pharmacokinetic studies in a canine model. Blood 1995 June 1;85(11):3247-9.

(63) Hassan M, Hassan Z, Nilsson C et al. Pharmacokinetics and distribution of liposomal busulfan in the rat: a new formulation for intravenous administration. Cancer Chemother Pharmacol 1998;42(6):471-8.

(64) Hassan Z, Nilsson C, Hassan M. Liposomal busulphan: bioavailability and effect on bone marrow in mice. Bone Marrow Transplant 1998 November;22(9):913-8.

(65) Malley LA, Slone TW, Jr., Makovec GT, Elliott GS, Kennedy GL, Jr. Chronic toxicity/oncogenicity of dimethylacetamide in rats and mice following inhalation exposure. Fundam Appl Toxicol 1995 November;28(1):80-93.

(66) Marino G, Anastopoulos H, Woolf AD. Toxicity associated with severe inhalational and dermal exposure to dimethylacetamide and 1,2ethanediamine. J Occup Med 1994 June;36(6):637-41.

(67) Kim SN. Preclinical toxicology and pharmacology of dimethylacetamide, with clinical notes. Drug Metab Rev 1988;19(3-4):345-68. 
WHITE JC. A phase I study of dimethylacetamide. Cancer Chemother Rep 1962 February;16:477-85.

(69) Palmen NG, Evelo CT, Borm PJ, Henderson PT. Toxicokinetics of dimethylacetamide (DMAc) in rat isolated perfused liver. Hum Exp Toxicol 1993 March;12(2):127-33.

(70) Silvia M, Vincenzo L, Arturo M, Giovanni GP. Microsomal metabolism of N,N-diethylacetamide and N,N-dimethylacetamide and their effects on drug-metabolizing enzymes of rat liver. Biochem Pharmacol 1994 August $17 ; 48(4): 717-26$.

(71) Barnes JR, Ranta KE. The metabolism of dimethylformamide and dimethylacetamide. Toxicol Appl Pharmacol 1972 October;23(2):271-6.

(72) Tolando R, Zanovello A, Ferrara R, Iley JN, Manno M. Inactivation of rat liver cytochrome P450 (P450) by N,N-dimethylformamide and N,Ndimethylacetamide. Toxicol Lett 2001 October 15;124(1-3):101-11.

(73) Roy P, Yu LJ, Crespi CL, Waxman DJ. Development of a substrateactivity based approach to identify the major human liver P-450 catalysts of cyclophosphamide and ifosfamide activation based on cDNA-expressed activities and liver microsomal P-450 profiles. Drug Metab Dispos 1999 June;27(6):655-66.

(74) Murdter TE, Coller J, Claviez A et al. Sensitive and rapid quantification of busulfan in small plasma volumes by liquid chromatographyelectrospray mass spectrometry. Clin Chem 2001 August;47(8):1437-42. 
(75) Habig WH, Pabst MJ, Jakoby WB. Glutathione S-transferases. The first enzymatic step in mercapturic acid formation. J Biol Chem 1974 November 25;249(22):7130-9.

(76) Linford JH. 2,3,5-Tris-ethylenimino-1,4-benzoquinone (Trenimon): some chemical and biological properties. Chem Biol Interact 1973 March;6(3):149-68.

(77) Krasnikov BF, Kim SY, McConoughey SJ et al. Transglutaminase activity is present in highly purified nonsynaptosomal mouse brain and liver mitochondria. Biochemistry 2005 May 31;44(21):7830-43.

(78) Hargrove JL, Wichman RD. A cystine-dependent inactivator of tyrosine aminotransferase co-purifies with gamma-cystathionase (cystine desulfurase). J Biol Chem 1987 May 25;262(15):7351-7.

(79) Pinto JT, Krasnikov BF, Cooper AJ. Redox-sensitive proteins are potential targets of garlic-derived mercaptocysteine derivatives. J Nutr 2006 March;136(3 Suppl):835S-41S.

(80) Cooper AJ. Purification of soluble and mitochondrial glutamine transaminase $\mathrm{K}$ from rat kidney. Use of a sensitive assay involving transamination between L-phenylalanine and alpha-keto-gamma-methiolbutyrate. Anal Biochem 1978 September;89(2):451-60.

(81) Cooper AJ, Pinto JT. Aminotransferase, L-amino acid oxidase and beta-lyase reactions involving L-cysteine S-conjugates found in allium extracts. 
Relevance to biological activity? Biochem Pharmacol 2005 January 15;69(2):20920.

(82) Washtien W, Abeles RH. Mechanism of inactivation of gammacystathionase by the acetylenic substrate analogue propargylglycine. Biochemistry 1977 May 31;16(11):2485-91.

(83) Cooper AJ, Pinto JT. Cysteine S-conjugate beta-lyases. Amino Acids 2006 February;30(1):1-15.

(84) Ritter CA, Sperker B, Grube M, Dressel D, Kunert-Keil C, Kroemer HK. Overexpression of glutathione S-transferase A1-1 in ECV 304 cells protects against busulfan mediated G2-arrest and induces tissue factor expression. $\mathrm{Br} J$ Pharmacol 2002 December;137(7):1100-6.

(85) Stevens JL, Jones DP. The mercapturic acid pathway: Biosynthesis, intermediary metabolism, and physiological disposition. Glutathione: Chemical, Biochemical Aspects.New York: John Wiley and Sons, Inc.; 1989. p. 45-8.

(86) Asquith RS, Carthew P. The preparation and subsequent identification of a dehydroalanyl peptide from alkali-treated oxidised glutathione. Biochim Biophys Acta 1972 December 28;285(2):346-51.

(87) Sokolovsky M, Sadeh T, Patchornik A. Nonenzymatic cleavages of peptide chains at the cysteine and serine residues through their conversion to dehydroalanine (DHAL). II The specific chemical cleavage of cysteinyl peptides. Journal of the american chemical society 1963;86(6):1212-7. 
(88) Naritomi Y, Terashita S, Kagayama A. Identification and relative contributions of human cytochrome $\mathrm{P} 450$ isoforms involved in the metabolism of glibenclamide and lansoprazole: evaluation of an approach based on the in vitro substrate disappearance rate. Xenobiotica 2004 May;34(5):415-27.

(89) Arellano C, Philibert C, Vachoux C, Woodley J, Houin G. Validation of a liquid chromatography-mass spectrometry method to assess the metabolism of bupropion in rat everted gut sacs. J Chromatogr B Analyt Technol Biomed Life Sci 2005 December 27;829(1-2):50-5.

(90) Lasker JM, Wester MR, Aramsombatdee E, Raucy JL. Characterization of CYP2C19 and CYP2C9 from human liver: respective roles in microsomal tolbutamide, S-mephenytoin, and omeprazole hydroxylations. Arch Biochem Biophys 1998 May 1;353(1):16-28.

(91) ROBERTS JJ, WARWICK GP. The mode of action of alkylating agents. III. The formation of 3-hydroxytetrahydrothiophene-1:1-dioxide from 1:4dimethanesulphonyloxbutane (myleran), S-ß-L-alanyl-tetrahydrothiophenium mesylate, tetrahydrothiophene and tetrahydrothiophene-1:1-dioxide in the rat, rabbit and mouse. Biochem Pharmacol 1961 June;6:217-27.

(92) Hassan M, Ehrsson H. Degradation of busulfan in aqueous solution. J Pharm Biomed Anal 1986;4(1):95-101.

(93) Waxman DJ, Attisano C, Guengerich FP, Lapenson DP. Human liver microsomal steroid metabolism: identification of the major microsomal 
steroid hormone 6 beta-hydroxylase cytochrome P-450 enzyme. Arch Biochem Biophys 1988 June;263(2):424-36.

(94) Faucette SR, Hawke RL, Lecluyse EL et al. Validation of bupropion hydroxylation as a selective marker of human cytochrome P450 2B6 catalytic activity. Drug Metab Dispos 2000 October;28(10):1222-30.

(95) Rae JM, Soukhova NV, Flockhart DA, Desta Z.

Triethylenethiophosphoramide is a specific inhibitor of cytochrome P450 2B6: implications for cyclophosphamide metabolism. Drug Metab Dispos 2002 May;30(5):525-30.

(96) Relling MV, Aoyama T, Gonzalez FJ, Meyer UA. Tolbutamide and mephenytoin hydroxylation by human cytochrome P450s in the CYP2C subfamily. J Pharmacol Exp Ther 1990 January;252(1):442-7.

(97) Fitzsimmons WE, Ghalie R, Kaizer H. The effect of hepatic enzyme inducers on busulfan neurotoxicity and myelotoxicity. Cancer Chemother Pharmacol 1990;27(3):226-8.

(98) Harkey MA, Czerwinski M, Slattery J, Kiem HP. Overexpression of glutathione-S-transferase, MGSTII, confers resistance to busulfan and melphalan. Cancer Invest 2005;23(1):19-25.

(99) Hassan M, Ljungman P, Ringden O et al. The effect of busulphan on the pharmacokinetics of cyclophosphamide and its 4-hydroxy metabolite: time interval influence on therapeutic efficacy and therapy-related toxicity. Bone Marrow Transplant 2000 May;25(9):915-24. 
(100) Ritter CA, Bohnenstengel F, Hofmann U, Kroemer HK, Sperker B. Determination of tetrahydrothiophene formation as a probe of in vitro busulfan metabolism by human glutathione S-transferase A1-1: use of a highly sensitive gas chromatographic-mass spectrometric method. J Chromatogr B Biomed Sci Appl 1999 June 25;730(1):25-31.

(101) Hassan M, Ehrsson H, Wallin I, Eksborg S. Pharmacokinetic and metabolic studies of busulfan in rat plasma and brain. Eur J Drug Metab Pharmacokinet 1988 October;13(4):301-5.

(102) Meister A. metabolism and function of glutathione. Glutathione: Chemical, Biochemical Aspects.New York: John Wiley and Sons, Inc.; 1989. p. $367-474$.

(103) BENESCH RE, LARDY HA, BENESCH R. The sulfhydryl groups of crystalline proteins. I. Some albumins, enzymes, and hemoglobins. J Biol Chem 1955 October;216(2):663-76.

(104) Orbach D, Brisse H, Doz F. [Central neurological manifestations during chemotherapy in children]. Arch Pediatr 2003 June;10(6):533-9.

(105) Santos GW, Tutschka PJ, Brookmeyer R et al. Marrow transplantation for acute nonlymphocytic leukemia after treatment with busulfan and cyclophosphamide. $N$ Engl J Med 1983 December 1;309(22):1347-53.

(106) Clift RA, Buckner CD, Thomas ED et al. Marrow transplantation for patients in accelerated phase of chronic myeloid leukemia. Blood 1994 December 15;84(12):4368-73. 
(107) Grochow LB, Jones RJ, Brundrett RB et al. Pharmacokinetics of busulfan: correlation with veno-occlusive disease in patients undergoing bone marrow transplantation. Cancer Chemother Pharmacol 1989;25(1):55-61.

(108) McDonald GB, Hinds MS, Fisher LD et al. Veno-occlusive disease of the liver and multiorgan failure after bone marrow transplantation: a cohort study of 355 patients. Ann Intern Med 1993 February 15;118(4):255-67.

(109) Kalayoglu-Besisik S, Yenerel MN, Caliskan Y, Ozturk S, Besisik F, Sargin D. Time-related changes in the incidence, severity, and clinical outcome of hepatic veno-occlusive disease in hematopoietic stem cell transplantation patients during the past 10 years. Transplant Proc 2005 June;37(5):2285-9.

(110) Wadleigh M, Ho V, Momtaz P, Richardson P. Hepatic venoocclusive disease: pathogenesis, diagnosis and treatment. Curr Opin Hematol 2003 November;10(6):451-62.

(111) DeLeve LD, Shulman HM, McDonald GB. Toxic injury to hepatic sinusoids: sinusoidal obstruction syndrome (veno-occlusive disease). Semin Liver Dis 2002 February;22(1):27-42.

(112) Slattery JT, Clift RA, Buckner CD et al. Marrow transplantation for chronic myeloid leukemia: the influence of plasma busulfan levels on the outcome of transplantation. Blood 1997 April 15;89(8):3055-60.

(113) Petros WP, Evans WE. Anti-Cancer Agents. In: Schentag JJ, Evans WE, Burton ME, editors. Applied Pharmacokinetics and Pharmacodynamics. Fourth ed. New York: Williams and Wilkins; 2006. p. 617-36. 
(114) Srivastava A, Poonkuzhali B, Shaji RV et al. Glutathione Stransferase M1 polymorphism: a risk factor for hepatic venoocclusive disease in bone marrow transplantation. Blood 2004 September 1;104(5):1574-7.

(115) DeLeve LD, Wang X. Role of oxidative stress and glutathione in busulfan toxicity in cultured murine hepatocytes. Pharmacology 2000 April;60(3):143-54.

(116) Dufour A, Hindre T, Haras D, Le Pennec JP. The biology of lantibiotics from the lacticin 481 group is coming of age. FEMS Microbiol Rev 2007 March;31(2):134-67.

(117) Linetsky M, LeGrand RD. Glutathionylation of lens proteins through the formation of thioether bond. Mol Cell Biochem 2005 April;272(1-2):133-44.

(118) Bouligand J, Deroussent A, Simonnard N et al. Induction of glutathione synthesis explains pharmacodynamics of high-dose busulfan in mice and highlights putative mechanisms of drug interaction. Drug Metab Dispos 2007 February;35(2):306-14.

(119) Perbellini L, Princivalle A, Caivano M, Montagnani R. Biological monitoring of occupational exposure to $\mathrm{N}, \mathrm{N}$-dimethylacetamide with identification of a new metabolite. Occup Environ Med 2003 October;60(10):74651.

(120) Andersson BS, Madden T, Tran HT et al. Acute safety and pharmacokinetics of intravenous busulfan when used with oral busulfan and 
cyclophosphamide as pretransplantation conditioning therapy: a phase I study.

Biol Blood Marrow Transplant 2000;6(5A):548-54.

(121) Kharasch ED, Thummel KE. Identification of cytochrome P450 2E1 as the predominant enzyme catalyzing human liver microsomal defluorination of sevoflurane, isoflurane, and methoxyflurane. Anesthesiology 1993

October;79(4):795-807. 